\title{
Development of a Ridership Forecasting Tool for Small Public Transit Systems Using GIS
}

\author{
Submitted by Stephanie L. McNeely, P.Eng., B.Eng. \\ Carleton University \\ Ottawa, Ontario, 1997
}

A thesis submitted to the Faculty of Graduate Studies and Research in partial fulfillment of the requirements for the degree of Master of Applied Science

\author{
Department of Civil and Environmental Engineering \\ Carleton University \\ Ottawa, Ontario
}

(C) Copyright 2007

Stephanie L. McNeely

The Master of Applied Science in Civil and Environmental Engineering Program is a joint program with the University of Ottawa, administered by the Ottawa-Carleton Institute for Civil Engineering. 


$\begin{array}{ll}\begin{array}{l}\text { Library and } \\ \text { Archives Canada }\end{array} & \begin{array}{l}\text { Bibliothèque et } \\ \text { Archives Canada }\end{array} \\ \begin{array}{l}\text { Published Heritage } \\ \text { Branch }\end{array} & \begin{array}{l}\text { Direction du } \\ \text { Patrimoine de l'édition }\end{array} \\ \begin{array}{l}\text { 395 Wellington Street } \\ \text { Ottawa ON K1A ON4 }\end{array} & \begin{array}{l}\text { 395, rue Wellington } \\ \text { Ottawa ON K1A ON4 } \\ \text { Canada }\end{array}\end{array}$

Your file Votre référence ISBN: 978-0-494-36828-2 Our file Notre référence ISBN: 978-0-494-36828-2

NOTICE:

The author has granted a nonexclusive license allowing Library and Archives Canada to reproduce, publish, archive, preserve, conserve, communicate to the public by telecommunication or on the Internet, loan, distribute and sell theses worldwide, for commercial or noncommercial purposes, in microform, paper, electronic and/or any other formats.

The author retains copyright ownership and moral rights in this thesis. Neither the thesis nor substantial extracts from it may be printed or otherwise reproduced without the author's permission.
AVIS:

L'auteur a accordé une licence non exclusive permettant à la Bibliothèque et Archives Canada de reproduire, publier, archiver, sauvegarder, conserver, transmettre au public par télécommunication ou par l'Internet, prêter, distribuer et vendre des thèses partout dans le monde, à des fins commerciales ou autres, sur support microforme, papier, électronique et/ou autres formats.

L'auteur conserve la propriété du droit d'auteur et des droits moraux qui protège cette thèse. $\mathrm{Ni}$ la thèse ni des extraits substantiels de celle-ci ne doivent être imprimés ou autrement reproduits sans son autorisation.
In compliance with the Canadian

Privacy Act some supporting forms may have been removed from this thesis.

While these forms may be included in the document page count, their removal does not represent any loss of content from the thesis.
Conformément à la loi canadienne sur la protection de la vie privée, quelques formulaires secondaires ont été enlevés de cette thèse.

Bien que ces formulaires aient inclus dans la pagination, il n'y aura aucun contenu manquant.

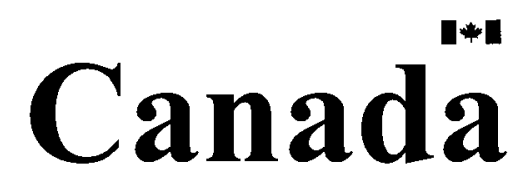




\begin{abstract}
Transit systems are under constant pressure to provide cost-effective service that is convenient, frequent and reliable. In smaller Canadian municipalities this pressure is exacerbated by low staffing levels and a necessary focus on day-to-day transit operations. Little time is available to pursue planning initiatives that would facilitate long-term system improvements, ultimately leading to ridership growth.
\end{abstract}

This thesis develops an analytical tool to assess transit ridership potential for the purpose of strategic transit planning. The intent is to supplement best practices in order to assist small transit systems in their planning efforts. Information related to advances in the transit applications of Geographic Information Systems (GIS) is a focal point.

The developed GIS-based tool uses data from the Statistics Canada Census and other readily available GIS information obtained from the City of Ottawa. The tool incorporates data related to demographics, travel to work patterns and information about major trip generators. It was tested through a case study of a suburban community in the City of Ottawa. 


\section{Acknowledgements}

I could not have completed this incredible journey without the support of my family and friends. I would like to thank my parents Tom and Claire for their continued support and encouragement in this endeavour in particular. I am grateful to my brothers Patrick and Matthew, sister Julie and grandmother Patricia for their understanding of my time constraints during the final months.

I thank my friends who talked me through the difficult times and found ways to distract me when I needed a break: Mark Saunders, Kim Hunton, Heidi Cousineau, Marc-Andre Poitras. I am indebted to my colleagues at Dillon Consulting who encouraged me in this process and accepted my balancing act: Shawn Doyle, Brad Schmidt and Bill Dwyer. My classmates Christopher Watson, Raoul Ky-Maka and Christiane Raab were wonderful conspirators during the coursework portion of this endeavour and I am fortunate to have journeyed with them.

With sincere thanks, I acknowledge the assistance of Dr. Ata Khan my thesis advisor who guided me along the way. I also wish to thank the wonderful and gifted staff in the Civil and Environmental Engineering Department at Carleton University who passed on their knowledge, passion and inspiration in so many different subject areas. In particular, I thank Dr. Deniz Karman, Dr. Sarah Wells, Dr.Guy Felio, Dan Patterson, Dr. Yasser Hassan, Dr. Jim Mehaffey. Many thanks also to the City of Ottawa staff who provided the data required for analysis. Finally, I am grateful to Kornel Mucsi who lead me down this path and whose leadership and conviction early in my career influenced my choices. 


\section{Table of Contents}

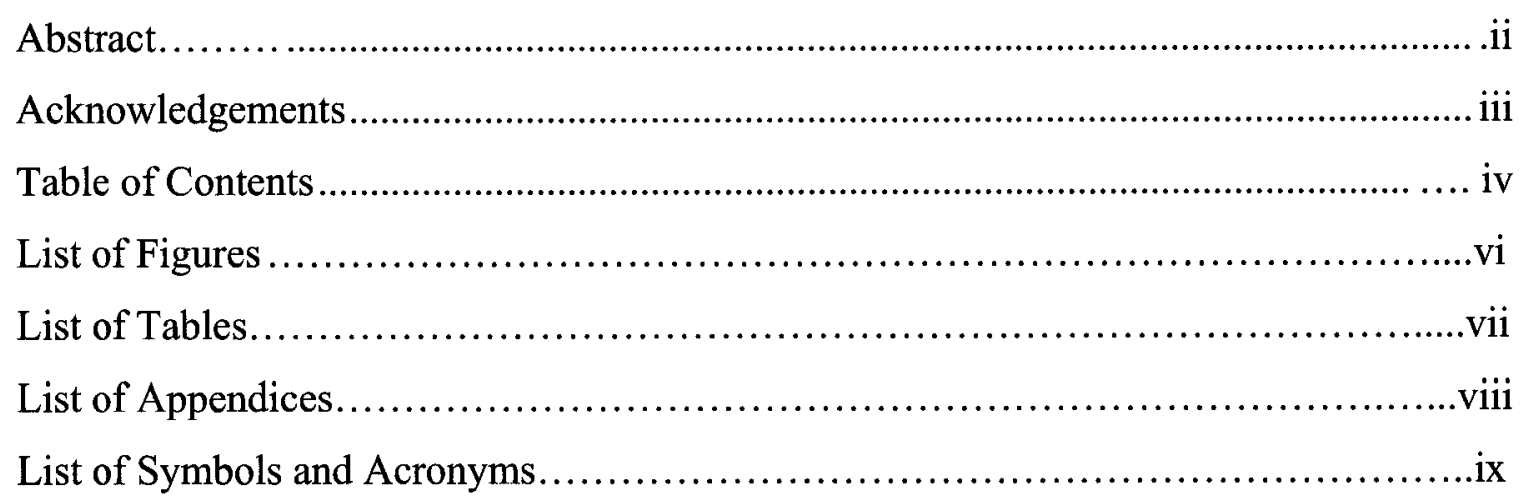

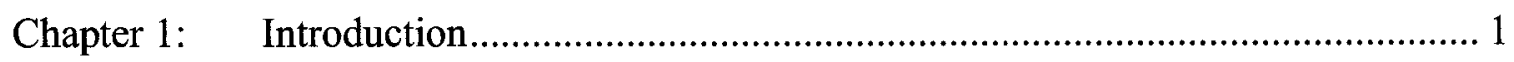

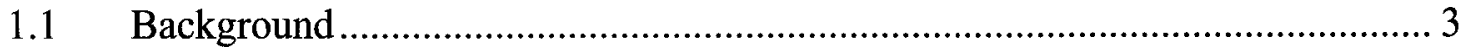

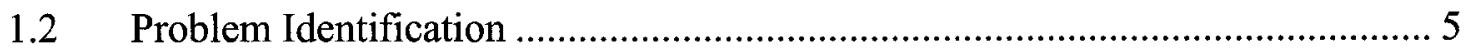

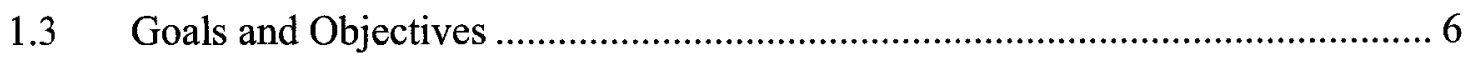

1.4 Research Framework and Study Methodology ............................................ 9

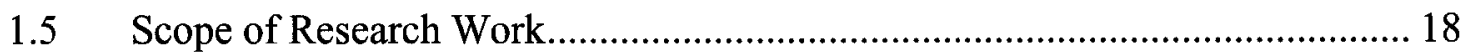

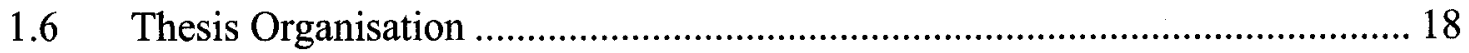

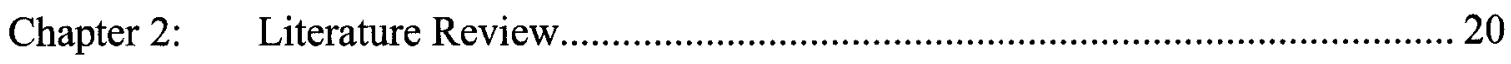

2.1 Introduction to Geographic Information Systems....................................... 20

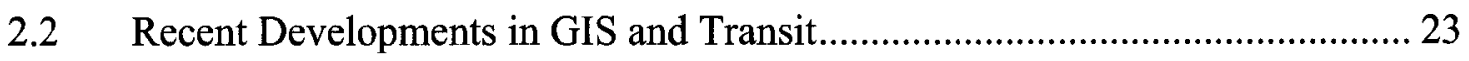

2.3 Relevant Ridership Forecasting Models ................................................... 29

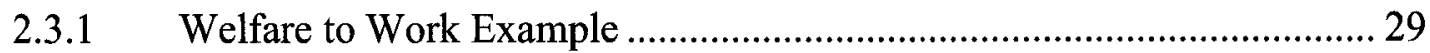

2.3.2 Transit Market Potential ...................................................................... 34

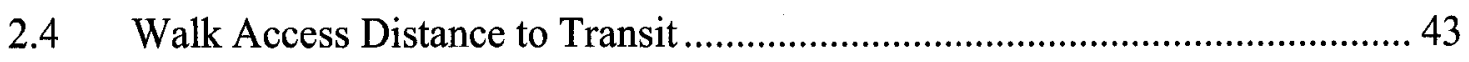

Chapter 3: Characterization of Smaller Canadian Transit Systems.......................... 45

3.1 Transit Challenges in Canada .................................................................. 50

3.2 Defining a "Small" Canadian Municipality .................................................. 52

3.2.1 Characteristics of a Small Municipality ............................................... 52

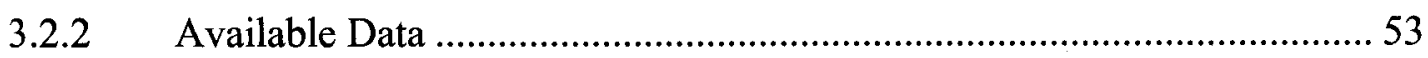


Chapter 4: Development of GIS-based Tool ......................................................... 56

4.1 Measurement Functions for Transit ............................................................. 57

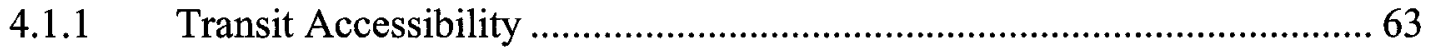

4.1.2 Prediction of Transit Use .................................................................... 64

4.1.3 Route Running Time........................................................................... 74

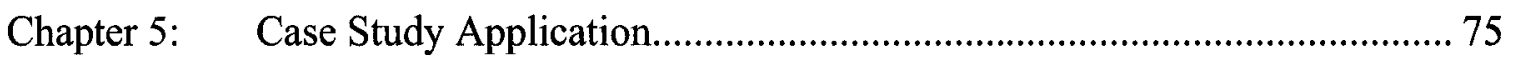

5.1.1 Available Data ................................................................................... 75

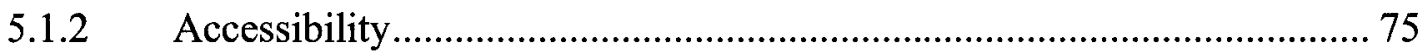

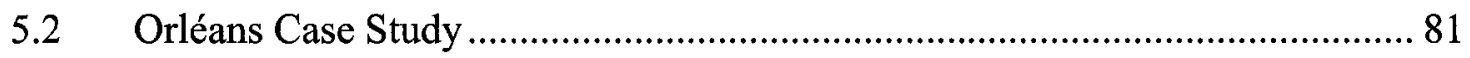

5.2.1 Development of a Method to Predict Transit Ridership ............................ 84

5.2.2 GIS Network Analysis ........................................................................... 88

5.2.3 Validation Data .................................................................................. 93

5.2.4 Prediction of Transit Use in Orléans........................................................ 96

5.3 Future Growth Considerations....................................................................... 113

Chapter 6: Conclusions and Recommendations ........................................................ 114

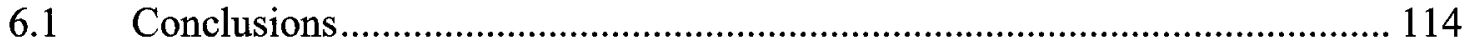

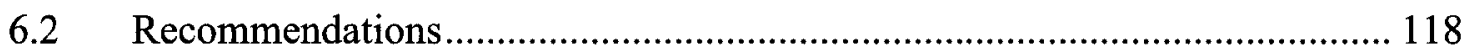

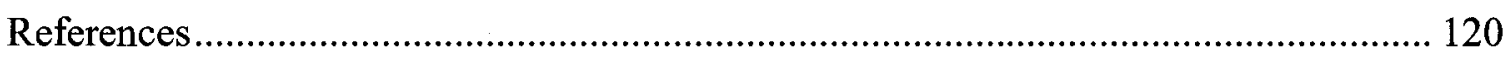




\section{List of Figures}

Figure 1.1 - Hierarchy of Transit Planning and Operations Activities ............................ 4

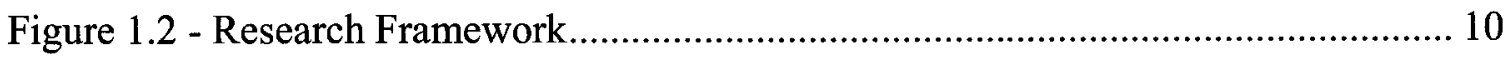

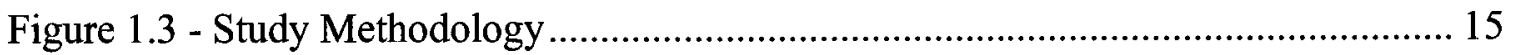

Figure 1.4 - Map of Orléans Community.................................................................... 17

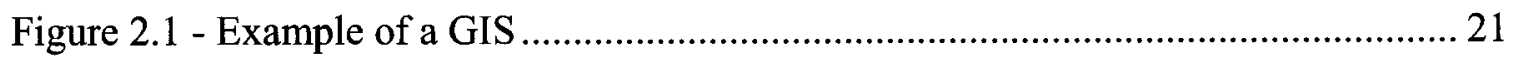

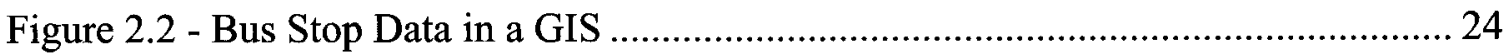

Figure 3.1 - Research Framework for Characterization of Small Municipalities............ 46

Figure 4.1 - Transit Ridership Variables.................................................................. 58

Figure 4.2 - Accessibility to Transit Origins and Destinations .................................... 59

Figure 4.3 - Interrelationship of Key Transit System Design Variables.........................60

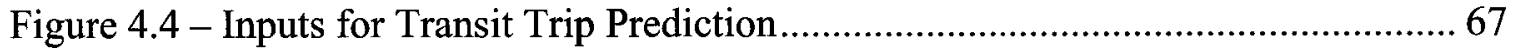

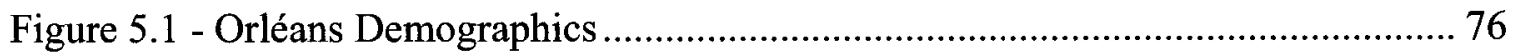

Figure 5.2 - Orléans Home Ownership and Family Income ....................................... 77

Figure 5.3 - Orléans Population and Public Transit Use ............................................. 78

Figure 5.4 - Orléans Trip Generators and Pedestrian Links ....................................... 83

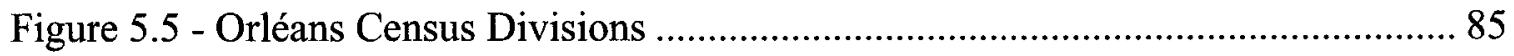

Figure 5.6 - Areas Within 400 metres from Bus Stops.............................................. 90

Figure 5.7 - Orléans Potential for Improvement to Accessibility ................................ 92

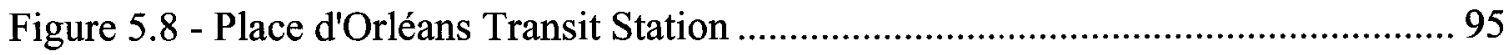

Figure 5.9 - Transit Mode to Work vs. Population ................................................... 100

Figure 5.10 - Trip Generators Within 400 metres from Bus Stop........................... 104

Figure 5.11 - Estimated Distance Between Points and Network ................................. 107

Figure 5.12 - Potential Transit Destinations within a Census District.......................... 108

Figure 5.13 - Comparison of Actual and Predicted Ridership ................................. 112 


\section{List of Tables}

Table 2.1 - Market Segment Elasticities .................................................................. 41

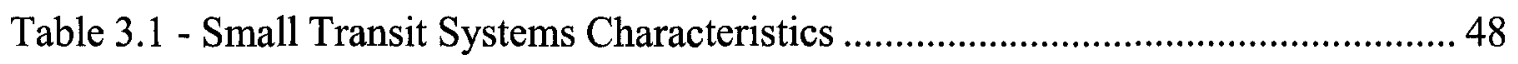

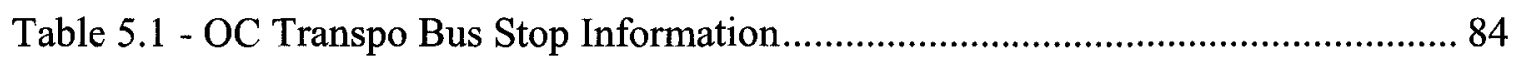

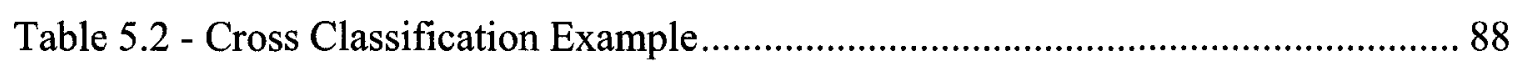

Table 5.3 - Potential for Accessibility Improvement................................................... 91

Table 5.4 - Actual and Adjusted Transit Ridership .................................................... 94

Table 5.5- NCR Trip Data by Trip Purpose................................................................. 98

Table 5.6 - Regression Statistics for Work-related Transit Trips ................................ 100

Table 5.7 - 2005 Origin-Destination Survey School Trip Data .................................. 101

Table 5.8 - Estimated Transit Use in Orléans Schools .............................................. 102

Table 5.9 - Transit Destination Potential .................................................................... 109

Table 5.10 - Regression Statistics for "Other" Transit Trips........................................ 110

Table 5.11 - Summary of Transit Ridership by Census District.................................. 111 


\section{List of Appendices}

Appendix A - Small Municipality Survey

Appendix B - Statistics Canada Census Divisions

Appendix C - Sample OC Transpo Data 


\section{List of Symbols and Acronyms}

AVL - Automatic Vehicle Location

APC - Automatic Passenger Count

CTPP - Census Transportation Planning Package

CUTA - Canadian Urban Transit Association

GIS - Geographic Information Systems

GPS - Global Positioning Systems

ISTEA - Intermodal Surface Transportation Efficiency Act

IT - Information Technology

ITS - Intelligent Transportation Systems

NCR - National Capital Region

OC Transpo - Ottawa-Carleton Transportation

TCRP - Transit Cooperative Research Program

TDM - Transportation Demand Management

TSF - Transit Service Facility 


\section{Chapter 1: Introduction}

Public transit plays an important role in providing mobility to Canadians in all sizes of municipalities. Its prominence within the range of available transportation modes has increased in recent years as all levels of government have come to the realization that increased funding for public transit promotes better utilization of the system and furthers environmental objectives among other benefits (Golden, 2007). This shift is evidenced through the changes in funding structure in recent years that have enabled a portion of gas tax revenues at the federal level and within certain provinces to be dedicated to transit (Department of Finance Canada, 2005; Ministry of Transportation Ontario, 2004).

With the advent of new funding, Canadian municipalities with transit systems have migrated to an enviable position of planning a new course of action for their business. Service expansions or improvements can be implemented and new or replacement infrastructure can be planned. Such enhancements positively affect customer satisfaction and lead to increased ridership (Golden, 2007).

Despite a surge in funding, transit systems continue to operate under continuous pressure to provide cost-effective service that is convenient, frequent and reliable. They must balance the needs of existing patrons while trying to establish new markets within growth areas. The difficulty with the latter is that new service should ideally be introduced prior to reaching required service area passenger base in order to influence transportation 
decisions at the earliest possible time (e.g. before an additional family vehicle is purchased).

Advances in the realm of Geographic Information Systems (GIS) have led to increasingly sophisticated software tools being developed and used by large municipalities and regional authorities to assess transit operations and test service delivery options for future demands. In addition, the quality and quantity of GIS data that is readily available has followed suit (e.g. road networks, demographic data, land use information) (Sutton, 2004).

GIS tools have not been as easy for smaller municipalities to obtain given the costs and human resources required to build, maintain and use such software tools. To some extent the relative novelty of GIS has also been a barrier in its adoption. However, this is changing with an increased use of GIS within different municipal departments for the purposes of asset tracking, mapping, and dissemination of information through the internet. GIS is used for water distribution systems, stormwater and sewer systems, roadway networks, recreational trails, facility tracking and mapping and a host of other systems which makes the business case easier to accept GIS use for the analysis of transit operations.

The power of a GIS lies in its ability to combine geography-based information (i.e. mapping) with data management capabilities (e.g. databases). This is an ideal tool for the geographic and data management inputs necessary for transit planning analysis (Sutton, 
2004; Multisystems Inc., 2000). As GIS use becomes more widespread and consequently more affordable opportunities will become available to make use of it for transit planning purposes.

The focus of this thesis is the development of an analytic tool to assess transit ridership potential to assist in strategic planning for small transit systems. Emphasis is placed on the use of data that is readily available or that would more commonly be used within municipal departments other than transit.

\subsection{Background}

Historically, transit planning in small municipalities has been carried out by industry practitioners who may be responsible for the full range of transit operations. Trying to balance the strategic goals of system growth, marketing and more recently accessibility issues is a difficult charge. Transit managers seldom take time away from their more pressing day-to-day issues that can range from labour management to customer service to fleet maintenance.

Transit functions can generally be divided into two segments: operations and planning. Operations focus on activities directly related to providing the level of service that has been scheduled such as assigning operators to routes, communications and dispatching, fueling, washing and maintaining transit vehicles, maintaining bus stops and related information, etc. Planning activities can have several timeline and these are typically 
longer than for operations activities. Planning for transit operations is a short-term task. Planning activities that are more "tactical" in nature include development of monitoring and control systems, adjusting or revising schedules, assessing revenue targets by route and reviewing service design. Longer term planning could be defined as "strategic" and includes activities such as corridor, route and fleet planning. Logically, for these activities a much longer horizon is considered than for tactical planning. The following figure (Figure 1.1) illustrates these three tiers of transit system activities.

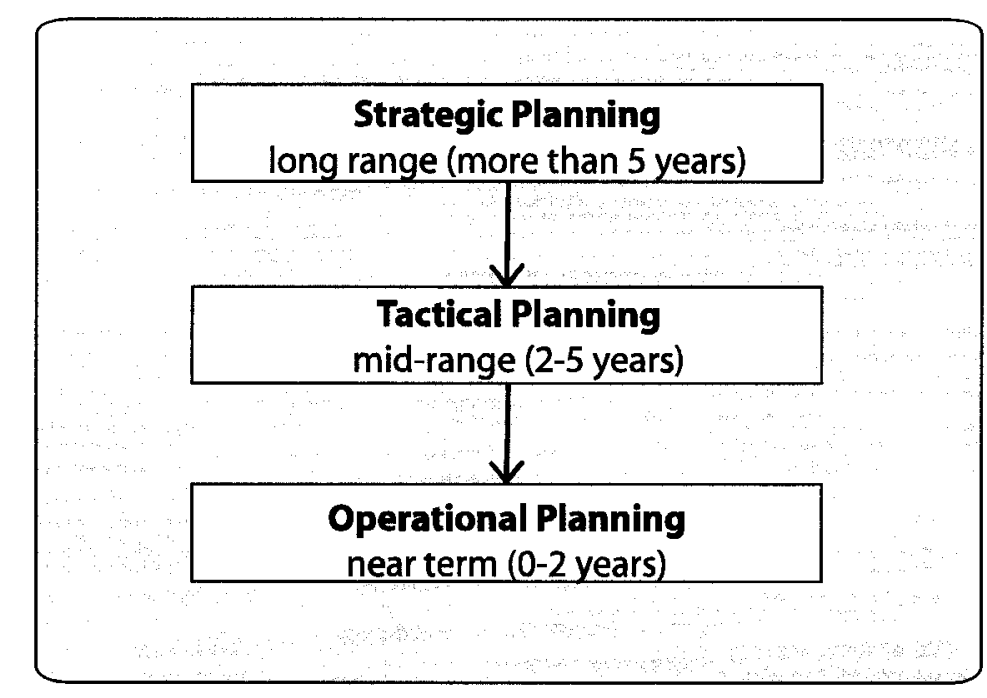

Figure 1.1 - Hierarchy of Transit Planning and Operations Activities

For the purposes of this thesis, a small Canadian municipality is considered to have a population of 40,000 to 170,000 residents, as described in Chapter 3 . In many small transit organizations human resources are limited. Those staff accountable for the range of operational and planning needs have many other responsibilities. GIS applications within these small transit systems tend to be focused on short-term, project-specific initiatives. Related personnel support for GIS within small to medium-sized U.S. transit 
systems have been reported to be in the range of one to two persons (Sutton, 2004). As such, strategic transit initiatives using GIS are not commonplace in small municipalities.

The relationship between transit and land use has become an important topic in the transit and planning sectors. The efficient provision of public transit service depends, to a large extent on urban density, land use, the design of subdivisions, and the overall planning of urban areas (Canadian Transit Handbook, 1993). Land use and accessibility to transit (i.e. walking distance to a transit stop) have continued to figure prominently as topics of study over the past decade (TRB, Special Report 257, 2001, Cervero et al., 2004). Advances in the integration of GIS for transit data collection and asset tracking combined with an increasing availability of other types of GIS data has furthered the potential for analysis and research in this area (Sutton, 2004).

\subsection{Problem Identification}

Transit systems are facing ever-increasing pressures to provide cost-effective transit service to existing users while exploring ways to improve service and expand into new markets. The novelty of GIS within a municipal context has somewhat limited its use within transit, a situation that is changing as GIS use becomes more ubiquitous (Sutton, 2004, Karimi et al., 2004, Riley, 2002).

Fortunately, advances in transit-related GIS are expanding the boundary of data management capabilities and increasing the quality and quantity of information readily 
available to transit planners. Small municipalities would benefit from a GIS-based tool to assist with long term planning by making use of readily-available data.

Transit must achieve certain service targets to be considered successful. Passengers expect service that is frequent, reliable and accessible (TRB, Special Report 257, 2001). A good decision-making tool would provide an assessment of geographic coverage of transit routes, have the ability to forecast transit ridership and would assist in establishing priorities for improvements.

Quantifying additional transit ridership that could be attracted to a transit service would give transit planners better information about benefits and costs for providing such service in the future. Increasing service levels by increasing service frequency or expanding areas served by transit could require additional transit operators and additional transit vehicles, elements that should also factor into an implementation plan for any proposed service changes. The impacts of increased service frequency were not considered within the scope of this work.

\subsection{Goals and Objectives}

The aim for this study was to develop a GIS-based tool for small municipalities that assists with long term planning for service expansion by forecasting transit ridership potential. The tool would assess system accessibility, demographics and other socioeconomic factors. The over-arching goal for the GIS tool was that it be easily understood and used by staff within small municipalities while still providing a meaningful 
assessment. Transit managers in smaller systems have too many competing priorities and an overly complex tool would not be especially useful and would inhibit its application.

The main objectives of the study were to:

- Learn from successes and failures of other tools or methods based on state-of-the art research into transit-related GIS applications;

- Determine which demographic and socio-economic indices could be used in assessing ridership potential;

- Develop an easy to use GIS-based tool that incorporates Census data and other readily-available information to forecast transit ridership potential; and

- Identify GIS data that is essential to the transit analysis tool so that the data is maintained by the municipality as a priority.

The research conducted for this study was undertaken to ascertain the state-of-the-art in transit-related GIS applications and to develop a GIS-based tool for assessing ridership potential. Given the novelty of GIS for transit, a scan of the industry was thought to be a useful means to determine what tools or projects other municipalities or transit systems had implemented in order to learn of successes and failures. An industry scan was also thought to be a good way to develop a set of best practices with respect to use of GIS.

It was considered essential to determine which accessibility, demographic and socioeconomic indices were relevant in the assessment and could readily be found for typical small municipalities. The over-arching goal for the GIS tool was that it be easily 
understood and easy to use so transit managers in smaller systems would use it in their strategic planning.

Larger metropolitan centres generally have access to fully staffed "geomatics" departments that are responsible for mapping, data updates and integration with different software or hardware for various municipal departments. Sometimes transit authorities maintain control of their own GIS data while for others this is a shared responsibility. On the opposite end of the spectrum, smaller municipalities do not typically assign many resources (if any) to the maintenance, upkeep and use of GIS (Sutton, 2004).

There are examples of all sizes of transit systems, including smaller ones, that have implemented data collection processes that link passenger activity data with GIScompatible or graphical software packages. However, in the case of smaller municipalities the responsibility for the GIS portion does not always rest with the transit department but is sometimes a corporate effort (Sutton, 2004).

As noted earlier, an objective of this study was to highlight which attributes are useful for transit analysis in an effort to place more importance on these and ensure that the necessary updates are given priority when "control" over GIS functions does not rest within the transit department. This would help to shape the transit department's needs with respect to GIS data (e.g. stop locations, route network, pedestrian access). 
Another objective was to ensure that the analysis focused on relevance to Canadian municipalities and that opportunities to improve the quality of data collected during the national census be identified as a study outcome. In the U.S. a high level of attention is paid to transportation planning needs within the census process (Multisystems Inc., 2000). Advances continue to be made on this front in Canada with respect to home to work travel patterns (Ruel, 2004).

Advances in Intelligent Transportation Systems (ITS) and GIS continue to be made however, the cost to procure such systems can be disproportionately high for small systems (Sutton, 2004). One final aim for this study is to assist the small municipalities

in their purchasing decisions by highlighting attributes or data collection capabilities that would benefit them in their system analysis for both existing service and future plans. This could also benefit ITS system developers as they might tailor their GIS or ITS products to meet additional goals (i.e. data collection and subsequent analysis).

\subsection{Research Framework and Study Methodology}

The broad methodology followed for this study included seven main components:

- Problem identification and problem definition

- Literature review,

- Study approach and identification of data sources

- Examination of characteristics of small Canadian transit systems,

- Development of a tool to forecast transit ridership potential

- Case study to test the transit service tool, and 
- Conclusions and recommendations.

Though each part was generally carried out independently, some overlap occurred between development of the tool to forecast transit ridership potential and use of a case study to test the tool. These two components were more inter-related than other study components. The research framework is illustrated in Figure 1.2. Each component is described in greater detail below.

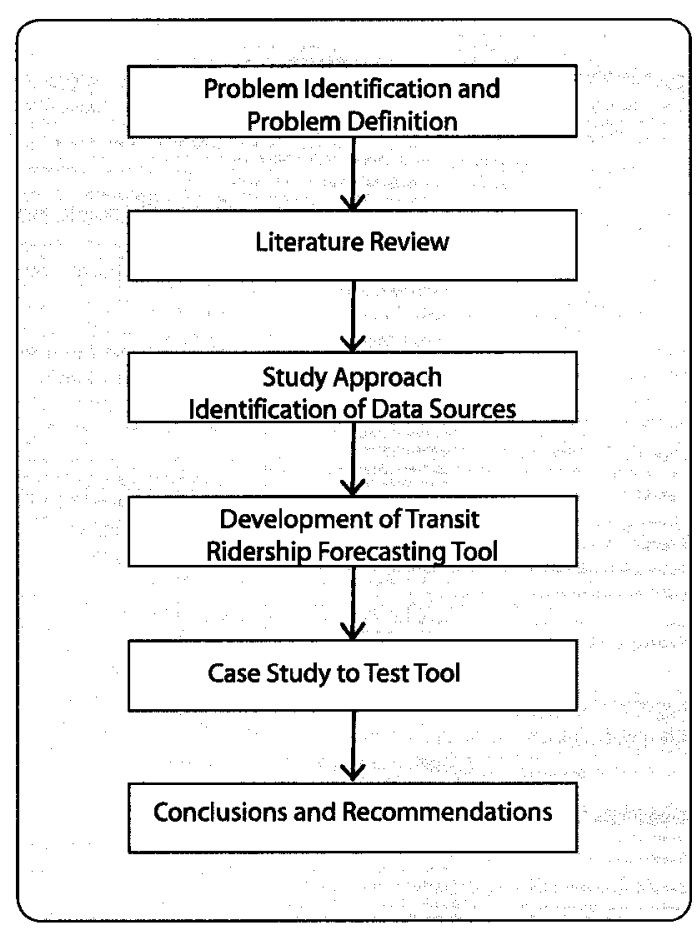

Figure 1.2 - Research Framework

\section{Problem Identification and Definition}

The initial stage of this study involved looking closely at the issues surrounding transit planning and ridership forecasting. It was determined that a number of tools exist within the transit industry to assist with long-range service planning. These are often 
combinations of commercially available software with some supplementary software of processes developed within a transit system (Sutton, 2004). The level of effort required to build and calibrate a transit planning model for a large municipality can range from several months to more than one year, depending on the resources available. There is a need within small transit systems to develop a less labour and cost-intensive means to forecast transit ridership potential in order to plan for future system needs.

\section{Literature Review}

The purpose of the literature review was first to determine whether a GIS-based tool already existed that had the capability to assess existing transit service and forecast future transit service needs within small municipalities. The secondary purpose was to determine how much information was available on the topic of transit-related GIS applications and associated best practices.

Sources consulted include journals, published research, reports, conference papers, public transit industry publications, relevant public transit manuals and discussions with transit managers employed by transit authorities in smaller municipalities.

\section{Examination of Characteristics of Canadian Transit Systems}

The transit ridership profile is different in Canada than in the U.S. with a broader crosssection and higher proportion of patrons taking transit in Canada. In addition, population and demographic information is collected differently in Canada than it is in the U.S. As such, this study focused on the Canadian context and sought to look at the 5-year census 
cycle as a good opportunity to capture meaningful information related to transit. Smaller municipalities could capitalize on the census data by avoiding the costs associated with individual municipal surveys.

In order to develop a tool specific to Canadian transit systems, it became necessary to define their particular characteristics. A list was developed of municipalities that participate in the Canadian Urban Transit Association's (CUTA) annual small transit systems roundtable sessions. Participation was solicited from twenty municipalities with transit systems to participate in a short survey. The complete list of municipalities solicited is included in Appendix A, along with the email request and survey forms. Surveys were completed by the following municipalities:

- $\quad$ Brandon, Manitoba

- $\quad$ St. Albert, Alberta

- $\quad$ Lethbridge, Alberta

- Belleville, Ontario

- Burlington, Ontario

- Cornwall, Ontario

- Guelph, Ontario

- $\quad$ Kingston, Ontario

- $\quad$ Milton, Ontario

- Kelowna, British Columbia

- $\quad$ Saint John, New Brunswick 
The twenty municipalities whose input was solicited had populations from 41,500 to 165,600 residents and this range was used to define small municipalities as described in more detail in Chapter 3.

\section{Development of a Tool to Forecast Transit Ridership Potential}

A number of software packages are available and commonly used by large transit systems to carry out level of service analysis or to undertake service planning. High end transit planning software can range from $\$ 10,000$ to $\$ 20,000$ (U.S. dollars) plus annual maintenance fees (e.g. Caliper's TransCAD software, PTV's VISUM software) (Urban Transportation Monitor, 2004). In addition municipal staff must be dedicated to building, calibrating and running these models or providing input and feedback to a third party. These are resources that smaller systems do not typically have easy access to. Another common concern among smaller transit systems is that insufficient staffing resources are available to undertake strategic planning (Sutton, 2004).

Within the literature reviewed only two relevant articles were found of which only one defined an applicable mathematical model to quantify transit potential ridership (Henk and Hubbard, 1996 and Pulugurtha and Nambisan, 1999).

An index of transit service availability was developed by Henk and Hubbard. The index was not intended to be used as a tool to gauge transit system measures of effectiveness but rather was focused on measuring three key factors of transit service availability, namely coverage, frequency and capacity. A temporal element was also included within 
the planning tool in order to assess service levels at different points through the day (Henk and Hubbard, 1996).

Pulugurtha and Nambisan took a number of factors into account in the evaluation and selection of transit stops along a specific route. Transit market potential was defined using a number of factors including accessibility and demographic characteristics. The analysis incorporated residential origins but stopped short of including destination-type locations (i.e. non-residential land uses) within the analysis (Pulugurtha and Nambisan, 1999).

The models developed by Henk and Hubbard and Pulugurtha and Nambisan were assessed to determine which elements should and could be applied toward a new tool for small transit systems. A number of elements within these models were then developed and tested to determine which worked best for the tool being developed to forecast transit ridership potential as part of this thesis.

The general process followed in the development of the analytic tool included:

1. review of key elements used in previous research work to determine or predict transit ridership;

2. review of data readily available from Statistics Canada census;

3. development of a tool to forecast transit ridership potential

4. analysis of data provided through the case study

5. testing of the analytical tool and validation using the case study data 
6. refinement of the analytical tool

The final product is a generic GIS tool applicable to smaller transit systems. Figure 1.3 outlines the methodology followed for this development of the analytic tool.

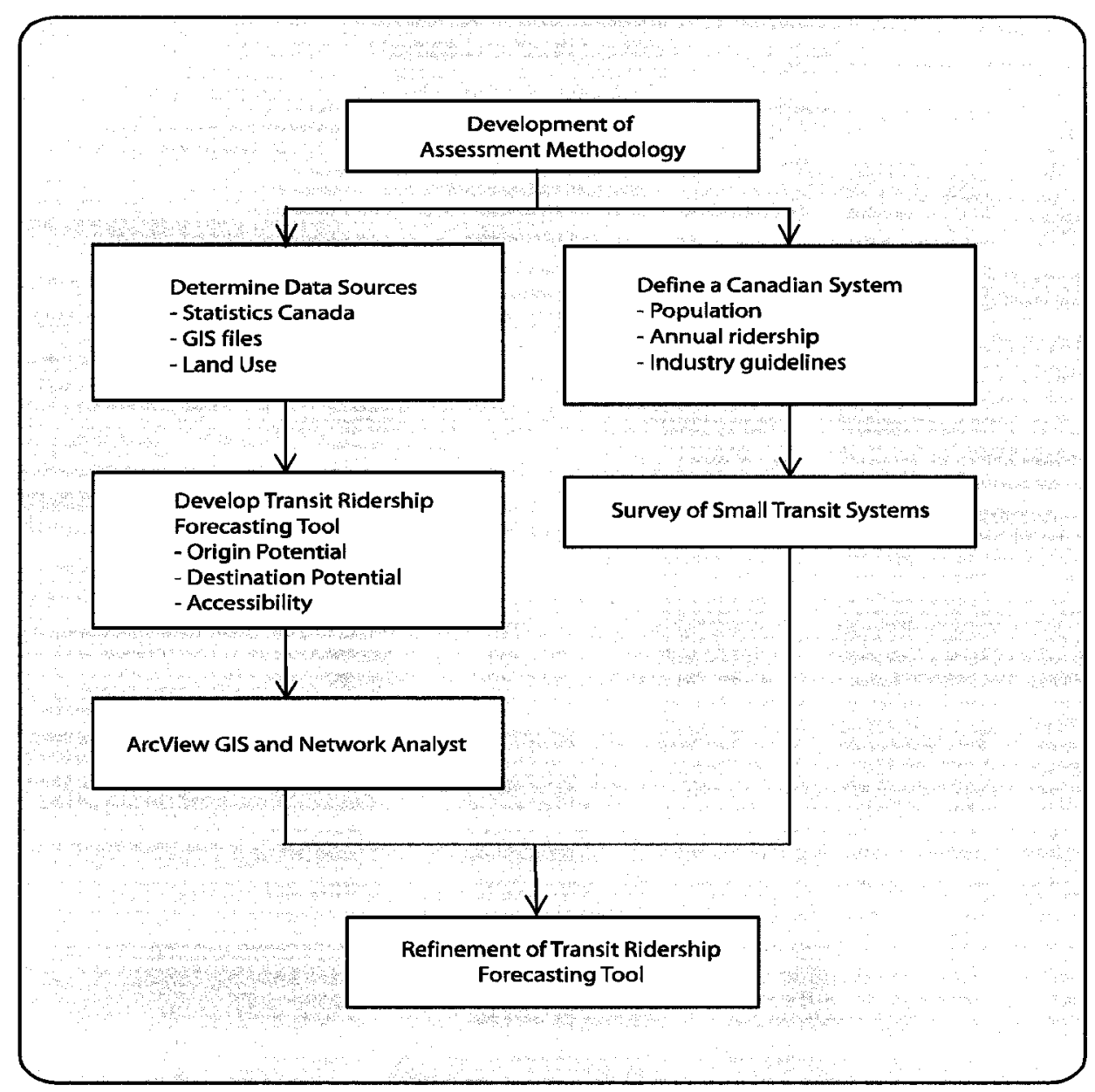

Figure 1.3 - Study Methodology

\section{Case Study}

A suburban community within the City of Ottawa, Ontario was used as a case study to test the tool developed to forecast ridership potential. The east end community of 
Orléans had a population of approximately 100,000 residents (2001 Census). In recent years, this has increased significantly, mainly through new residential development. Orléans was its own city prior to municipal amalgamation in 2000 and it is geographically separate from the larger City of Ottawa. It is located within the outer edge of the City of Ottawa's Greenbelt, a wide belt of agricultural lands surrounding the urban core. As such, it is a good representation of a small city, as shown in Figure 1.4 and it was easy to isolate trips to and from Orléans.

Data for the case study was provided by the City of Ottawa Transportation and Transit Department, also known as Ottawa-Carleton Transportation (OC Transpo). Data related to GIS files (e.g. road network, land use, parks, schools) as well as Automatic Passenger Count (APC) data from the transit department. Both types of data (GIS and APC) were used to test the tool developed. Other information gaps were found and supplemented as needed (e.g. pedestrian pathway information).

As mentioned above, actual land use, census and transit data was used to test the analytic tool that was developed. This allowed refinements to occur within the development phase.

The Case Study analysis was for a suburban community within the larger City of Ottawa. As such, more detailed data was available than would be typical for smaller municipalities. This allowed for a validation of the analytic tool by comparing actual data against predicted data. 


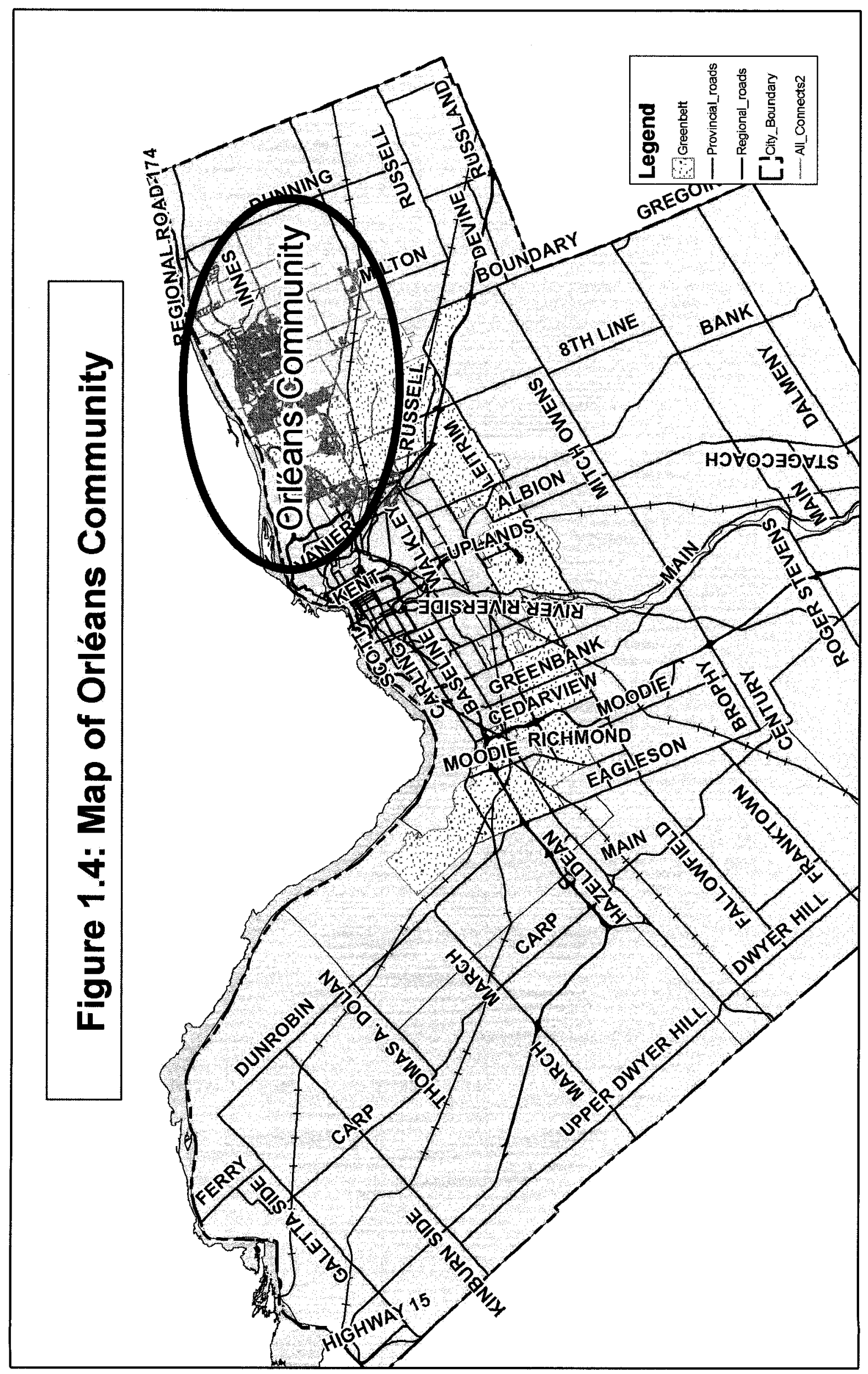

17 
ESRI's ArcGIS product was used for convenience and familiarity with the software (ESRI, 2006). The functions of the software extension employed (Network Analyst) are available from other GIS software products.

\section{Study Conclusions and Recommendations}

A summary of study conclusions and recommendations was compiled once the transit ridership forecasting tool was developed to provide guidance for future refinements.

\subsection{Scope of Research Work}

The research work carried out for this thesis was meant to provide a general sense of current advances within the transit industry while understanding that this is an emerging area of development. A number of powerful software tools are currently available to carry out more refined analysis of transit market share and system performance however, the inner workings of such software applications are proprietary and their complexity is not well suited to the assessment needs of smaller municipalities.

\subsection{Thesis Organisation}

This thesis report is organized into several chapters to facilitate comprehension. The four main chapters relate to:

- Literature review 
- Characterization of small Canadian Municipalities

- Development of a GIS-based tool

- Case Study Application

Each chapter is further broken down into sections as appropriate to bring an additional level of detail forward.

Much reliance is placed on the GIS and census aspects of the analytic tool. As such, a major component of this report relates to use of specific GIS functions. Descriptions of these GIS functions have been included within this thesis to better describe the capabilities of the GIS tools utilized. 


\section{Chapter 2: $\quad$ Literature Review}

The literature review conducted for this thesis had a number of purposes. Firstly, it was directed at establishing the state-of-the-art in transit-related GIS applications. The second purpose was to determine whether any tools or models had been developed to assess transit ridership potential. A third purpose was to document best practices in the use of GIS such that smaller municipalities embarking in its use could benefit. Each of these subsets of the literature review is discussed separately below.

In order to facilitate further discussion, a brief introduction to Geographic Information Systems (GIS) is presented below.

\subsection{Introduction to Geographic Information Systems}

Geographic information systems (GIS) technology is a combination of cartographic data (i.e. mapping) and tabular data (e.g. database). It allows users to input, manipulate, analyze and output data, adding a spatial dimension to data analysis. A relevant example of a GIS related to this thesis is highlighted in Figure 2.1.

The first element shown is a table listing travel to work characteristics related to each individual Census District. The second element shown is a map of the suburban community of Orléans within the City of Ottawa, Ontario, separated into Census Districts as established by Statistics Canada. The third part of Figure 2.1 is the combination of both elements within a GIS. 
Figure 2.1 - GIS Example

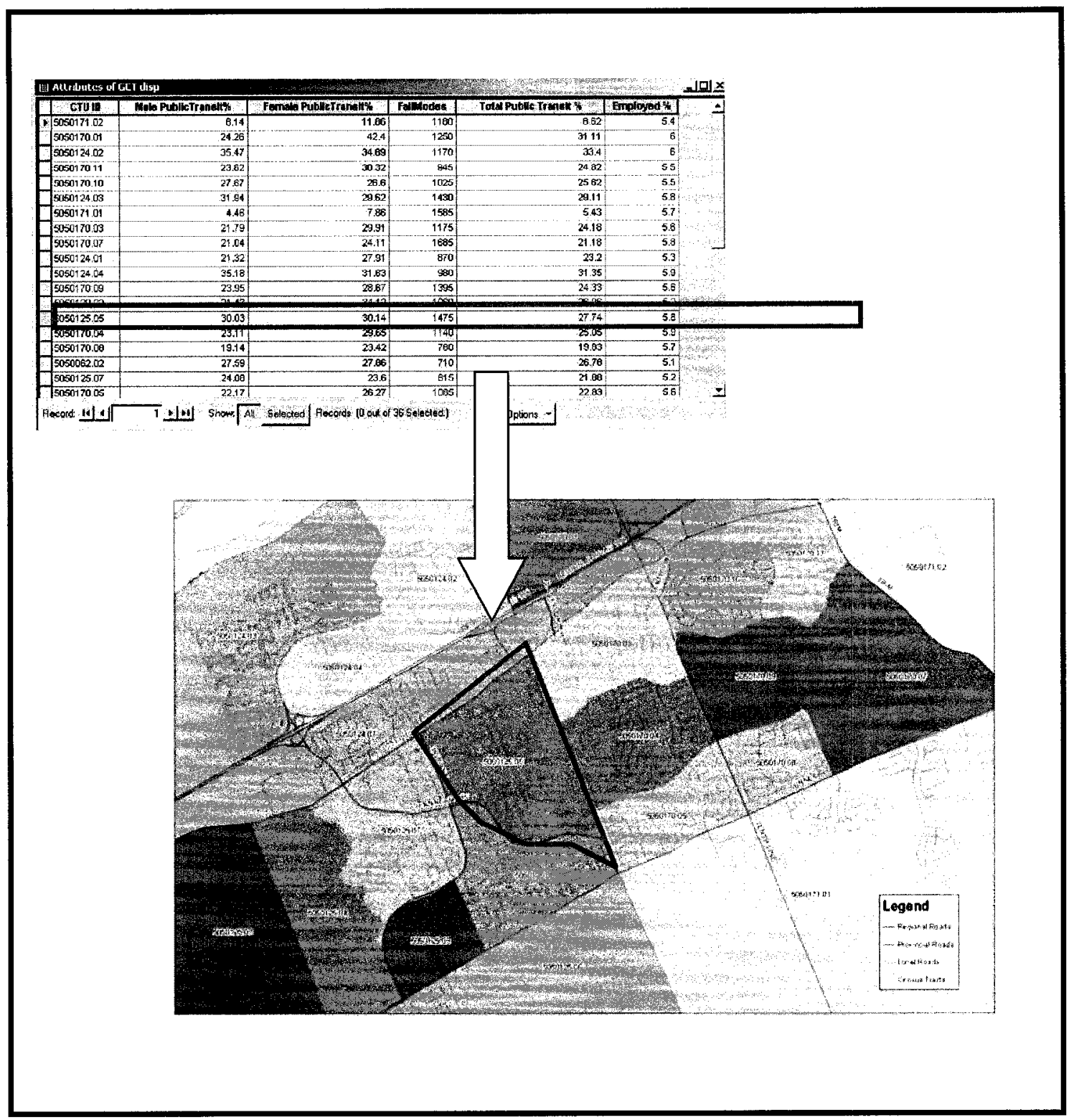


The software is displaying Census Districts shaded based on their unique identification number. The table links the respective transit modal share information for each Census Tract as recorded during the 2001 census survey. The Census District with the highest reported transit mode share is highlighted. Any number of such queries can be completed within a GIS.

Generally, map features are represented through one of three types of features:

- Point features, e.g. bus stops, timepoints, landmarks;

- Line features, e.g. road centreline, transit route; and

- Polygon features, e.g. census district, municipal boundary.

Tabular data related to a given feature is then "linked" to the GIS through a unique identification code that is common in both the GIS feature and the tabular data set. In the case of transit analysis, a GIS allows integration and subsequent analysis of a wide range of geographic information including:

- Transit routes

- Transit stops and stations

- Street network

- Pedestrian network

- Land use

- Census areas

- Population and employment areas

- Points of interest (e.g. major trip attractors and generators) 
A traditional transit route analysis might include reviewing passenger activity along a given route to determine whether existing stops are well utilized. A GIS would allow transit planners to visually assess this information. For example, bus stops that fell within defined passenger activity thresholds could be highlighted by running GIS data queries. To do this, a bus stop point feature would have to be available in a geographically referenced file within a GIS and given unique identification codes. Bus stop utilization data would have to be organized in tabular or database format using the defined identification code.

A relevant example of a GIS related to this thesis is highlighted in the following graphic (Figure 2.2). It includes tabular and graphical representations of bus stop information.

\subsection{Recent Developments in GIS and Transit}

Continuous advances in GIS are leading to an increase in its use and value in the realm of public transit. In addition, the ubiquity of GIS within many sectors other than transit is leading to greater affordability of software products and an increased level of comfort with the technology (Multisystems Inc., 2000). It is increasingly common to find some level of GIS use in smaller municipalities in any number of service areas (e.g. road maintenance, wastewater operations, building code inspections). 


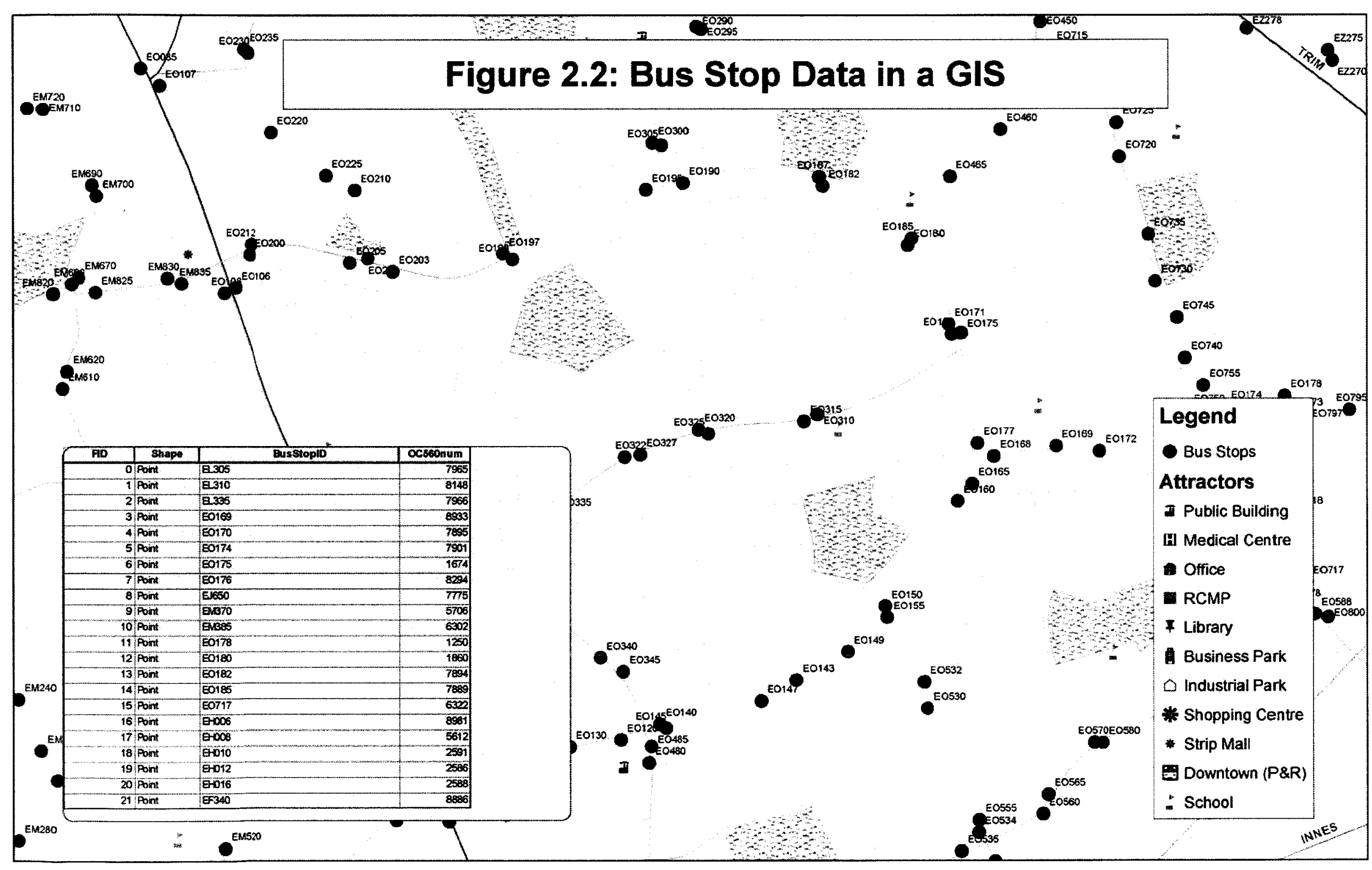


Within the transit realm, GIS is being used in conjunction with a number different technologies:

- Automatic Vehicle Location (AVL) for transit planning/ data analysis through use of Global Positioning System (GPS) technology;

- Web-based, real-time arrival info for passengers (integration with GPS) to assist with route planning;

- Asset management related to fleet and facilities (including bus shelters, bus stops) (Sutton, 2004).

One of the challenges this widespread use of GIS presents is that the range of transit software applications in use have different data requirements, standards or precision levels for the GIS data. This complicates matters when software applications use the same feature (i.e. point, line or polygon) but with different precision levels. An example of this could relate to the tracking of a bus stop point feature that has attributes of "with" and "without" passenger shelters for asset management or maintenance purposes versus an application that uses the bus stop point feature for tracking on-time performance at bus stops along a given route (Federal Transit Administration, 2005).

In the above example, the level of detail is coarse for inventorying or tracking purposes, requiring only a rough estimate of geographic location. However, using this coarse level of detail within an Automatic Vehicle Location application may not be sufficient, requiring data for bus stops to be input again. This either duplicates effort or requires 
that two separate sources of data be created and maintained, neither of which is desirable, especially if technical support is limited within the transit department or municipality.

A 2004 publication by the Transit Cooperative Research Program (TCRP Synthesis 55) examined GIS use within small to large transit organizations (Sutton, 2004). TCRP Synthesis 55 - Geographic Information Systems Applications in Transit: A Synthesis of Transit Practice included the results of a survey of over one hundred transit agencies but focused its assessment on five large transit systems. The synthesis highlighted that GIS use requires information technology (IT) capabilities and regular maintenance of spatial data (Sutton, 2004).

The TCRP Synthesis 55 raised concerns about potential compatibility issues between older spatial data that is proprietary to transit agencies and more current GIS formats used by software vendors. There are trends toward "open source" programming that may address this. Also, the use of more advanced geospatial technologies such as Global Positioning Systems (GPS) and products that can orthorectify (i.e. spatially correct) remote-sensed data may remove some of the challenges associated with data compatibility (Sutton, 2004).

In some respects, it is suggested that it may be best to migrate to more current GIS formats when initiating a new project instead of employing another element of software technology to "correct" or re-format older data. TCRP Synthesis 55 cautions about 
relying on software tools too heavily and relying on a user's analytical ability too little (Sutton, 2004).

Within the large transit agencies surveyed, GIS use is generally classified into one of three categories (Sutton, 2004):

- project-specific,

- departmental and

- enterprise.

Project-type use as the name suggests is meant for single goal applications such as bus stop location inventorying or ridership analysis. Departmental use would apply to a route planning initiative within the transit department. Enterprise level use of GIS is more closely intertwined with Information Technology (IT) services and would be part of an organization's way of doing business (Sutton, 2004).

New and smaller transit systems are entering the "business" of GIS for assistance with transit operations and planning analysis. While this has typically been the domain of larger municipalities, a number of factors are making this a wise choice for small systems. Of the three types of GIS use listed above, the project level seems best suited for smaller municipalities.

Before starting a project, smaller municipalities should understand what the desired outcomes are. Future functionality could be compromised by early decisions about level 
of detail of spatial data (e.g. use of GIS for managing bus stop amenities as an asset may not require the same level of detail as AVL applications might). According to Sutton (2004), the main areas of the transit business in which GIS is used are:

- planning,

- IT,

- management,

- operations, and

- customer service.

For the purpose of this thesis the focus was on planning. It was important to determine the ease with which socio-economic information and other required GIS data could be obtained. This is discussed in Chapter 4. Another consideration for smaller municipalities is the level of staffing support available to maintain spatial data and perform analyses (Multisystems Inc., 2000).

The transit organizations that have employed GIS have included the following as benefits (Sutton, 2004):

- Better geographic and visual representation of transit data (e.g. ridership data, stop locations) that aids communication with decision makers and the public;

- Ability to match demographic information with bus routes;

- Ability to analyze more complex scenarios;

- Strong tool for analyzing repercussions of decisions affecting population served, market share, ridership forecasts, etc.; 
- Ability to assist with vehicle tracking and scheduling tasks, and

- Ability to link to regional travel model.

Opportunities for improvements exist in trying to sell the usefulness of GIS to management. Data sharing and links with the Internet are also areas to improve upon. The ability to integrate different GIS software packages generally requires more effort.

\subsection{Relevant Ridership Forecasting Models}

The GIS tool developed for this thesis had the objective of forecasting transit ridership for the purposes of transit planning. A number of sources were found that contained information relevant to these objectives (Sutton, 2004, Multisystems Inc., 2000, Pulugurtha and Nambisan, 1999, Henk and Hubbard, 1996, Alshalalfah and Shalaby, 2007). Where applicable, the information gleaned from these sources has been summarized in the sections below.

\subsubsection{Welfare to Work Example}

A relevant source consulted for this thesis related to a study of a U.S. welfare to work program. This example was worth exploring because of the origin-destination type analysis included within the research. Research from the TCRP Report 60 described spatial and temporal "mismatches" whereby workers from either rural or central city residential areas were assigned difficult to reach suburban employment areas or worked hours that were not conducive to transit use (Multisystems Inc., 2000). 
Other issues explored included having multiple destinations within an overall home to work trip (e.g. interim daycare or school stop) and changing travel needs as employment status or location changed.

TCRP Report 60 suggested that the application of GIS could relate to four areas (Multisystems Inc., 2000):

- policy development,

- service planning,

- trip planning, and

- program evaluation.

\section{Policy Development}

In the first instance a GIS could point out problems with the current matches between program participants and employment characteristics in much the same way that a conventional transit system could assess whether its target markets are well-served.

While less precision is required in the assessment of transportation policy and service planning, other factors come into play such as service available by time of day, service frequency, type of service (e.g. local, express, "skip stop") or other characteristics related to ease of use (e.g. route interlining and transfers). Assessments could lead to new policies about percentage of recipients (or target market segments) for which transit service is matched to their needs (Multisystems Inc., 2000). 


\section{Service Planning}

In terms of service planning, a forecast of where future program jobs might be located would help staff target candidate employers within transit accessible areas as opposed to areas where service is not well-suited. Information about existing employment areas can be gleaned from regional planning authorities, chambers of commerce, employment departments and in the U.S., through census data and the Bureau of Labor Statistics. This approach would also work well for conventional transit service planning and would require input from long-range planning authorities to gauge residential, employment and other growth relevant to transit. While planning for growth is important, the same is also true for reductions in population or employment levels (Multisystems Inc., 2000).

In the U.S., information related to work trips is captured through the Census Transportation Planning Package (CTPP), a state-sponsored data collection initiative. Since the survey is only administered on a five-year cycle, it may be somewhat dated in areas experiencing rapid change. This survey contains data relating to housing units, number of persons per household, number of workers (i.e. similar but more detailed than what the Canadian Census collects). It also includes work-trip information which can be used by transportation planners to assess transportation needs related to the work force and specifically the welfare to work program (Multisystems Inc., 2000).

Origin-destination relationships are an important part of understanding transportation demands. Some GIS packages have special functions that facilitate the visual depiction of these relationships. To reach this point, however, sufficient data must first be 
available. In the absence of work-related trip information such as that collected in the CTPP, individual surveys would be required to gain an understanding of the travel patterns (e.g. volume and distribution of trips).

\section{Trip Planning}

Important information about employers includes work hours, number of employees and number of available welfare to work jobs. Given the nature of welfare to work trips, the availability of on-site daycare at employment sites can be a factor in trip planning and may influence how easily a workplace can be reached using transit, if this is even an option. Availability of Transportation Demand Management (TDM) programs is also key. Ride sharing, flexible work hours increase the ease with which a work place can be reached. These factors all apply to conventional transit service and can help system planners understand whether transit service has enough of a potential market to be successful or whether additional demands can be satisfied through increased service levels (Multisystems Inc., 2000).

The key GIS elements for such trip planning applications and analysis are transit routes, bus stops, streets (including pedestrian accesses to key destinations such as a shopping mall) and landmarks. 


\section{Program Evaluation}

The success of a welfare to work program is dependant on a number of factors including strong matches between recipients and available transportation services. A GIS can be an important tool in assessing whether program recipients have access to and make good use of the public transportation systems in place. Through follow up information, analysts can determine which types of employment and transportation matches were more successful and base future program policies and services on these findings (Multisystems Inc., 2000).

The public transportation industry is continually changing and adapting to its customers' needs. As such, a GIS would also be a useful tool for transit planners to employ when evaluating the effectiveness of new initiatives.

\section{Other Considerations}

Software and human resource requirements are important considerations in a decision to embark on a GIS-based initiative. It is important to understand the project, program and assessment needs before moving ahead. A commitment to having dedicated staff may be required, depending on the scope of work unless GIS resources are already available within a department if a GIS section is already in place for other purposes (Multisystems Inc., 2000). 


\subsubsection{Transit Market Potential}

Attracting and retaining ridership has long been an important goal for transit agencies. In the province of Ontario this has recently become even more key through implementation of a ridership-based provincial funding formula. All new and existing transit systems in Ontario compete for their share of funds levied through a gas tax (Ministry of Transportation Ontario, 2004).

Transit systems are striving to keep their existing customers satisfied while expanding or enhancing service to attract more riders. A number of publications were found related to transit ridership or "market potential" (Henk and Hubbard, 1996 and Pulugurtha and Nambisan, 1997, Pratt et al., 2004). The most relevant defined the latter according to a combination of demographic characteristics and ability and ease with which a user could access transit (Pratt, 2004, Multisystems Inc., 2000). The measure of transit potential is represented by an index based on demographic criteria such as employment, household size, vehicle ownership, etc. (Pulugurtha and Nambisan, 1999).

Pulugurtha and Nambisan describe a Transit Service Facility (TSF) location as playing a significant role in the attractiveness of transit to the user. A TSF is a bus stop, rail station or other multimodal centre from which a user has direct access to public transit service. Accessibility is further defined as walking distance or walking time from a user's point of origin to a given TSF (Pulugurtha and Nambisan, 1999, Victoria Transportation Policy Institute, 2007). 
Advances in GIS analysis capabilities have made the quantification of such metrics as walking distance easier through the use of specialized network tools (e.g. software package add-ons). Previous estimates based accessibility on a buffer distance from a given transit route. This has the effect of over-estimating accessibility since, in reality, a given transit route can only be accessed through a TSF point. The accessible transportation facilities in the vicinity of one TSF include all roads, sidewalks and other pedestrian linkages that connect to potential trip origins (residences, employment areas, schools, etc.).

The overall success of a transit system is linked to more than user accessibility. Other factors influencing success include the frequency with which service is provided, the fare structure, the reliability of service, the location of TSF's, the ease with which TSF's can be accessed and less tangible elements such as comfort, convenience and safety (Pulugurtha and Nambisan, 1999, Chavarria and Volinski, 2004).

TSF spacing and location are prime influences on system availability and reliability (Regional Transportation Commission of Clark County, 1999). Accessibility, or access opportunity, is defined as "the spatial quality of the relation between location of infrastructure facilities and the location of the users" (Bach, 1981). In simpler terms, this is the walking distance between a user's origin and the transit stop.

There is no set limit within the transit industry of maximum walking distance or walking time to a TSF. A walking time at average speed of 5 minutes generally coincides with a 
350 to 400 metre walking distance which, according to Pulugurtha and Nambisan, is a generally accepted threshold with most transit operators.

TSFs can have several functions including transfer site between different routes, time point for schedule adherence purposes and typical passenger loading/alighting stops. It is important to note that typical stops have the most flexibility to be changed, in terms of location. Stop locations that link other routes in the transit network or that are time points cannot easily be changed.

There are a number of options to increase ridership potential through greater accessibility. Additional transit routes can be used to cover a greater geography using a set TSF spacing or TSFs can be located more frequently along given transit routes (i.e. closer spacing), requiring buses to stop more often. Adding more routes to serve a higher number of TSFs while maintaining the same service on existing routes involves greater transit operating costs due to the additional buses and bus operators required to provide such a service. A cost-effective solution would be to optimize the location of TSFs, in order to maximize the number of transit trip "origins" within each of their catchment areas. Yet a third option would be to target additional TSFs (i.e. with closer spacing) within areas of higher ridership potential.

Decisions to add or remove service must be made in conjunction with a review of passenger loading characteristics. Where bus loads reach capacity for longer periods than 
desired, additional service frequency could be warranted somewhat independently of TSF location.

On-board Automatic Vehicle Location technology combined with Automatic Passenger Count capabilities would provide a municipality with ample data to determine how well utilized TSFs are during different times of day. Manual counts or use of an AVL system combined with appropriate fare box technology are also suitable methods to obtain sufficient data for analysis.

Other than fare structure, the factors listed below are considered to be key in influencing transit use (Pulugurtha and Nambisan, 1999):

- Age and gender (less than 18 years and greater than 55 years)

- Income for the household (less than $\$ 15,000$ per year)

- Size of household (greater than 3)

- Auto-ownership within the household (less than or equal to 1)

- Number of unemployed persons

- Number of physically handicapped persons

These factors are not fixed and others should be added as local circumstances dictate or as research findings suggest. In Canada, for example, transit ridership among the working population is high and, as a consequence, should be a strong consideration in system design. 
Transit trip origins can include residential, employment and institutional land uses among others. The transit potential within a given area (e.g. containing varying land use types) can better be determined by reviewing its census information. While it is important for potential transit riders to be within close proximity to a TSF, ridership potential varies by income level, age group, employment status, level of physical ability, etc. That is, proximity to a TSF alone does not necessitate that one will choose to travel using transit.

An index of transit potential was developed to assess the potential "captive" transit riders within a given area (Pulugurtha and Nambisan, 1999). Captive riders were defined as the population segment that does not have access to any other modes of transportation and by virtue of income level or employment status does not have a choice other than being transit users.

The index of "captive riders" established is based on a ratio of users in the transit accessible area to total users in the study region (multiplied by 1000 for normalization), summed for all variables (Pulugurtha and Nambisan, 1999).

Index of Transit Potential ${ }_{j}=\Sigma_{i}\left(n_{i j} / N_{i} \times 1000\right)$

where:

$j$ is the TSF number

$i$ represents the characteristic assessed (e.g. income, age, vehicle ownership, etc.)

$n_{i j}$ is the number of users belonging to characteristic $i$ within the region served by TSF $j$

$N_{i}$ is the total number of users belonging to characteristic $i$ within the study area 
This index of transit potential formula shows all variables as having the same weight, however it is suggested that these can be weighted if desired to more closely reflect local conditions or circumstances.

A case study was assessed that tested the above index along an existing transit route within the Las Vegas metropolitan area (Pulugurtha and Nambisan, 1999). Potential TSFs were located at 120 metre spacing along one entire route to determine which had the highest ridership potential. The route was redrawn using proposed TSFs with the highest potential ridership and a maximum distance between TSF of two times the maximum walking threshold (i.e. 722 metres). This maximum walking distance ensures that two TSFs don't overlap and that a transit user living between both points would still only have to walk 366 metres.

The same overall number of TSFs was maintained in the proposed network as in the existing case. For all seven indices selected, the proposed network and grouping of TSFs encompassed areas of greater transit potential, even though the single TSF with the highest potential was only captured within the existing network.

The proposed TSF were different from those that the local transit systems had independently assessed and selected. The case study only included an assessment of residential potential and it was acknowledged that inclusion of other important land use types would have influenced the analysis (Pulugurtha and Nambisan, 1999).

Socioeconomic and political factors were also not included. 
A more detailed assessment might have included more practical TSF locations or locations that fit with existing municipal practices (e.g. policy to use far side stops).

Also, examining all routes within a given corridor or area would give a truer measure of service provided given that it is possible that not all routes operate at all TSFs along a corridor (e.g. "skip stop" operations). The researchers suggested taking all routes and all TSF locations within the system into account. They further suggested that road classification and pedestrian restrictions be considered within any further analysis (e.g. highways are not actually accessible to pedestrians and could provide false indices for accessibility).

TCRP Report 95: Chapter 10 contains a chapter related to bus routing and coverage. A section on transit accessibility reinforces the importance of walk time to reach transit service. A 1991 Boston study of work-purpose trips reported much higher percentages (over 55\%) of residents boarding transit within $1 / 4$ mile of a transit stop, with ridership declining proportionately as distance to the transit stop increased for residents (Pratt, 2004).

TCRP Report 95: Chapter 10 also included an analysis of ridership characteristics for a number of cities in the United States. Elements of Table 2.1 that align with data collected through the Canadian Census are replicated below for the data set in the 50,000 to 200,000 population range and include a range of transit use indices under the following potential market segments: 
- Sex;

- Vehicle ownership;

- Age of worker;

- Education; and

- Annual household income.

It should be noted that the average transit share for this size of municipality is very low, shown to be between 0.8 and $3.3 \%$ for those included in the study. The following table (Table 2.1) was extracted from TCRP Report 28A (Rosenbloom, 1998) and presents consolidated indices for the market segments that were shown in TCRP Report 95, Chapter 10.

Table 2.1 - Market Segment Elasticities

\begin{tabular}{|l|c|}
\hline Market Niches & $\begin{array}{c}\text { Population Range } \\
\mathbf{5 0 , 0 0 0} \text { to 200,000 }\end{array}$ \\
\hline Sex & $0.62-0.95$ \\
Men & $1.06-1.42$ \\
Women & \\
\hline Immigration Status & $0.64-0.95$ \\
\hline Non-immigrant & $1.13-2.15$ \\
Immigrant & \\
\hline Vehicle Ownership & $7.06-13.45$ \\
\hline No Car & $0.48-0.69$ \\
One or More Cars & \\
\hline Personal Limitations & $2.29-5.20$ \\
\hline Work Limitation & $0.47-14.68$ \\
Mobility Limitation & \\
\hline Age of Worker & $1.15-1.30$ \\
\hline 17-29 & $0.80-1.02$ \\
30-39 & $0.69-0.87$ \\
40-49 & $0.82-1.08$ \\
50-59 & $0.50-2.16$ \\
\hline $60-69$ & \\
\hline Education & $1.31-7.46$ \\
\hline No/ Elementary School & \\
\hline
\end{tabular}




\begin{tabular}{|l|l|}
\hline Jr./ Some High School & $1.36-2.46$ \\
High School/ Some College & $0.58-1.07$ \\
College/ Grad. School & $0.51-1.18$ \\
\hline Annual Household Income & \\
\hline Less than $\$ 10,000$ & $0.91-1.90$ \\
$\$ 10-\$ 20,000$ & $0.74-1.54$ \\
$\$ 20-\$ 30,000$ & $0.20-1.28$ \\
$\$ 30-\$ 50,000$ & $0.48-0.80$ \\
$\$ 50-\$ 70,000$ & $0.31-0.83$ \\
Greater than $\$ 70,000$ & $0.30-0.91$ \\
\hline
\end{tabular}

Source: Rosenbloom, 1998 and Pratt, 2004.

While the scope of this thesis did not include the introduction of new transit systems, an interesting study was found on this topic during the literature review. A presentation was made at the Institute of Transportation Engineers annual meeting in 2005 describing formulation of a transit plan for the community of Deming, New Mexico in the United States.

A market assessment for a new transit service was carried out through an evaluation of Census data and land use information. Transit dependant populations were identified and mapped using GIS. These potential "captive" transit riders included people with limited mobility, low income, ages greater than sixty and/or those not owning vehicles. A transit route was identified based on the potential riders (Czerniak, 2005).

Key activity centres were identified within the GIS as point features and included schools, health care facilities, government establishments, retail centres, etc. A transit route was ultimately identified based on these potential destinations. Both transit routes were then reconciled into one transit route that would most effectively serve passenger 
origins and destinations. The "lessons learned" portion of the presentation indicated that weighting of different ridership groups may have been a useful technique to incorporate but no indication was given as to how to weight these factors.

\subsection{Walk Access Distance to Transit}

A case study of walking access to transit was conducted of the City of Toronto (Alshalalfah and Shalaby, 2007). This case study examined the walking distance that transit passengers travelled to gain access to the transit system. A GIS was used to determine airline distance between a home-based point of origin and a transit stop. The analysis examined the relationship between access walk distance to transit and socioeconomic and demographic characteristics of the transit users.

Travel characteristics examined included trip purpose (limited to work and school), length of trip and number of transfers made but these were found to have a weak relationship with walk access distance. Transit user characteristics examined included type of household (limited to houses or apartments), number of vehicles in the household, age, gender, possession of a transit pass and possession of a driver's license.

The study concluded that in a City such as Toronto transit service characteristics (i.e. route spacing, frequency and geographic area within the City) have an obvious relationship to walk access distance to transit. Transit users were generally willing to walk an additional 100 metres to access higher order transit (i.e. subways). Over $60 \%$ of transit users within the Toronto area were found to live within 300 metres (airline 
distance) to transit service, while $80 \%$ live within 500 metres. The study concluded that transit users were willing to walk farther than existing 300 metre standard used by the Toronto Transit Commission to define transit service area (Alshalalfah and Shalaby, 2007).

Most relevant to this thesis, it was found that socio-economic and demographic characteristics had $\mathbf{n}$ relationships with walk access distance to transit. Transit user characteristics ' to walking access distance using a univariate empirical approach. It was sugge. ultivariate modelling approach such as regression analysis might have addressed this limitation (Alshalalfah and Shalaby, 2007). 


\section{Chapter 3: Characterization of Smaller Canadian Transit Systems}

A Canadian context was selected for this thesis primarily because of the difference in quantity and quality of data available through the Canadian and U.S. census programs. A more detailed survey is undertaken in the U.S. and as such the scope of analysis Canadian municipalities can undertake with Statistics Canada data is more limited. There are other differences between the U.S. and Canada that also warrant separate analysis.

"With few exceptions, public transit has a more prominent role in Canada and Western Europe than in the United States. This is true not only in large cities, but also in many smaller communities and throughout entire metropolitan areas. Transit is used for about 10 percent of urban trips in Western Europe, compared with about 2 percent in the United States. Canadians use public transit about twice as much as Americans, although there is considerable variation across Canada, just as there is in Western Europe and the United States"1

An additional reason for focusing attention on Canadian systems is that GIS information follows slightly different standards in Canada as compared to the U.S. That does not necessarily impact the findings contained within this thesis, nor the applicability of the tool developed to smaller U.S. transit systems but was a consideration.

\footnotetext{
${ }^{1}$ Making Transit Work. Transportation Research Board, 2001, p1
} 
Larger transit systems generally have sufficient human and capital resources to purchase complex GIS-based computer software packages or to develop their own in-house programs to assess and plan their commensurately complex transit systems. Smaller transit systems typically have limited staff. Their time is predominantly spent attending to day-to-day operational issues. Time and resources are not generally constrained with respect to undertaking planning or strategic-type initiatives.

The research framework followed for this portion of the thesis included preparation of a survey for small municipalities, selection of candidate municipalities to which surveys would be administered, follow-up contact to ensure that response was sufficient, compilation of survey responses and summary of findings, as shown in Figure 3.1.

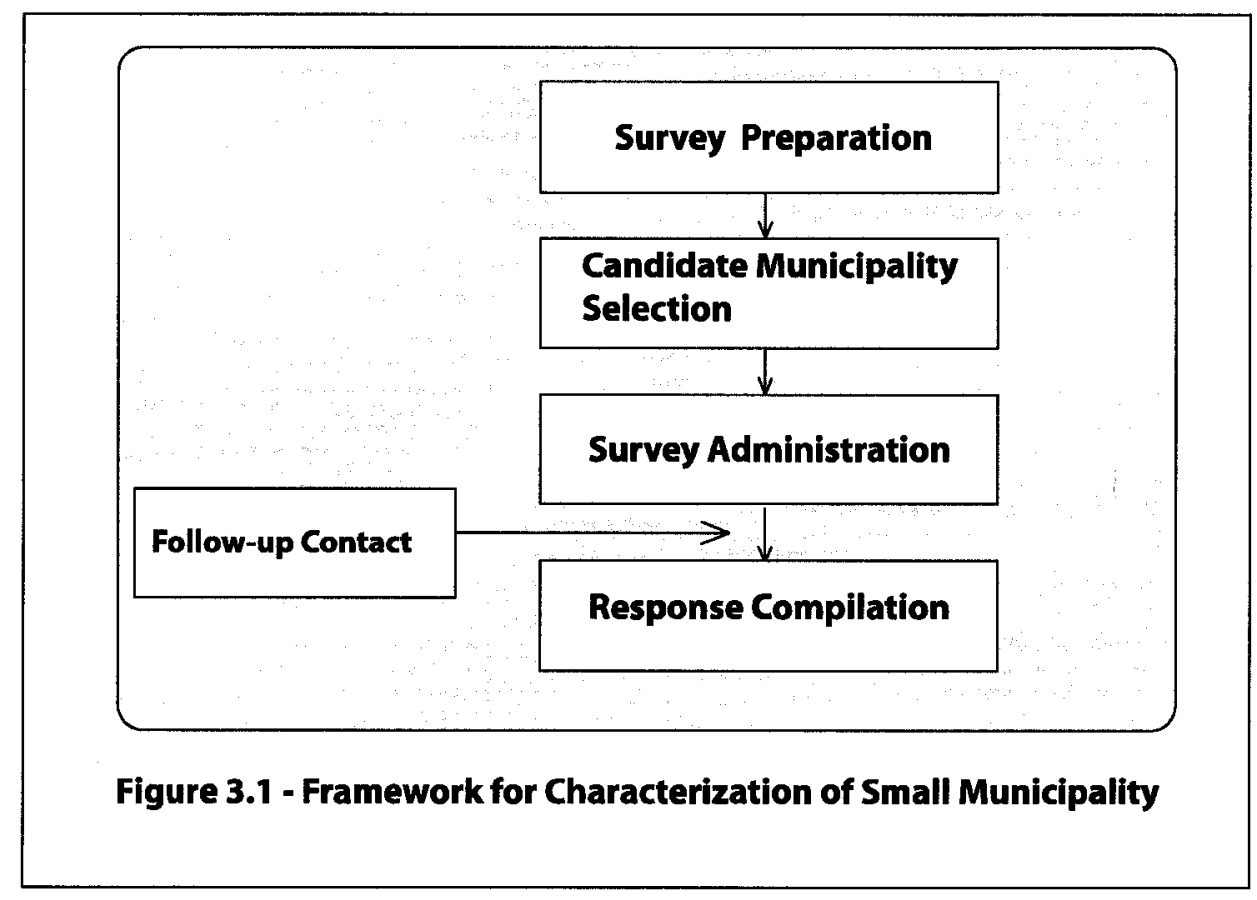




\section{Preparation of Survey for Small Municipalities}

A survey was prepared that could easily be administered to transit planning staff within small municipalities. The survey included a short questionnaire and a request for statistics about the municipality and its transit operations. Questions posed related to:

- Amount of time spent on transit operations versus planning;

- Use of indices to predict the effect of service changes;

- Use of GIS-based tools for data collection, service planning, information dissemination or other;

- Human resource capacity within the organization to learn to use and apply a GIS-based tool to gauge the effect of service planning changes;

- Importance of predicting the impact of transit service improvements; and

- Estimate of transit mode share within the municipality.

The survey also sought data pertaining to other municipal and transit system characteristics. A copy of the survey package is included in Appendix A.

\section{Selection of Candidate Municipalities}

For the purposes of this thesis, a small municipality is defined as having a population between 40,000 and 170,000 residents at the upper threshold. A number of Canadian Transit properties were contacted to gauge staffing levels and degree to which planning initiatives were carried out. It was also of interest to determine the level of GIS use within transit or corporately as well as to ascertain the degree of technology used on 
board transit vehicles either for passenger data collection or for schedule adherence purposes.

A number of indicators were reported by each of the municipalities to get an understanding of each system's unique circumstances. Table 3.1 lists the municipalities that responded to the survey and highlights service area population, land mass, ridership, revenue kilometers and finally, number of management or planning staff within the transit system. Where data was available transit mode share was reported. Of the transit systems surveyed, transit mode share ranged from $2 \%$ to $8 \%$.

Table 3.1 - Small Transit Systems Characteristics

\begin{tabular}{|c|c|c|c|c|c|c|c|}
\hline City & Province & Population & $\begin{array}{l}\text { Land } \\
\text { Mass } \\
\text { Total } \\
\text { (sq.km) }\end{array}$ & $\begin{array}{l}\text { Land Mass } \\
\text { Served by } \\
\text { Transit } \\
(\text { sq.km) }\end{array}$ & $\begin{array}{l}\text { Ridership } \\
\text { (annual) }\end{array}$ & $\begin{array}{c}\text { Revenue } \\
\text { Kilometres }\end{array}$ & $\begin{array}{c}\text { Number of } \\
\text { Management/ } \\
\text { Planning staff }\end{array}$ \\
\hline Brandon & Manitoba & 41,500 & 76.9 & 61 & 977,376 & $1,138,645$ & 1 \\
\hline Cornwall & Ontario & 46,000 & 61.5 & $53(85 \%)$ & 505,000 & 780,000 & $\begin{array}{c}\text { 0.5: Part of } \\
\text { Division } \\
\text { Manager's role }\end{array}$ \\
\hline Belleville & Ontario & 48,800 & 246.8 & 241.7 & 917,258 & 694,485 & $2^{*}$ \\
\hline Milton & Ontario & 54,000 & 366.6 & - & 85,994 & 353,858 & 1 \\
\hline St. Albert & Alberta & 57,700 & 36.0 & 36.0 & $1,140,433$ & $1,812,207$ & 3 \\
\hline Saint John & $\begin{array}{l}\text { New } \\
\text { Brunswick }\end{array}$ & 68,000 & 315.5 & 235 & $2,600,000$ & $1,791,601$ & $\begin{array}{c}\text { 2: General } \\
\text { Manager and } \\
\text { Operations } \\
\text { Manager }\end{array}$ \\
\hline Lethbridge & Alberta & 78,713 & 124.3 & $70-80$ & $2,268,468$ & $2,133,062$ & $\begin{array}{l}\text { 1: Planning } \\
\text { Manager }\end{array}$ \\
\hline Kelowna & $\begin{array}{l}\text { British } \\
\text { Columbia }\end{array}$ & 106,700 & 211.7 & - & $3,118,000$ & $1,520,000$ & $\begin{array}{c}\text { Alternative } \\
\text { Service Delivery }\end{array}$ \\
\hline Guelph & Ontario & 115,000 & 88.0 & 88 & $5,115,929$ & $3,915,929$ & 5 \\
\hline Kingston & Ontario & 117,207 & 450.4 & 131,170 & $2,952,643$ & $2,701,360$ & $\begin{array}{c}\text { 5: Manager plus } 4 \\
\text { Operational } \\
\text { Supervisors)* }\end{array}$ \\
\hline Burlington & Ontario & 164,400 & 185.7 & 98 & $1,672,787$ & $2,738,975$ & 7 \\
\hline
\end{tabular}

A more qualitative approach was taken to determine the level of planning effort that takes place within smaller transit systems. Respondents provided feedback on a number of 
questions related to time available for planning initiatives as opposed to operations; type of indices used to gauge service improvements and availability of staff for use of a GISbased tool for planning.

In terms of planning efforts, responses indicated that anywhere from $5 \%$ to $30 \%$ of efforts were directed at transit planning initiatives with the balance of time dedicated to operations. This varied according to the range of staffing support available. The only exception was the City of Kelowna where operations are contracted out and a combination of municipal staff and BC Transit (the provincial crown agency delivering transit service for the entire province except the Vancouver region) concentrate on planning. Many reported that operations demand full attention until specific planning initiatives are set in motion at which point the focus shifts until the initiative is complete. Examples of planning initiatives include route changes, service expansions, cyclical system reviews, etc.

If indices are indeed in use to gauge success of service changes, these include quantitative and qualitative measures. Surveys or observations (e.g. feedback from operators) are used to determine success for new service or service expansion. Cost recovery ratios are also commonly used. Some municipalities have set service standards for cost recovery and accessibility (or service coverage) or targets for travel time. Others base the success of their initiative on performance comparisons with similar routes (e.g. overall ridership, passenger boardings per hour, compatibility with land use and demographics). 
In terms of GIS use within the realm of transit some respondents indicated that their mapping is done through GIS. Generally, smaller transit systems have fewer staff available to concentrate on planning initiatives and as such, use of any GIS tools would have to be delegated to resources external to the transit department (e.g. City staff or specialist staff with GIS capabilities).

All respondents indicated that it was very important to have the capability to predict the impacts of service planning changes, especially as this related to municipal budget cycle input. This allows for better tracking of actual versus expected performance and gives transit management the opportunity to intervene if planning efforts don't materialize.

\subsection{Transit Challenges in Canada}

Generally, funding for transit is a challenge for Canadian municipalities. Though the funding climate at provincial and federal levels has improved in recent years, a lack of stable funding for transit operations led most systems to rely solely on municipal funds to support operations and capital projects.

The most recent development has been the allocation of a portion of the federal gas tax levy for transit as part of the "New Deal" for cities and communities (Department of Finance Canada, 2005). The equivalent of five cents per litre of fuel is now set aside and re-invested in transit. Certain provinces have followed suit. 
In Ontario, two cents for every litre of gasoline sold in the province is redistributed to municipalities that operate transit systems or are planning new start-up systems. The annual allocation of funds is based on a transit system's overall share of ridership within the province (Ministry of Transportation Ontario, 2004). This places emphasis on all techniques to increase ridership. Increases in future years' funding are dependant on a transit system's ability to increase ridership levels above those of other systems.

While some municipalities and regional transportation authorities have started to use innovative methods to fund and deliver transit services, these have not spread across all jurisdictions. Smaller transit systems continue to compete for funds within municipal budgets.

In the U.S. the Intermodal Surface Transportation Efficiency Act (ISTEA) serves as an integrated national transportation strategy that includes transit among the transportation system solutions recommended for funding. There is not a parallel initiative in place in Canada to assess all transportation issues as a whole. At the time of writing, the federal government's Infrastructure and Transport departments were moving toward a National strategy for transit (CUTA, 2007).

The challenge for Canadian transit systems is to find sufficient funds to maintain and expand operations in order to stimulate and accommodate ridership growth. For smaller municipalities this challenge is compounded because of limited human resources on the more strategic side of transit: planning. Despite this, an increase in the use of GIS at a 
municipal level and better technology tools for transit data collection may provide options for smaller transit systems in the analysis of ridership potential.

\subsection{Defining a "Small" Canadian Municipality}

This research seeks to develop a GIS-based tool for smaller municipalities to use in their assessment of their transit route operations and planning. Large municipalities generally have sufficient funds and staff resources to implement large transportation or transit models to undertake route analysis. These typically include a study of origin-destination relationships and related forecasting.

Transit systems in smaller cities often do not have the resources for additional staffing or technological resources and must rely on their knowledge of their transit system to assess how their system is doing. Some have developed indices to gauge performance while others make assessments based on years of hands-on experience.

\subsubsection{Characteristics of a Small Municipality}

Municipalities can be different even if they fall within a similar size in terms of population. Socio-economic and demographic factors weigh in to define one municipality's populace as having higher income levels, higher education levels, greater mobility, or higher seniors representation than another. Such factors can help define how many potential transit riders a community might hold. Assessing the transit market potential and comparing it to service already provided (or using it to establish a new 
transit service) would equip decision makers with important information with which to undertake modifications to their transit system design.

There are a number of ways in which a municipality can obtain information related to its socio-economic and demographic status. Undertaking a survey of the population is one means. However, this can be a fairly onerous and expensive exercise depending on the response rate sought. A statistically valid sample is required and the number of questions included in the survey must be kept to a minimum. As such, a more commonly used method is for transit properties to conduct their own surveys of existing customers in order to obtain information related more specifically to transit. However, this is a labour and time-intensive undertaking and a more cost-effective means to obtain this information would be to rely on available data such as that obtained through a cyclical census survey.

Certain provinces undertake periodic updates to population and growth information. However, these updates are mainly related to demographics and do not include additional information related to home-to-work trips that census surveys could incorporate.

\subsubsection{Available Data}

Statistics Canada is the country's national statistical agency. Every five years, it conducts a census of the Canadian population. The most recent census available is for 2001 though at the time of writing, data related to population and dwelling counts for the 2006 Census had been released and other reports were being prepared. 
It is a legal requirement for Canadian residents to complete one of two census forms, distributed randomly: a long form and a short form. The former requests information related to basic demographics (e.g. age, language, ethnicity). The latter is more detailed and includes questions related to travel to work, which were added to the Census in 1996. This information allows transportation professionals to assess and track travel mode choices made by the working population.

By contrast, the Census Transportation Planning Package (CTPP) includes work-trip information which can be used to better define origin-destination patterns, an initiative the Canadian Census is refining.

It is important to incorporate a number of characteristics to properly assess a small municipality's transit performance in relation to its potential. These characteristics include:

- Socio-economic measures (income level, education level, etc.)

- Demographics (age distribution)

- Land use patterns (e.g. Origin-Destination relationships, settlement type, development plans)

- Transit service provided (ridership, service hours, route structure, revenuepassenger kilometres, etc.)

- Auto environment (travel time comparison, modal split) 
Another useful benchmark is to understand the level of existing GIS or GPS technologies in place within the transit department or municipality as a whole. This helps to understand how amenable an organization would be to the introduction of a GIS-based transit tool. Often this is tied to the level of resources available within the transit organization. 


\section{Chapter 4: Development of GIS-based Tool}

Transit operations include everything from ensuring the fleet is in sound mechanical condition, to strategic placement of bus stops, to monitoring of schedule adherence. Transit planning on the other hand is more removed from day-to-day activities and focuses on longer term or strategic initiatives. Transit planning involves an assessment of how well transit services are being delivered and, through analysis of performance and ridership data, places emphasis on initiatives to improve quality of service and increase ridership (CUTA, 1993).

For the purpose of this thesis, an assessment of transit service coverage is suggested in order to determine how well routes capture latent transit ridership demand (i.e. "captive riders") and cover major destinations. Trip origins and destinations are equally important in a transit system's design and both must be optimized in order to satisfy the greatest number of customers' travel needs. Service frequency, reliability and ability to transfer are also important considerations but these are beyond the scope of this thesis.

The ridership forecasting tool developed in this thesis adopts bus stop locations as a proxy for the level of service delivered by the transit agency in a small municipality. Generally, the provision of higher order transit such as subways or light rail, is not costeffective in small municipalities. Transit service is most typically delivered on-street by buses that follow fixed routes. Service frequency during typical weekdays normally ranges from 20 minutes to one hour. 


\subsection{Measurement Functions for Transit}

There are a number of variables to consider in assessing existing transit service's ability to meet customer needs. It can be argued that accessibility (i.e. walking distance) is an important factor for passenger origins and destinations (Kittelson \& Associates Inc. et al, 2003). In addition, potential transit ridership can be defined using characteristics such as income level, age group, employment status, level of education, etc (Pulugurtha and Nambisan, 1999).

The following figure (Figure 4.1) illustrates some of the relationships between characteristics. As shown, transit ridership potential is based on having a sufficient number of transit patrons with certain characteristics as well as having a transit service that reaches places of interest to transit patrons. A successful transit system also provides a high quality service to patrons which includes good accessibility and service frequency and efficient route run times (Kittelson \& Associates Inc. et al, 2003). 


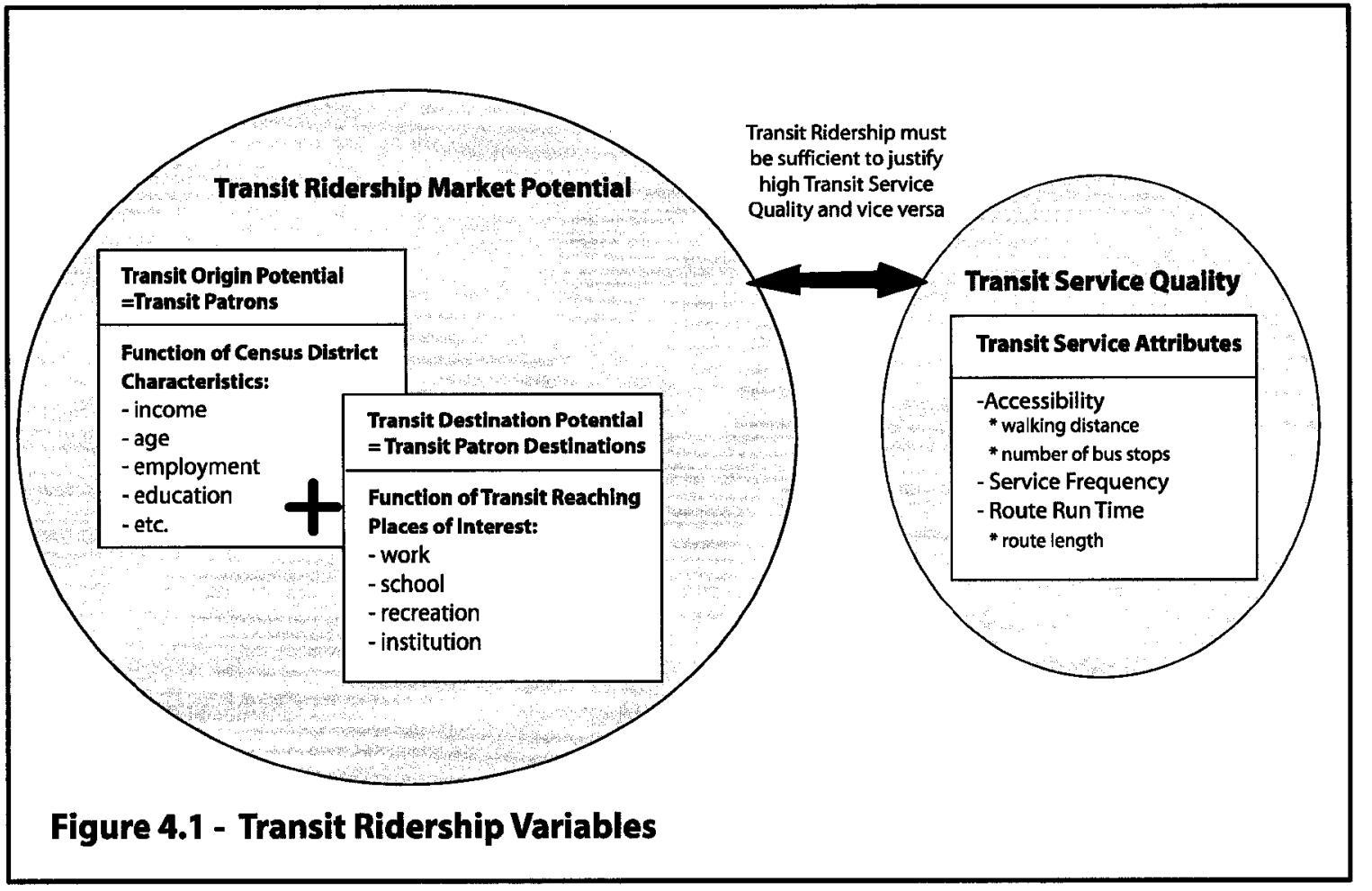

Transit riders gain "access" to the transit system at given points (i.e. bus stops) along transit routes. Maximizing the number of bus stops increases the accessibility of transit but also has other impacts on the delivery of service. Increasing accessibility would be a simple task of adding stops along a given route except that this would negatively impact overall transit travel speed. More customer service time could potentially be added with each new stop that is added, requiring buses to decelerate, process passengers and accelerate at every stop.

Figure 4.2 illustrates the interaction between accessibility and transit ridership. The GIS-based ridership forecasting tool assesses accessibility to both transit trip starts (i.e. 
origins) and transit trip end points (i.e. destinations). Both the start and end of a transit trip must be within accessible walking distance to maximize transit ridership potential.

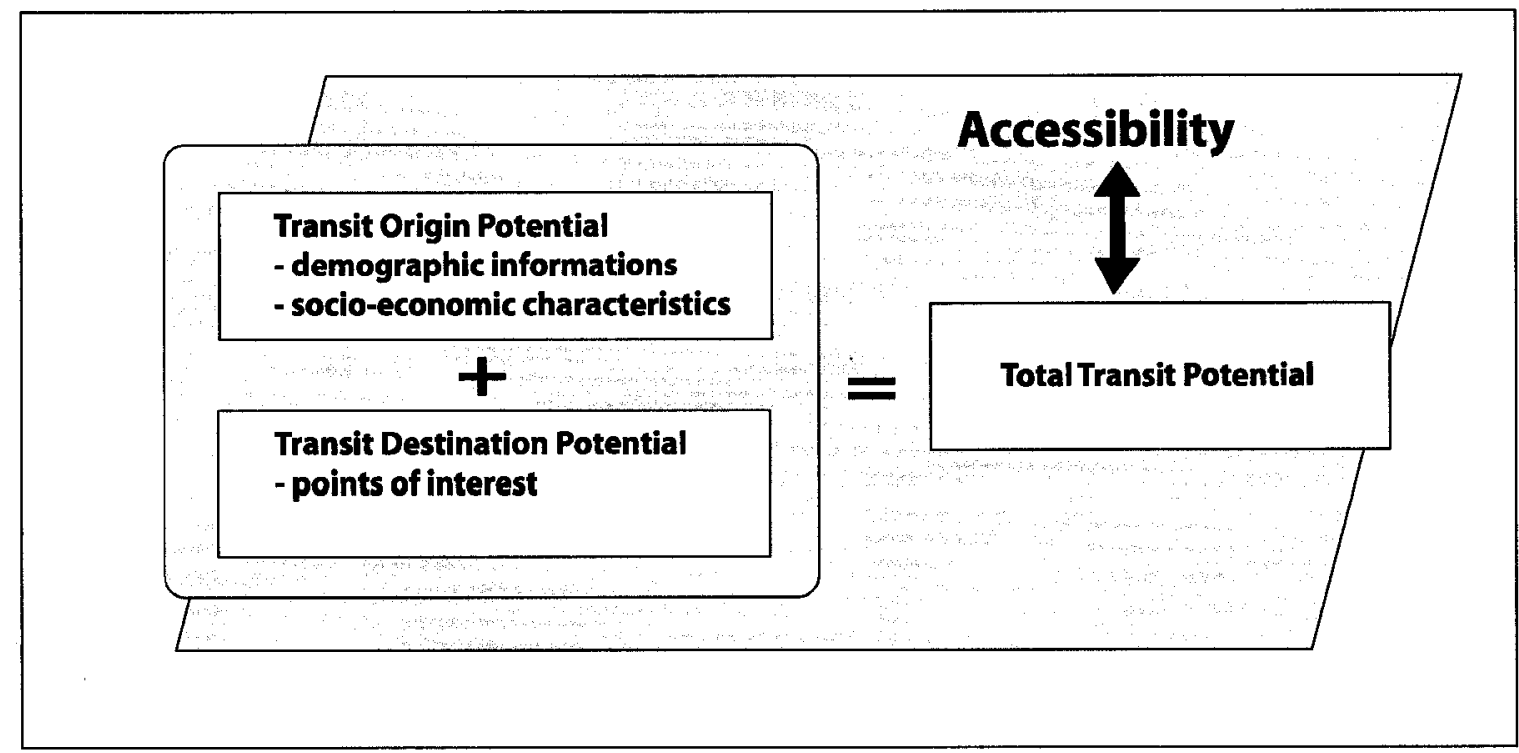

Figure 4.2 - Accessibility to Transit Origins and Destinations

The following functions describe the relationships between transit system accessibility, number of bus stops and route run time:

System Accessibility [ $\mathrm{km}$ to Bus Stop] $=f\{$ Number of Bus Stops $\}$

$$
\text { Route Run Time [minutes] }=f \underset{\text { Number of Bus Stops }}{\{\text { Route Length }}\}
$$

At a certain point adding too many bus stops within close proximity to each other is inefficient. Though it increases system accessibility it also increases the overall route running time and affects service reliability. 
One other relationship in service design is important to note, that of service frequency. A service that is frequent and reliable is more attractive to users but also more expensive to deliver. In small transit systems where the number of transit vehicles is limited, the ability to provide a given service frequency is tied to the route run time.

\section{Service Frequency $=f\{$ Route Run Time [minutes] $\}$}

On the other hand, if fleet size can be regarded as a variable, service frequency becomes a function of route run time and fleet size. See Figure 4.3 for the interrelationship of key transit system design variables.

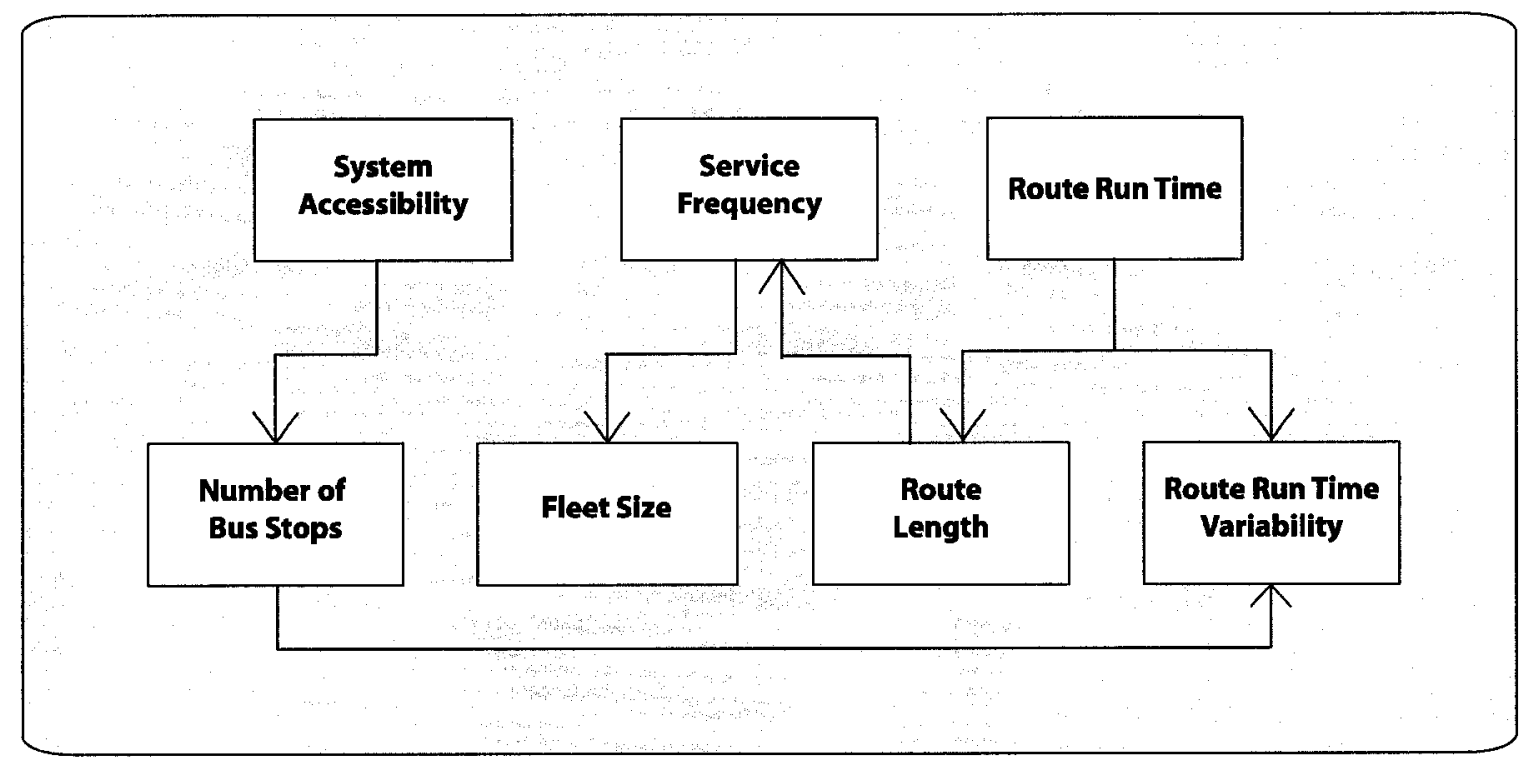

Figure 4.3 - Interrelationship of Key Transit System Design Variables

If a one-hour service frequency is scheduled, transit vehicles operating on a radial system (i.e. routes "radiate" out from a central point such as a downtown core, and follow the 
same route in reverse) are limited to the distance that can be covered reliably within less than thirty minutes, at which point they must begin their reverse trip. The same applies to routes that follow a continuous loop. The loop must be reliably completed within less than an hour to maintain the one hour service schedule. The emphasis on reliability relates to the need for passengers to complete route transfers in a timely fashion.

In the transit scheduling domain, it is critically important for buses to arrive on time. Departing from a stop earlier than scheduled is just as detrimental to passenger perception of service quality as arriving to a terminal or connecting route too late. Both occurrences should be minimized. In small systems, missing a connecting trip can result in delays equivalent to service frequency (e.g. 30 minutes or one hour) which can significantly impact customer satisfaction. Transit schedules are essentially a transit service provider's contract with the customer and must be respected in order to maintain and increase transit ridership.

Small transit systems operate cost-effectively when service designs (i.e. service frequency) are matched with the number of transit vehicles available. Extra buses are dispatched in many municipalities during the peak hours when transit vehicles are found to exceed their scheduled run times. This is done at an increased cost because additional transit operators and vehicles are put in service (e.g. wages, operation and maintenance costs). But this is essential to minimize missed connections and to ensure that passengers receive the service that is scheduled. Reducing the number of extra buses needed would 
present significant cost savings to some transit properties and thus the importance of carefully designing routes.

A number of factors contribute to transit attractiveness for patrons. Accessibility and frequency of service are two important pieces. It must be easy and quick to reach the start and end transit stops and, once there, service must be frequent. Combining the system accessibility function and service frequency yields the following relationship:

Transit Attractiveness $=f\{$ System Accessibility, Service Frequency $\}$

Expressed differently, we see that the number of bus stops can either positively or negatively impact transit attractiveness:

$$
\text { Transit Attractiveness }=f[f\{\text { Number of Bus Stops }\}, f \underset{\text { Number of Bus Stops }}{\{\text { Route Length }}\}]
$$

It is important that bus stops be located as frequently as possible so that they are in close proximity to as many potential users as possible, however in order to keep route run times to a minimum, the number of transit stops should be kept low. Therefore, a balance must be struck between these competing goals. There is an optimal number of stops that should satisfy the accessibility and service frequency needs.

As with traffic operations, the peak periods for transit operations are used for system design with resource requirements generally decreasing during non-peak parts of the day. 
Ridership profiles vary throughout the day with home-to-work and home-to-school trips dominating morning and afternoon peak periods and more discretionary trips occurring within non-peak periods. The analysis presented herein focuses on daily transit ridership levels and system accessibility which is a component of Transit Attractiveness identified above.

\subsubsection{Transit Accessibility}

As indicated earlier, the literature review for this thesis identified a transit accessibility index related to residential or home-based land use. The index captures the characteristics about a population that is within a given walking distance or walking time from a transit stop (Pulugurtha and Nambisan, 1999).

In this thesis the "accessibility index" is used to gauge the potential contribution that could be made to the number of transit riders. If few bus stops are located within an area or near a "travel generator", the accessibility index will be low and consequently, few transit riders will be expected. It follows that an area or place of interest in proximity to well-placed bus stops would yield more transit riders.

The accessibility index is used to qualify the degree to which the road and pedestrian networks and bus stop locations facilitate transit use. This provides a means to prioritize transportation infrastructure improvements within the community as they related to 
transit (e.g. providing a connecting recreational path between a residential area and a retail area).

The transit accessibility index for a Census district is a ratio of the number of kilometers of transportation facilities within 400 metres of a bus stop (i.e. accessible transportation links) divided by the total number of transportation facility kilometers within the census area, as follows:

Transit Accessibility Index ID $=\left(d / D_{\text {ID }}\right)$

where:

$d$ is the number of kilometers of transportation facilities within 0.4 kilometres of bus stop (i.e. the sum in kilometres of unique segments of roadway, recreational path or sidewalk that a transit user can walk along from all area bus stops), and $D_{I D}$ is the total number of kilometers of transportation facilities in the census area

\subsubsection{Prediction of Transit Use}

Information from the Census survey is available for a number of standard geographic areas. The level of refinement is defined by Statistics Canada and at the most detailed level, includes data related to a street "block face". For each of the census division areas a number of data packages are available.

The main variables included in this study were drawn from four Census reports:

- Population and Dwelling counts 
- Income and Social and Economic Characteristics of Individuals, Families and Households; Housing Costs and Religion, and

- School Attendance, Education, Field of Study, Highest Level of Schooling and Earnings, and

- Labour Force Activity, Class of Worker, Occupation, Industry, Place of Work, Mode of Transportation, Language of Work and Unpaid Work.

Over seventy Census characteristics were examined within the Census reports listed above in order to establish key population and demographic characteristics to predict transit use as an input for the GIS-based tool. A number of approaches were explored to incorporate the appropriate characteristics into the tool and to establish their relationship to transit ridership potential as described in more detail in the Chapter 5 case study. These include using Microsoft's Solver, regression analysis, cross classification method and Artificial Neural Networks. The method selected involved regression analysis and included both a Census-based component and a "geography-based" component related to specific land uses (e.g. institutional, employment, commercial).

The total transit ridership was set as the actual number of transit passenger movements (i.e. boardings and alightings) within each census district as obtained from OC Transpo data for 2002 (referred to as the Transit Activity Total). The initial objective was to explain the actual ridership levels using a combination of Census data and key transit land uses. This sets the baseline transit ridership and permits the user to assess future 
scenarios where population levels change and/or new developments are planned within the municipality.

The existing transit ridership levels (i.e. "Transit Activity Total") were predicted using a four step process that included:

1. Establishing "work-related" transit use;

2. Establishing "school-related" transit use;

3. Establishing transit use for "other" purposes than for work and school, and

4. Combining all three types of transit use.

The Census survey includes one question related to travel to work. As such, the number of transit users within a Census district that employ transit to reach their destination is identified. School-related trips were divided into those related to a Census-district's demographic composition and those related to the institution's geographic location. The former were combined with trips that were neither work-related nor school-related, as well as transit trips to geography-based key destinations to form a category of "other" trips. Figure 4.4 highlights the inputs into the prediction of existing transit trips. 


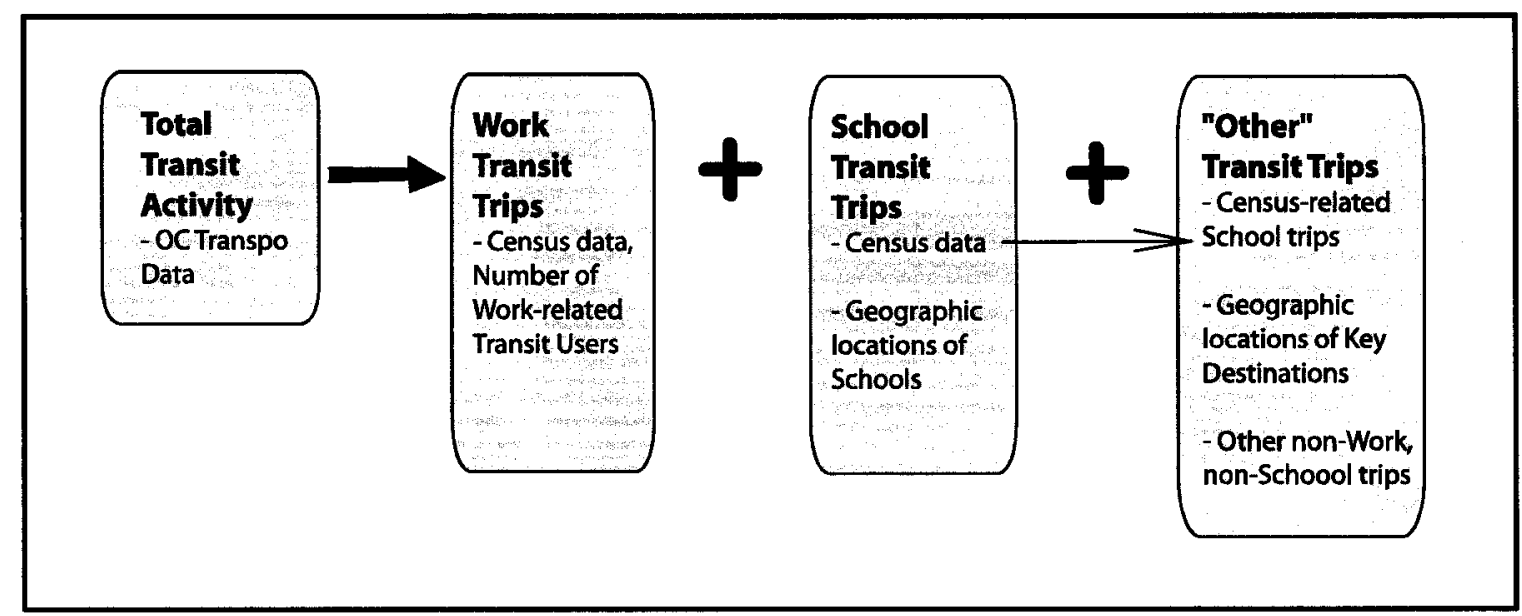

Figure 4.4 - Inputs for Transit Trip Prediction

The "geography-based" component of "other" transit trips was included to capture transit market potential for accessible locations. Key land uses were identified if they were considered to be potential trip attractors and if they were within the defined "accessible" range of a bus stop. Given that this transit ridership forecasting tool is geared toward small municipalities, it is considered that relevant details (i.e. staffing numbers, hours of operation, student transit usage, etc.) could easily be obtained for each of the key employment, institutional or recreational attractors. This could be done through individual telephone surveys or knowledge of the transit ridership potential at each location.

The methodology adopted to quantify "geography-based" potential for key destinations involved assigning one of three transit potential qualifiers to each site: low, medium or high. With the low end of the spectrum generating very low, if any transit ridership 
potential (e.g. storage warehouse complex). A rank of "high" would represent a trip attractor with very high potential (e.g. core business area).

The potential ridership level assigned to each qualifier should reflect geographic location (i.e. proximity to urban core), synergies from adjacent land uses, and existing patronage. Consideration should also be given to hours of operation and parking supply characteristics. To assess future conditions, additional attributes should be defined to reflect scale of potential ridership and to identify whether peak hours of operation overlap with typical transportation peaks (e.g. if there is a heavy night shift at a factory, this may not be very well matched with transit operations). Municipalities could also opt to provide a more definitive potential for ridership if such information was available to them.

The transit potential resulting from "key destinations" being located within a given Census district would have the following inputs:

Transit Destination Potential ID $=\left(\mathrm{k}_{\mathrm{l}} * \Sigma_{\mathrm{ID}} \mathrm{P}_{\mathrm{lID}}\right)+\left(\mathrm{k}_{\mathrm{m}} * \Sigma_{\mathrm{ID}} \mathrm{P}_{\mathrm{m} I D}\right)+\left(\mathrm{k}_{\mathrm{h}} * \Sigma_{\mathrm{ID}} \mathrm{P}_{\mathrm{h} I D}\right)$ where:

$I D$ is the Census area identification number

$P$ represents the number of destinations of each type;

$k$ represents a transit ridership potential constant for each rank type (low, medium, high) for destinations;

$\mathrm{k}_{1}$ represents the transit ridership potential for the "low" ranked destinations; 
$\mathrm{k}_{\mathrm{m}}$ represents the transit ridership potential for the "medium" ranked for destinations; and

$k_{h}$ represents the transit ridership potential for the "high" ranked for destinations.

\section{Walking Distance}

A number of methods are available by which to measure "network" accessibility using GIS. Since Census data is organized through a variety of progressively smaller census areas, the accessibility of a given stop must also be translated to a spatial area. It is not sufficient to calculate a buffer area adjacent to a transit route since this over-represents the area that is within a given walking distance (e.g. residents located adjacent to a route but physically located between two bus stops have a much longer walking distance to cover than a "route buffer" distance would assume). Transit can only be accessed at bus stop points and as such, these points must be converted to coverage areas as opposed to using a route buffer.

A number of methods are available to measure coverage area in the vicinity of transit stations. These range from measuring on-street (or other transportation facilities) lengths directly to using a buffer area extending from the street edge at a given distance. There are pros and cons associated with either the "linear" or area approaches.

Neither of these methods can provide an exact quantification of how much of a census area is accessible from a given bus stop. The "percentage" of linear roadway network method does have its flaws. For example, arterial class roadways (or higher order) 
generally have limited access. As such, a transit stop that covers 800 metres of arterial roadway generally would not link as many residents to transit as would a stop covering 800 metres of local roadway. The linear roadway percentage method does not explicitly address this and the area method also has shortcomings.

Road classification is generally included within the attributes of roadway GIS files. To address the issue raised above, the analysis should incorporate different tiers of road classification: high access (collectors down to local roads) and low access (arterials and higher class roadways). This distinction could then be changed on a case-by-case basis to reflect any obvious classification issues with individual road segments (e.g. arterial class roadway with many fronting residential properties).

\section{Network Analysis Tool}

Roadway files in GIS are typically comprised of individual line segments joined to other segments at common points referred to as "nodes". Attributes generally include segment length, "from" and "to" node identification codes, road class, road name (name, prefix and suffix).

Other attributes can include municipal addressing ranges, speed limits, directional restrictions (e.g. one ways) and municipal authority where different jurisdictions are responsible (e.g. neighbouring municipality, provincial, federal authorities). 
For the purpose of this analysis, ESRI's ArcGIS software was used. Other commercially available GIS software packages are able to carry out similar analysis but these were not explored as part of this work. Use of a network analysis tool within a GIS software package requires that the road network have a specific format with appropriate feature attributes. It is essential to have proper connectivity points (i.e. nodes) defined between those adjacent road segments that are connected.

A routing dataset should be created that contains the road network information. Any additional required attributes should be added to the road shapefile. ESRI's technical paper on the use of the Network Analyst software extension lists other attributes such as:

- elevation of road link nodes (e.g. for overpass or underpass modelling);

- impedance factors (e.g. cost);

- restriction values (e.g. one ways); and

- hierarchy values.

In this case, it was not determined to be necessary to list road restrictions since these do not generally apply to pedestrians. They can typically travel in both directions on one way streets. Instead of listing "driving" restrictions, it would be more important to list availability of sidewalks or proper pedestrian infrastructure which have a far greater impact on pedestrian routing. 
In a similar way, the hierarchy attribute could be useful to define "high access" and "low access" roads but this will not factor into the analysis of accessible routes. All routes from a given bus stop will be identified, regardless of their accessibility qualifier.

Other attributes can be added to the transportation network, depending on the application. In addition to those listed above, commercially available navigational tools would use street names, highway shields and boundaries to provide proper directions to users. Such details are not required for the purposes of the transit accessibility analysis.

Once the road network contains the attributes required for the analysis a "turn" feature class can be created. This is part of the street dataset and defines which road links form part of turns, and which are restricted. Combining the turn feature with the street feature provides sufficient information to then analyze which road segments are within proximity to a bus stop. It was not deemed necessary to define turns for this analysis. In addition to being a long process (i.e. turns must be coded into the network manually) turn definitions should not affect pedestrian walking routes the way they affect motorist route selection.

\section{Population Density Considerations}

Using area as a proxy for the number of residents within a census area does have shortcomings. It presumes an even population density throughout the area and would not account for higher density buildings or other important targets for transit routing. Another option would be to use land ownership parcels whose attributes include an 
indicator of density (e.g. units per hectare, persons per dwelling) but such information may not be readily available within a municipality.

It is suggested that high density residential occupancies could be treated the same way as other "key destinations". These would be identified separately from the process outlined above for establishing residential "potential" within census zones. Higher density residential occupancies could then be factored into the market potential assessment with different demographic criteria if desired.

\section{Accessibility Ratio for Individual Transit Stops}

Through use of the ESRI's Network Analyst tool, a ratio can be developed for transit stops within each census zone. The ratio would compare the kilometers of transportation facilities within a given distance from transit stops to the total kilometrage of such facilities within the census zone, for all system transit stops (i.e. within all census zones). Such an index would then allow transit planners to make adjustments to individual transit stops to improve the coverage of poor performance or less well utilized transit stops. This assessment would show whether one transit stop had higher or lower than average transit potential. Such an assessment relates more closely to transit operations and as such was beyond the scope of this work. 


\subsubsection{Route Running Time}

No literature was found related to the effect of route running time on ridership.

Intuitively, reduced and reliable running times should be contributors to passenger satisfaction and thus have a positive impact on ridership. However, this may be difficult to isolate from other factors.

Route running time is a good system assessment characteristic because of its impact on transit operating cost. The longer the route running time, the more likely that additional buses (i.e. "extras") might have to be dispatched in the peak period, especially within radial route systems where timed transfers are critical.

Given the complexities associated with temporal analysis, route running time was raised as an important transit system consideration but was not incorporated within this research. 


\section{Chapter 5: Case Study Application}

In order to test and further refine the GIS tool developed analysis was carried out for the Orléans community, a suburban area within the City of Ottawa. Orléans had a population of approximately 100,000 residents at the time of the 2001 Census. In recent years, this has increased significantly, mainly through new residential development.

\subsubsection{Available Data}

As described earlier, a wide range of variables are included within the Statistics Canada Census. Each variable can be attached spatially to the geographic area it is describing. A number of variables were examined as part of familiarization with the Census data. The following figures highlight a number of demographic and socio-economic factors related to the study area. Figure 5.1 shows total population and age distribution for the Orléans area. Figure 5.2 shows home ownership and income information. Figure 5.3 shows population and reported transit use (i.e. for work purposes) information, respectively.

\subsubsection{Accessibility}

The journal article by Pulugurtha and Nambisan describes a multi-step process using a GIS that leads to the identification of transit market potential for a given transit route within residential land uses adjacent to "Transit Service Facility" (TSF) locations. The 


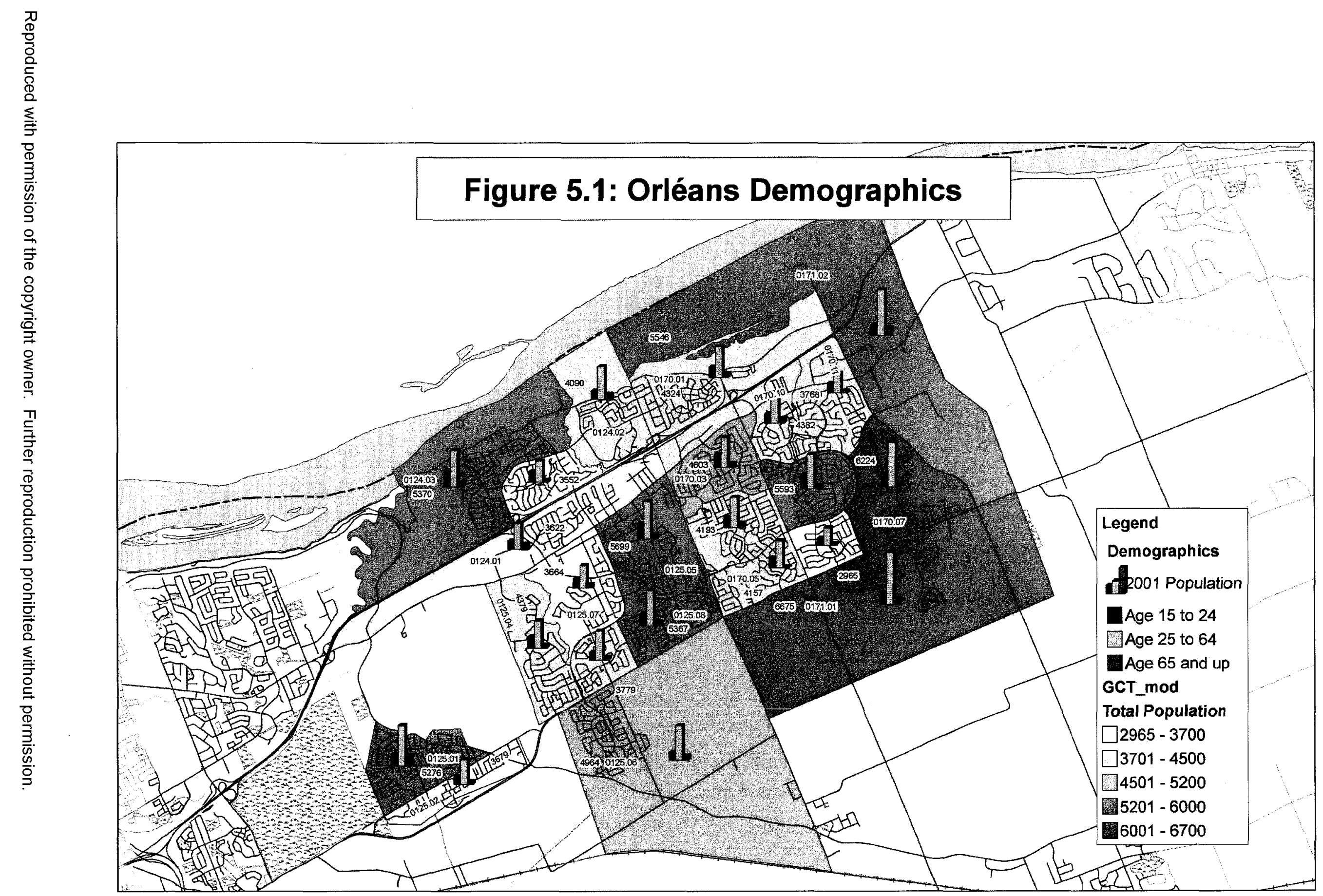




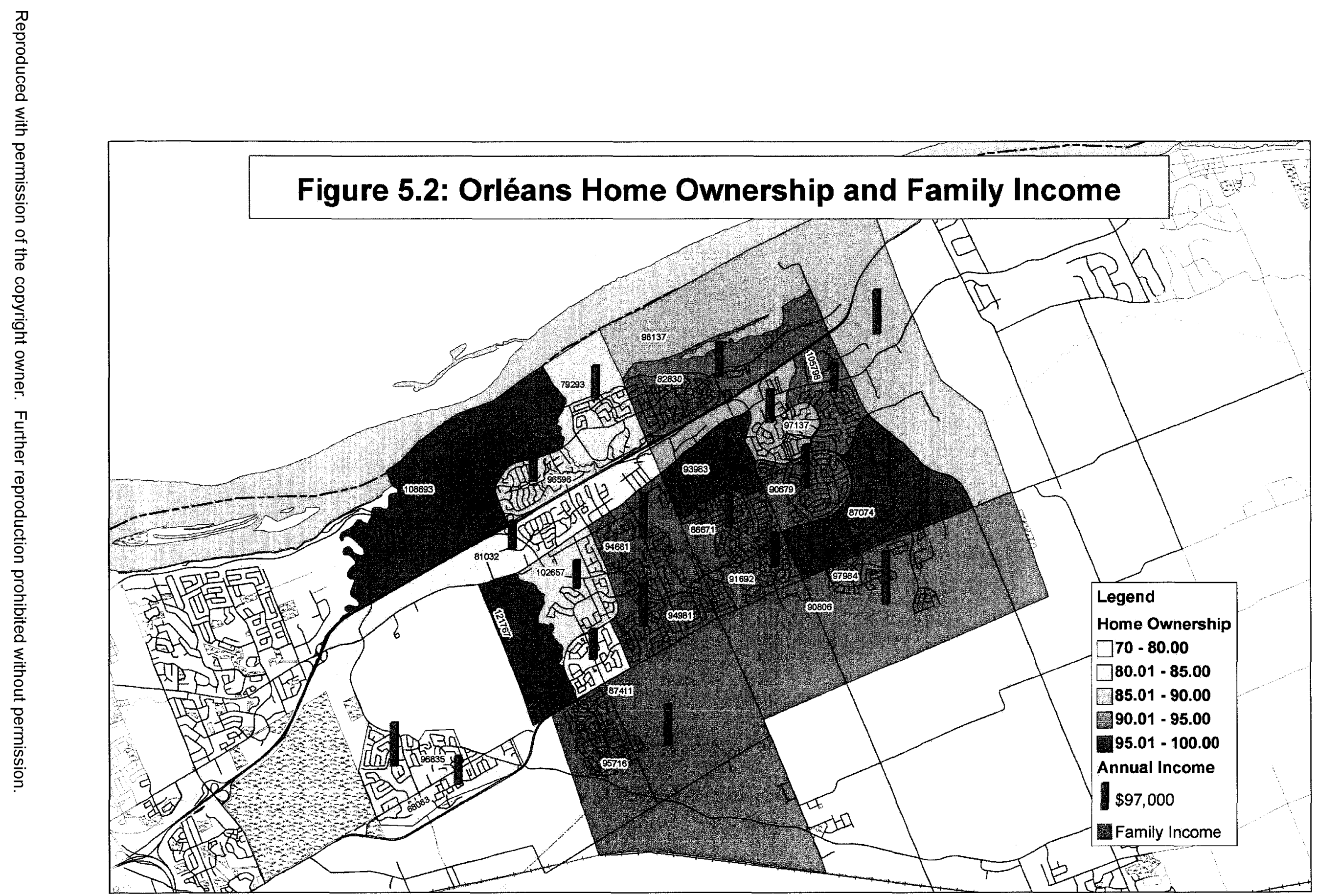




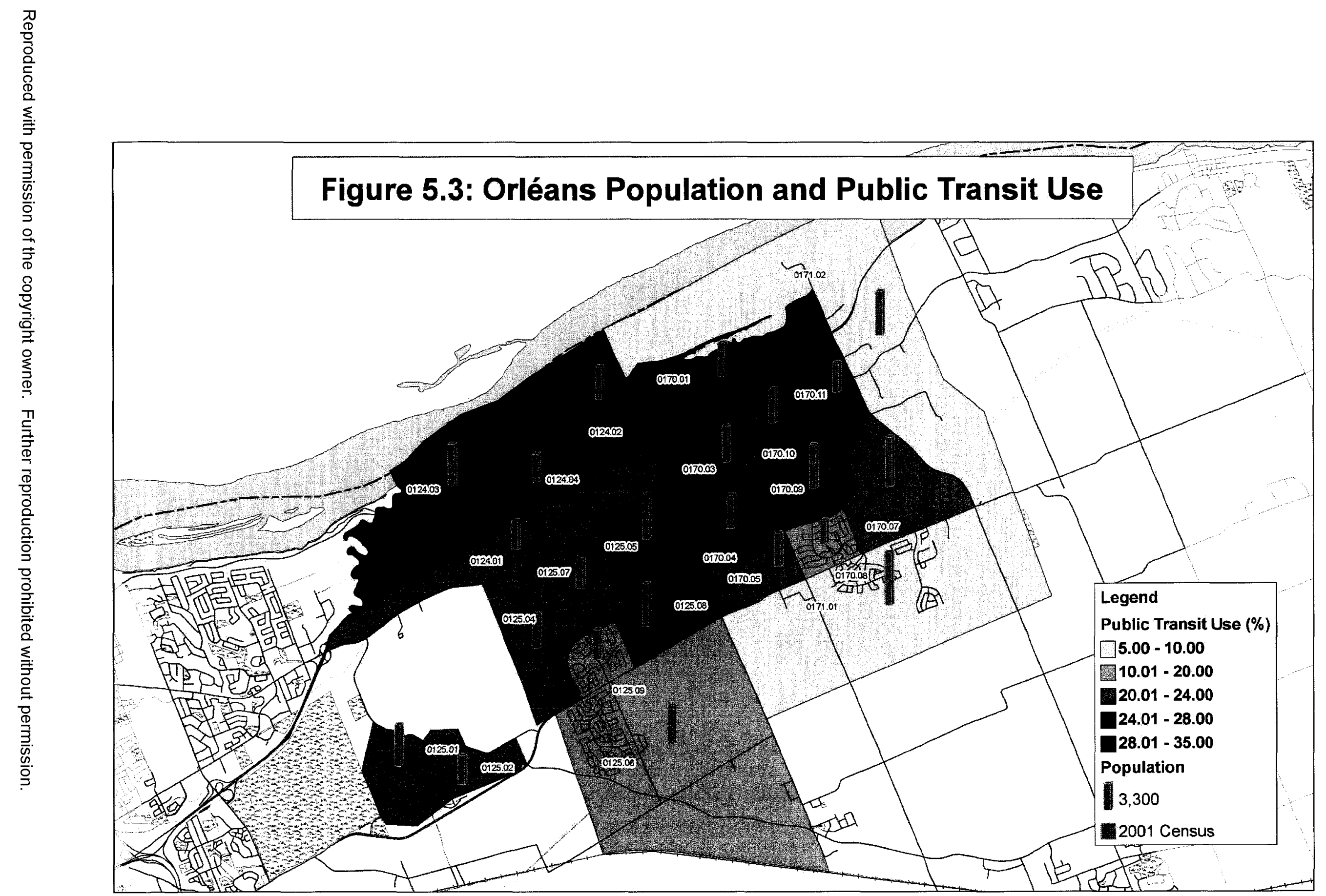


general methodology included using the road network, transit routes and TSF to establish buffers within which the transit route was considered to be "accessible".

The potential of existing TSF was compared to that of other TSF locations which were essentially points located at equal spacing along a given transit route. Pulugurtha and Nambisan's methodology was aimed at increasing ridership potential along the route. As such, the siting of potential transit stops was limited to the corridor within which that route fell as opposed to other locations with high ridership potential that were outside this route.

It was decided that a route bias would not be included within the development of a new ridership forecasting tool. The roadway network as a whole would provide additional opportunities to uncover potential transit ridership. Smaller systems can accommodate route structure changes to include such potential transit hubs.

An accessible transit zone was defined for the purposes of this case study as a location within 400 metres of a transit patron's point of origin. This is consistent with service standards in use within the City of Ottawa. At an average walking speed of 1.2 metres per second this equates to a five minute walk which is considered acceptable within transit service best practices. Given the relationship between such service standards and transit operation costs this is a factor that should be confirmed by the municipality in question prior to undertaking any analysis. 
Three different methods of identifying transit ridership potential within a given buffer distance from a TSF were tested by Pulugurtha and Nambisan (1999).

These included:

1. Arc Lengths of Accessible Arcs: Allocating demographic info to the street network and considering that the sum of accessible arcs from a given TSF in comparison to total length of streets within a census area represented the transit potential. The drawback is that a "border" street can only be assigned as potential to one bordering census area.

2. Buffer Around Accessible Streets: Creating a buffer surrounding the accessible arcs to a given TSF and comparing the resulting buffer area and related land use points to the total census area and key land use points within it.

3. Hull Polygon Method: Joining all extremities of accessible area together to form a polygon, then allocating to each overlapping area, or portion thereof.

A combination of the Arc Lengths ratio method and the Hull Polygon Method were selected for the tool developed herein given the type of data available for analysis (Pulugurtha and Nambisan, 1999). 
The first step in creating a GIS to use in the analysis is to ensure that all required inputs are present. The most critical are a valid transportation network, bus stop locations and census areas.

\subsection{Orléans Case Study}

Data for the case study was provided by the City of Ottawa Transportation and Transit Department, also referred to as Ottawa-Carleton Transportation (OC Transpo). GIS data related the road network, land use, parks, schools, etc. was available from the City's geomatics group. Automatic Passenger Count (APC) data was provided by the transit department. Both types of data were used to test the GIS tool developed. Other information gaps were identified and either supplemented as needed (e.g. pedestrian pathway information) or listed as areas for further refinement.

As mentioned above, actual land use, census and transit data was used to test the GIS tool that was developed. This allowed refinements to occur within the tool development phase.

\section{Transportation Network and Points of Interest}

A number of steps were required to prepare the various elements of the GIS for analysis. Given the importance of pedestrian access, the first step involved enhancing the road network by adding pedestrian linkages where applicable. These are important connections in each neighbourhood allowing better accessibility to and from transit stops through pathways, sidewalks and other informal access points. 
In ArcGIS, there is a formal process to follow to ensure that the transportation network is properly established for the purposes of conducting network analysis. This process likely varies depending on the software package selected.

In addition to manually adding pedestrian links within the GIS, a number of other features were included. Key trip generators were added as point features within the study area. Based on local knowledge of the study area various sites with potential transit ridership were added to the GIS. These included existing employment, commercial and institutional points. As mentioned earlier, each was assigned a transit potential index of low, medium or high depending on size.

Three major transit stations were also included within the list of key trip generators. Given the role that Ottawa's downtown core plays within the Orléans community, it was deemed appropriate to add these in as trip generators. They essentially act as proxies for a downtown business district which would be more typical of small municipalities. The Place d'Orléans transit station is discussed in more detail in later sections.

A snapshot of pedestrian links and identified trip generators is provided in Figure 5.4.

\section{Transit Elements}

Transit stop information was obtained from OC Transpo (Ottawa's Transit authority). All transit stops were provided in a tabular format including $\mathrm{x}-\mathrm{y}$ coordinates. This 
allowed for easy inclusion within the GIS using a tool specifically designed for this type of geographic input. All bus stop points were loaded into the GIS along with their respective unique identification code. Table 5.1 includes a representative sample of the bus stop data.

Table 5.1 - OC Transpo Bus Stop Information

\begin{tabular}{|c|c|c|c|c|c|c|}
\hline BusStopID & OC560num & Location & XCOORD & YCOORD & SourcelD & SourceOID \\
\hline EL305 & 7965 & TENTH LINE / REGIONAL ROAD 174 & 382645 & 5039153 & 1 & 2275 \\
\hline EL310 & 8148 & TENTH LINE / REGIONAL ROAD 174 & 382701 & 5039095 & 1 & 2278 \\
\hline EL335 & 7966 & JEANNE D'ARC / HARLEQUIN & 382445 & 5039243 & 1 & 2225 \\
\hline EO169 & 8933 & VALIN / CHARLEMAGNE & 384874 & 5037608 & 1 & 1504 \\
\hline E0170 & 7895 & CHARLEMAGNE / MERKLEY & 384664 & 5037834 & 1 & 1584 \\
\hline E0174 & 7901 & VALIN / HENNESSY & 385212 & 5037687 & 1 & 2191 \\
\hline E0175 & 1674 & CHARLEMAGNE / MERKLEY & 384683 & 5037836 & 1 & 1584 \\
\hline E0176 & 8294 & PORTOBELLO / GARDENWAY & 385316 & 5037471 & 1 & 2194 \\
\hline EJ650 & 7775 & BELCOURT / LEBLANC & 381433 & 5036962 & 1 & 372 \\
\hline EM370 & 5706 & DU GRAND BOIS / PARK GROVE & 383079 & 5035897 & 1 & 2255 \\
\hline EM385 & 6302 & DU GRAND BOIS / DES PINS & 383066 & 5035886 & 1 & 2255 \\
\hline E0178 & 1250 & VALIN / PORTOBELLO & 385332 & 5037709 & 1 & 2193 \\
\hline E0180 & 1860 & CHARLEMAGNE / WATTERS & 384577 & 5038013 & 1 & 1584 \\
\hline
\end{tabular}

\section{Census Areas}

Statistics Canada makes the Census standard geographic areas available as GIS elements. Each area has a unique identification code that enables linking of tabular information directly into the GIS. For this study, the smallest area used was the Census Tract area as shown in Figure 5.5. A description of the hierarchy of Census standard geographic areas is included Appendix B.

\subsubsection{Development of a Method to Predict Transit Ridership}

As indicated in Section 4.1.1, over 70 socio-economic and demographic characteristics were identified within the Census data that could relate to transit ridership potential. Several different approaches were explored to incorporate an appropriate number of characteristics and to establish their relationship to transit ridership potential. These 


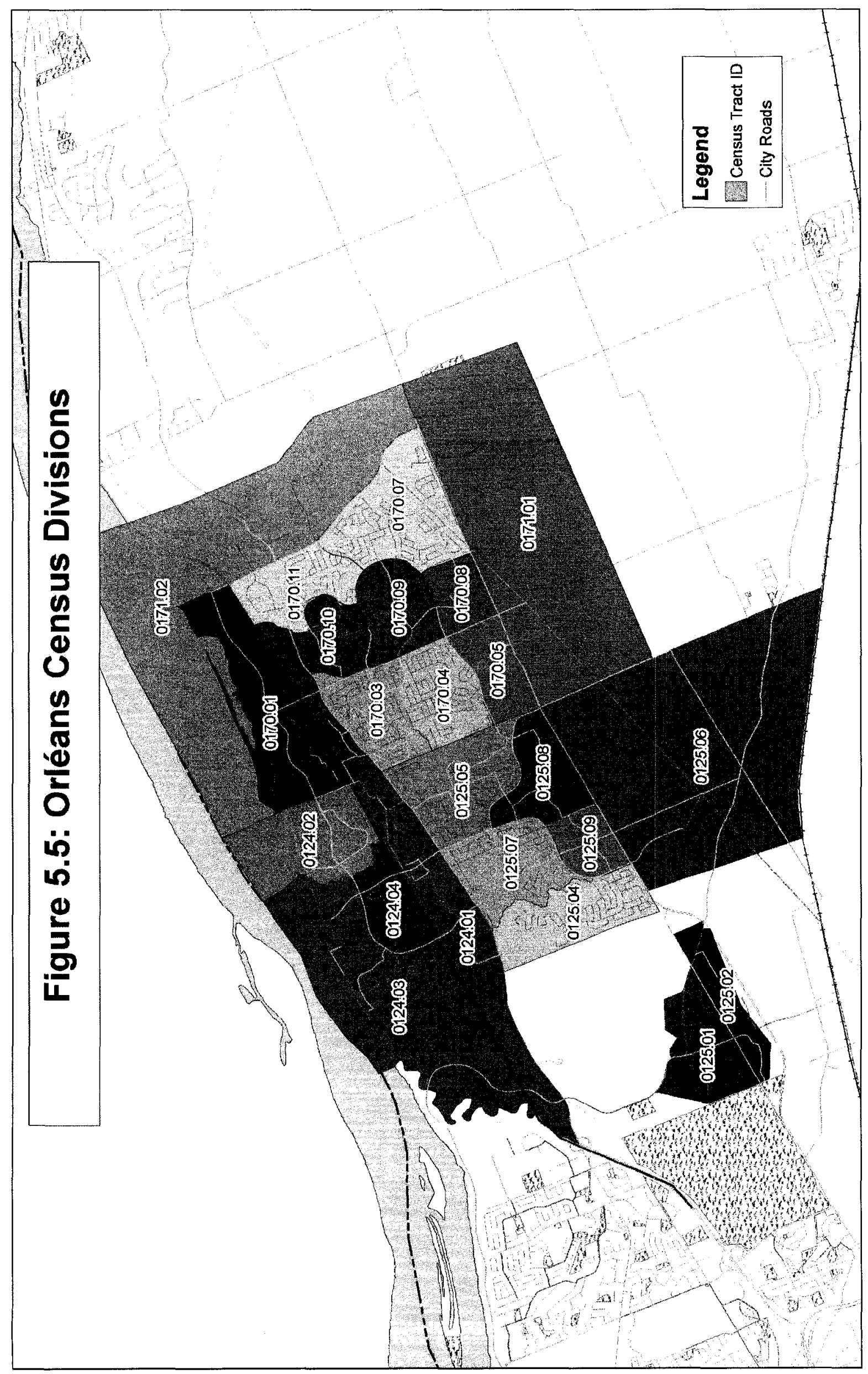


include using Microsoft's Solver, regression analysis, cross classification method and Artificial Neural Networks.

Starting with the Microsoft Solver tool, an average value for all 23 census districts was calculated for each of the following variables, selected based on the findings of the literature review:

- Number of persons with family income less than $\$ 50,000$;

- Number of persons living in rented homes;

- Number of persons with education level of Grade 13 or less; and

- Number of persons employed.

The Microsoft Excel Solver tool was used on the Census district averages to determine a typical contribution to transit ridership that each characteristic would bring. The general formula tested was:

Transit Origin Potential $\mathrm{ID}=\Sigma_{\mathrm{a}}\left(\mathrm{k}_{\mathrm{a}} * \mathrm{~N}_{\mathrm{a} \text { ID }}\right)$ where:

$I D$ is the Census area identification number $a$ represents the characteristic assessed (e.g. family income) $\mathrm{k}_{\mathrm{a}}$ is a constant related to the characteristic $\mathrm{N}_{\mathrm{a} \text { ID }}$ is the number of people with characteristic $a$ within the Census area

For the four characteristics selected, the Transit Potential would result in the following: 
Transit Origin Potential ID $=\left(\mathrm{k}_{\mathrm{a}} * \mathrm{~N}_{\mathrm{a} \text { ID }}\right)+\left(\mathrm{k}_{\mathrm{b}} * \mathrm{~N}_{\mathrm{b} \text { ID }}\right)+\left(\mathrm{k}_{\mathrm{c}} * \mathrm{~N}_{\mathrm{c} \text { ID }}\right)+\left(\mathrm{k}_{\mathrm{d}} * \mathrm{~N}_{\mathrm{d} \text { ID }}\right)$

where:

$a$ represents the family income less than $\$ 50,000$ characteristic;

$b$ represents the home ownership characteristic;

$c$ represents the education level characteristic; and

$d$ represents the employment characteristic.

The Solver was used to determine the relative contribution to transit ridership of each of the constants $\left(\mathrm{k}_{\mathrm{i}}\right)$ related to the four characteristics. The only constraints were that each of the constants had to be positive values. A number of initialization values for the Solver were tested however, it was not possible to find a unique solution using this approach.

Two other solutions were explored to resolve this problem before adopting regression analysis as the best-suited approach. The Cross Classification method measures changes within one variable while holding another variable constant. An example is shown in Table 5.2 whereby the number of trips produced by a given household size is linked to automobile ownership (Wright, 1996). Cross Classification was determined to be unsuitable given that in depth household surveys were not available for the case study municipality. In addition, such surveys would not typically be available in small municipalities given the high level of effort required to collect this data. 
Table 5.2 - Cross Classification Example

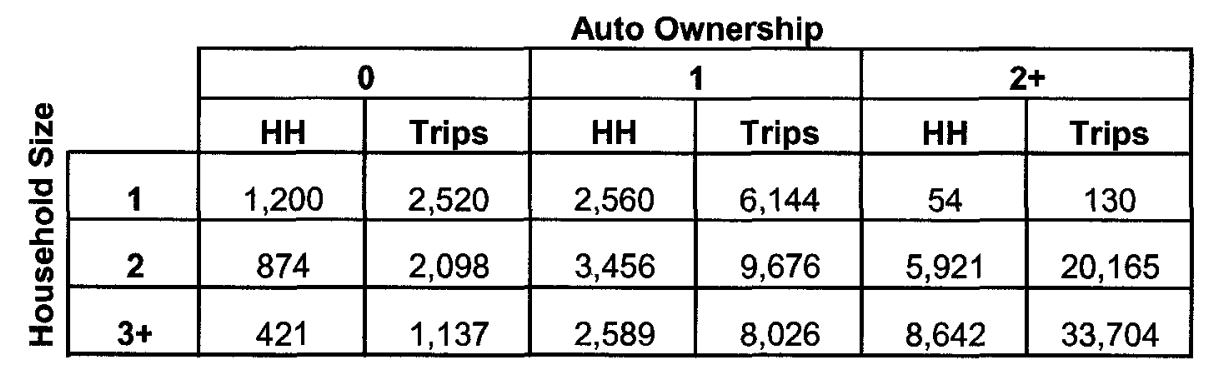

(Source: Wright, 1996)

Neural Networks software developed by MatLab was evaluated however was found to not be suitable given the limited number of data points for the study area (i.e. 23 Census districts). The latter would be more applicable in analyzing transit rider profiles. A large amount of data is required to "train" Neural Networks. One publication recommended having at least ten times as many records for training as input columns (i.e. independent variables).

Regression analysis was undertaken to determine whether it represented a more appropriate solution. The regression analyses lead to a refinement of the general methodology for determining transit ridership.

\subsubsection{GIS Network Analysis}

All transportation infrastructure elements of a pedestrian's walking network were entered into the GIS, including roads, sidewalks, school paths, etc. Through a number of data processing and file management steps, this information was readied for use within ArcGIS using ESRI's Network Analyst software extension. 
The Network Analyst extension allows GIS users to employ the transportation links as conduits within a system. This is a more advanced software use than would typically apply to a GIS road file, The latter is usually used to store information or attributes such as name, municipal addressing information, classification and length. The Network Analyst extension provides the ability to perform routing analysis, service market assessments and origin-destination costing. The first two applications (routing and service market analysis) were utilized in this case study.

Using the bus stop locations as inputs, a 400-metre transit market area was defined for the study area. As discussed earlier, this is representative of a five-minute walk for the average transit patron. This distance was used to identify all accessible segments of the transportation network from given points (i.e. bus stops). The total length of accessible road or transportation network segments were then compared to total network kilometers within each Census district. Figure 5.6 illustrates the extent of bus stop accessibility within the study area. From this assessment it is observed that in Orléans, most developed areas are located within 400 metres of a bus stop. 


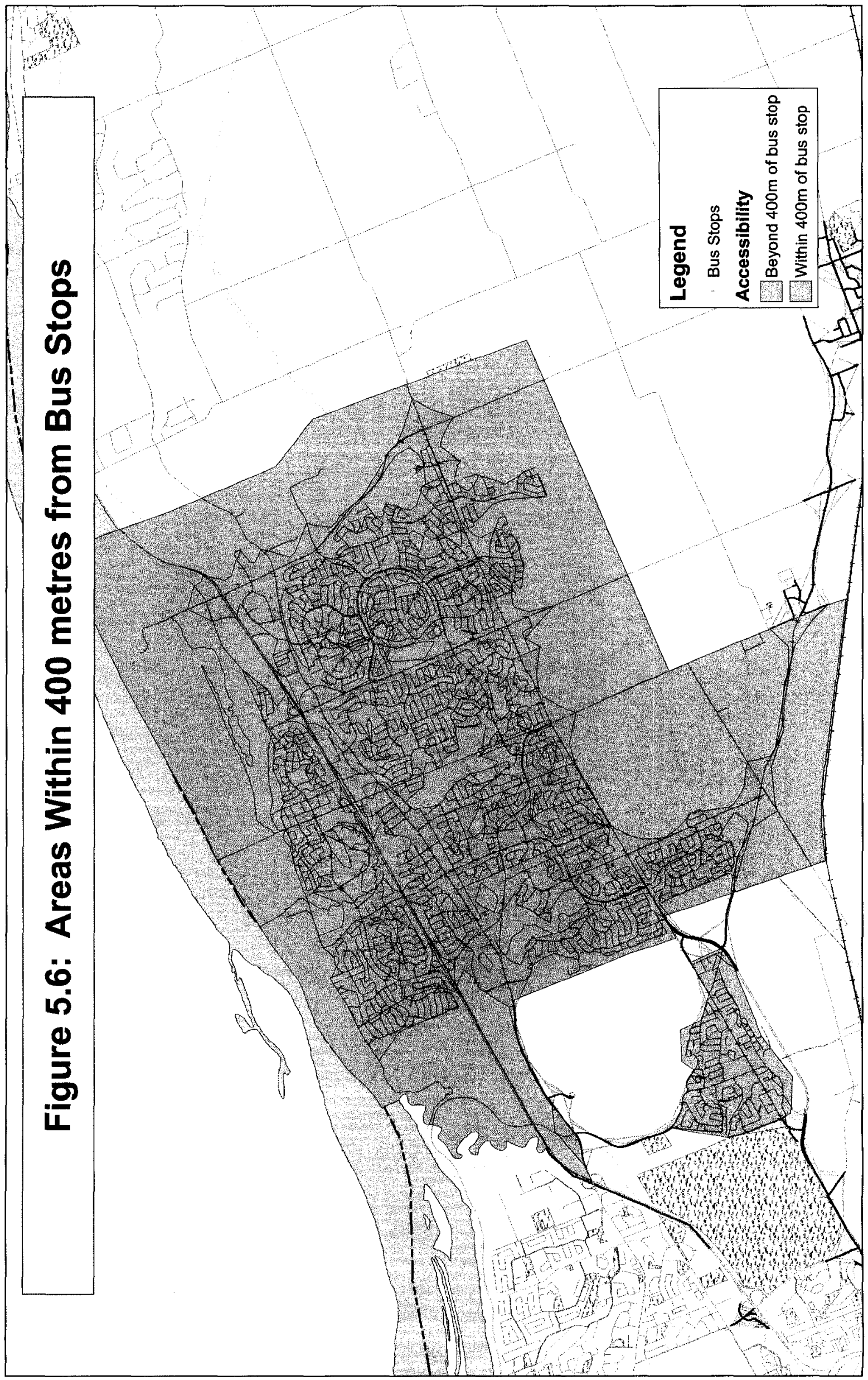


A comparison of accessible versus total Census district network kilometres was carried out to determine what potential existed to improve transit service coverage through improvements to accessibility. Improvements would include addition of bus stops or improvements to pedestrian routing (e.g. new paths or sidewalks). The resulting accessibility ratio for each Census district is depicted graphically in Figure 5.7 and in tabular format in Table 5.3.

Table 5.3 - Potential for Accessibility Improvement

\begin{tabular}{|c|c|c|c|c|c|}
\hline \multirow{2}{*}{ Census ID } & \multicolumn{2}{|c|}{$\begin{array}{c}\text { Census District } \\
\end{array}$} & \multicolumn{2}{|c|}{ Accesslble Polygons } & \multirow{2}{*}{$\begin{array}{c}\text { Accesslble to Total } \\
\text { Comparison }\end{array}$} \\
\hline & Network Lengths & Segment Count & Network Lengths & Segment Count & \\
\hline 5050124.01 & 25,619 & 173 & 16,630 & 137 & $64.9 \%$ \\
\hline 5050124.02 & 16,394 & 95 & 12,068 & 79 & $73.6 \%$ \\
\hline 5050124.03 & 14,259 & 87 & 13,283 & 83 & $93.1 \%$ \\
\hline 5050124.04 & 23,677 & 140 & 16,955 & 119 & $71.6 \%$ \\
\hline 5050125.01 & 34,753 & 236 & 21,926 & 169 & $63.1 \%$ \\
\hline 5050125.02 & 17,148 & 121 & 15,500 & 111 & $90.4 \%$ \\
\hline 5050125.04 & 24,027 & 159 & 20,926 & 143 & $87.1 \%$ \\
\hline 5050125.05 & 28,193 & 170 & 22,002 & 160 & $78.0 \%$ \\
\hline 5050125.06 & 15,128 & 124 & 11,752 & 85 & $77.7 \%$ \\
\hline 5050125.07 & 18,623 & 134 & 15,613 & 117 & $83.8 \%$ \\
\hline 5050125.08 & 19,997 & 133 & 16,872 & 117 & $84.4 \%$ \\
\hline 5050125.09 & 20,557 & 160 & 19,497 & 154 & $94.8 \%$ \\
\hline 5050170.01 & 11,173 & 65 & 11,173 & 65 & $100.0 \%$ \\
\hline 5050170.03 & 14,564 & 94 & 13,429 & 91 & $92.2 \%$ \\
\hline 5050170.04 & 13,071 & 102 & 11,827 & 95 & $90.5 \%$ \\
\hline 5050170.05 & 16,196 & 120 & 14,288 & 108 & $88.2 \%$ \\
\hline 5050170.07 & 14,886 & 83 & 11,070 & 72 & $74.4 \%$ \\
\hline 5050170.08 & 31,147 & 149 & 24,055 & 130 & $77.2 \%$ \\
\hline 5050170.09 & 10,347 & 80 & 9,599 & 78 & $92.8 \%$ \\
\hline 5050170.10 & 18,950 & 122 & 16,872 & 109 & $89.0 \%$ \\
\hline 5050170.11 & 9,932 & 75 & 8,360 & 65 & $84.2 \%$ \\
\hline 5050171.01 & 23,904 & 134 & 15,555 & 112 & $65.1 \%$ \\
\hline 5050171.02 & 8,772 & 29 & 2,903 & 17 & $33.1 \%$ \\
\hline
\end{tabular}

The highlighted rows in Table 5.3 represent Census districts with "accessible" versus total kilometre ratios less than $75 \%$. A municipality could realistically set a target to which new developments would be required to conform. Planned road and pedestrian networks would have to be designed such that accessibility was maximized. Increasing accessibility for established neighbourhoods would be more difficult to achieve. Areas identified as "deficient" could be identified for future consideration if road reconstruction or redevelopment options arose. 


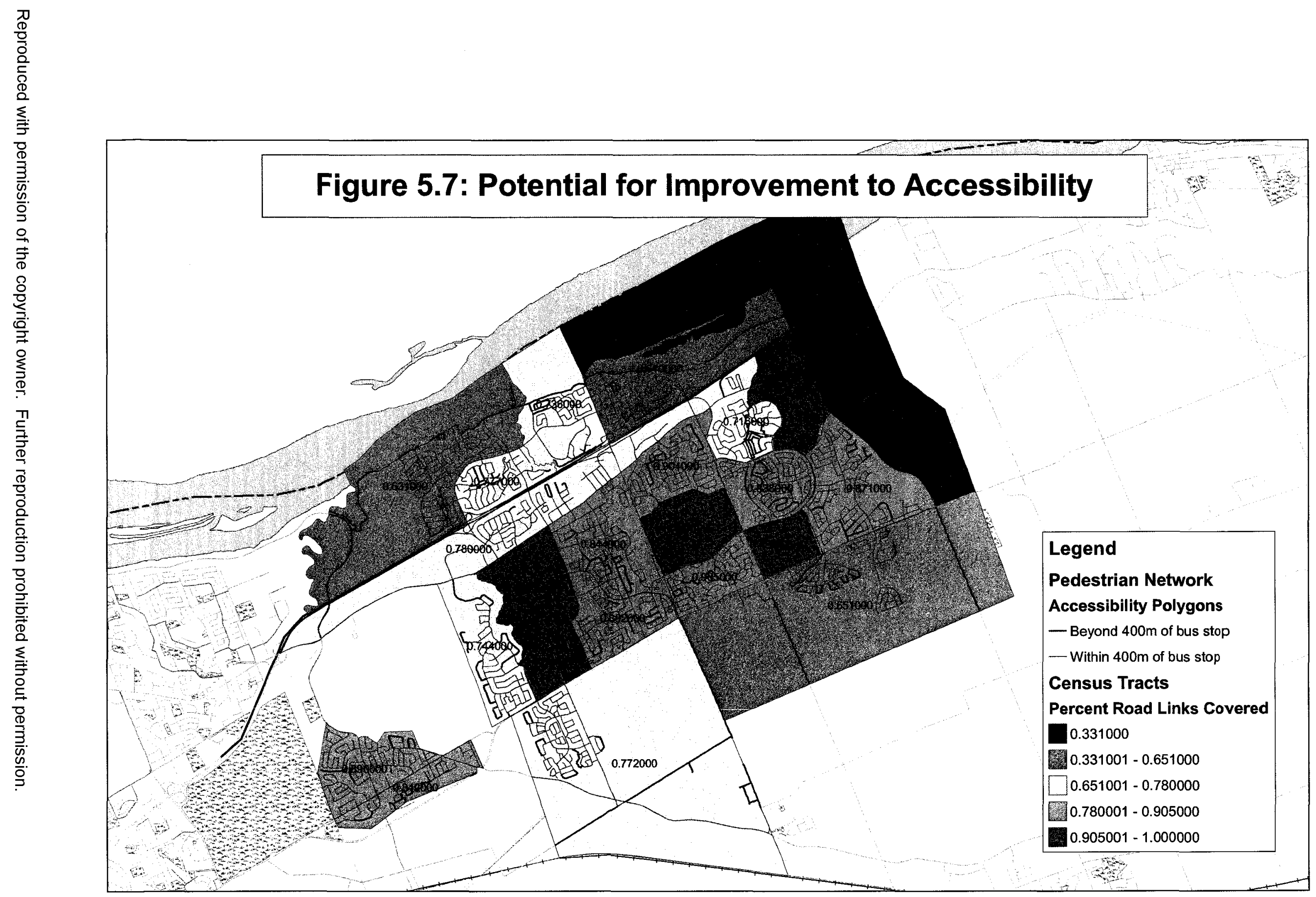


The potential for improved accessibility was shown to be highest in the outlying parts of the study area and lowest within the more compact, central parts. This is largely due to the lengths of limited access roadways that extend to other parts of the community and into the larger City of Ottawa. These roadways are parkways, highways and arterial roadways with little transit ridership potential. It would be useful to eliminate such roadways from the analysis so as not to unduly influence the results.

\subsubsection{Validation Data}

Actual transit ridership data was obtained for the year 2002 from OC Transpo. The Automatic Passenger Counting (APC) system was undergoing changes in 2001 and as such, 2002 represented a more reliable year for data. A sample of the APC reports and explanatory notes are included in Appendix C.

All day passenger activity data was obtained for all bus stops within the study area, grouped by Census district for ease of use. In 2002, the Place d'Orléans transit station (see Figure 5.8) included the highest activity stops within the study area. Most local and express routes running within the eastern half of Orléans passed through the Place d'Orléans transit station. This meant that many passengers transferred at the station from a local service to other routes (e.g. expresses and transitway routes) destined for downtown Ottawa or locations outside Orléans. In this study area example, the Place d'Orléans transit station essentially represents a downtown business district in a more traditional small municipality. 
All passenger boarding and alighting data obtained through OC Transpo was assessed within each Census district to determine the actual level of activity. In order to avoid double counting passengers that transferred at the Place d'Orléans transit station (on its own, it is neither a significant origin nor destination) the passenger activity at the station stops was subtracted from that Census district's total activity (i.e. Census ID $5050124.01)$.

The following table (Table 5.4) lists the total ridership (i.e. boarding and alighting counts) for each Census district for a typical day.

Table 5.4 - Actual and Adjusted Transit Ridership

\begin{tabular}{|l|c|c|}
\hline Census ID & $\begin{array}{c}\text { Actual Ridership } \\
\text { (on and offs) }\end{array}$ & $\begin{array}{c}\text { Adjusted } \\
\text { Ridership (on } \\
\text { and offs) }\end{array}$ \\
\hline 5050124.01 & 22,860 & 4,210 \\
\hline 5050124.02 & 2,836 & 2,836 \\
\hline 5050124.03 & 3,773 & 3,773 \\
\hline 5050124.04 & 1,813 & 1,813 \\
\hline 5050125.01 & 1,234 & 1,234 \\
\hline 5050125.02 & 1,504 & 1,504 \\
\hline 5050125.04 & 1,259 & 1,259 \\
\hline 5050125.05 & 2,015 & 2,015 \\
\hline 5050125.06 & 1,062 & 1,062 \\
\hline 5050125.07 & 1,606 & 1,606 \\
\hline 5050125.08 & 1,154 & 1,154 \\
\hline 5050125.09 & 1,032 & 1,032 \\
\hline 5050170.01 & 1,121 & 1,121 \\
\hline 5050170.03 & 1,464 & 1,464 \\
\hline 5050170.04 & 1,268 & 1,268 \\
\hline 5050170.05 & 1,012 & 1,012 \\
\hline 5050170.07 & 1,974 & 1,974 \\
\hline 5050170.08 & 1,070 & 1,070 \\
\hline 5050170.09 & 1,733 & 1,733 \\
\hline 5050170.10 & 2,087 & 2,087 \\
\hline 5050170.11 & 851 & 851 \\
\hline 5050171.01 & 763 & 763 \\
\hline 5050171.02 & 6 & 6 \\
\hline \hline Total & 55,497 & 36,847 \\
\hline
\end{tabular}


In preparing the data for this comparison it was necessary to adjust the actual data to account for the transfer of passengers at the Place d'Orléans station. Approximately 22,900 passenger boardings and alightings take place within the Census district containing the station. Of these, 19,000 were passenger transfers at the Place d'Orléans station. The remaining 4,200 passenger trips in this Census district are considered to be related to either Census or geographic-type land uses.

\subsubsection{Prediction of Transit Use in Orléans}

The development of a predictive method to explain 2001 transit use was determined to be an important part of the transit ridership forecasting tool. Once key characteristics to predict baseline transit ridership levels are established it is a relatively straightforward process to incorporate future considerations. The effects of population growth on transit ridership can be modelled and also, new land uses such as schools, employment or commercial can be included.

Transit usage for each Census zone within the Orléans area was predicted using a combination of existing transit ridership data from OC Transpo and Census data from Statistics Canada. These sources reflect the years 2002 and 2001, respectively. Supplemental data was obtained from the National Capital Region (NCR) origindestination survey for the year 2005 .

The existing transit ridership levels were predicted using a four step process that included: 
1. Establishing "work-related" transit use;

2. Establishing "school-related" transit use;

3. Establishing transit use for "other" purposes than for work and school, and

4. Combining all three types of transit use.

\section{Local Transit Use Characteristics}

A group comprised of all three levels of government (municipal, provincial and federal) currently holds the responsibility for coordinating transportation planning efforts within the NCR. The group is called the TRANS Committee and includes the National Capital Commission, the Ministère des Transports du Québec, the Ministry of Transportation of Ontario, Ville de Gatineau, the City of Ottawa, and the Société de transport de l'Outaouais.

The TRANS Committee's most recent undertaking is an update to its long-term transportation forecasting model. An origin-destination survey was undertaken to accomplish this. Through telephone interviews with 5\% of all NCR households the survey sought to determine a variety of trip-making characteristics including trip purpose, trip time, location and mode and demographics.

The NCR survey was conducted in 2005 which is a different horizon than other key data sources used for this analysis. Census data and City of Ottawa data are from 2001 and 2002 as noted above. Significant population growth has occurred within Orléans over the past decade which introduces a disparity between the two sets of data as the total number 
of trips has likely increased proportionately. As such, the 2005 NCR person-trip data was only used to calculate proportions of trips made for different trip purposes (e.g. work, school and other) instead of relying on magnitude of trips made.

The NCR survey estimates that $27 \%$ of transit trips' purpose is "to work", $20 \%$ is "to school" and 6\% are other purposes as shown in Table 5.5. A "return home" trip purpose is also identified as $47 \%$ of all daily transit trip purposes. The trips identified as "return home" were assumed to be the return portions of "to work" and "to school" trips. In general, the NCR survey data regarding trip purpose shows that fewer "discretionary" trips (e.g. shopping, recreational, social) are made by transit users than by auto users.

\section{Table 5.5- NCR Trip Data by Trip Purpose}

\begin{tabular}{|c|c|c|c|c|}
\hline Trip Purpose & $\begin{array}{c}\text { Transit } \\
\text { Person-trips }\end{array}$ & $\begin{array}{c}\text { Percent of Total } \\
\text { Transit Trips }\end{array}$ & $\begin{array}{c}\text { Auto } \\
\text { Person-trips }\end{array}$ & $\begin{array}{c}\text { Percent of Total } \\
\text { Auto Trips }\end{array}$ \\
\hline Work & 13,450 & $27 \%$ & 39,192 & $18 \%$ \\
\hline School & 9,715 & $20 \%$ & 5,213 & $2 \%$ \\
\hline Shopping & 813 & $2 \%$ & 25,553 & $11 \%$ \\
\hline Recreation & 660 & $1 \%$ & 13,604 & $6 \%$ \\
\hline Restaurant & 33 & $0 \%$ & 5,281 & $2 \%$ \\
\hline Visit friends/family & 766 & $2 \%$ & 6,545 & $3 \%$ \\
\hline Medical/Dental & 305 & $1 \%$ & 4,261 & $2 \%$ \\
\hline Drive someone somewhere & 18 & $0 \%$ & 11,360 & $5 \%$ \\
\hline Pick someone up & 206 & $0 \%$ & 8,676 & $4 \%$ \\
\hline Return home & 23,264 & $47 \%$ & 94,429 & $42 \%$ \\
\hline Other & 378 & $1 \%$ & 8,935 & $4 \%$ \\
\hline Total & 49,607 & $100 \%$ & 223,048 & $100 \%$ \\
\hline
\end{tabular}

\section{Work Trips}

The number of daily transit boardings and alightings in Orléans in 2001 was 36,000, based on APC data obtained from OC Transpo. The number of passenger boardings and 
alightings was adjusted to account for the high number of passenger transfers at the Place d'Orléans station, as indicated above. In addition, the Census zones were adjusted to exclude two predominantly rural census districts from the analysis. The latter were considered to be outliers given their high population base and low or non-existent transit ridership (i.e. due to lack of transit service).

The 2005 NCR origin-destination survey estimate of the proportion of transit trips related to work for 2005 assuming that trips "from" work are equal to trips "to" work. Trips to school were identified as representing $20 \%$ of total daily trips. This represents 19,500 trips of the total daily transit trips made in Orléans in 2001.

For each Census district, the number of employed persons who use transit as the mode of choice to get to work is provided within the Census data. A total of 13,100 transit users were identified within the urban Census districts in Orléans, excluding the two rural areas discussed earlier. Given that these 13,100 transit users likely made the 19,500 trips recorded by APC equipment, an average trip generation rate of 1.5 trips per user was established for work-related transit trips.

Work-based transit trips were assumed to be directly related to the number of residents within each Census district. A regression analysis was carried out to determine the relationship between Census District population and number of work-related transit users. The regression analysis yielded the following relationship: 


$$
\text { Work-related Transit Users Census ID }=0.139 *(\text { Population Census ID })+5.1
$$

Table 5.5 includes the regression statistics that apply to this data set. Figure 5.9 shows the graphical relationship between Work-related Transit Users and Census District population.

Table 5.6 - Regression Statistics for Work-related Transit Trips

\begin{tabular}{ll}
\hline \multicolumn{2}{c}{ Regression Statistics } \\
\hline Multiple R & 0.689 \\
R Square & 0.474 \\
Adjusted R Square & 0.446 \\
\hline
\end{tabular}

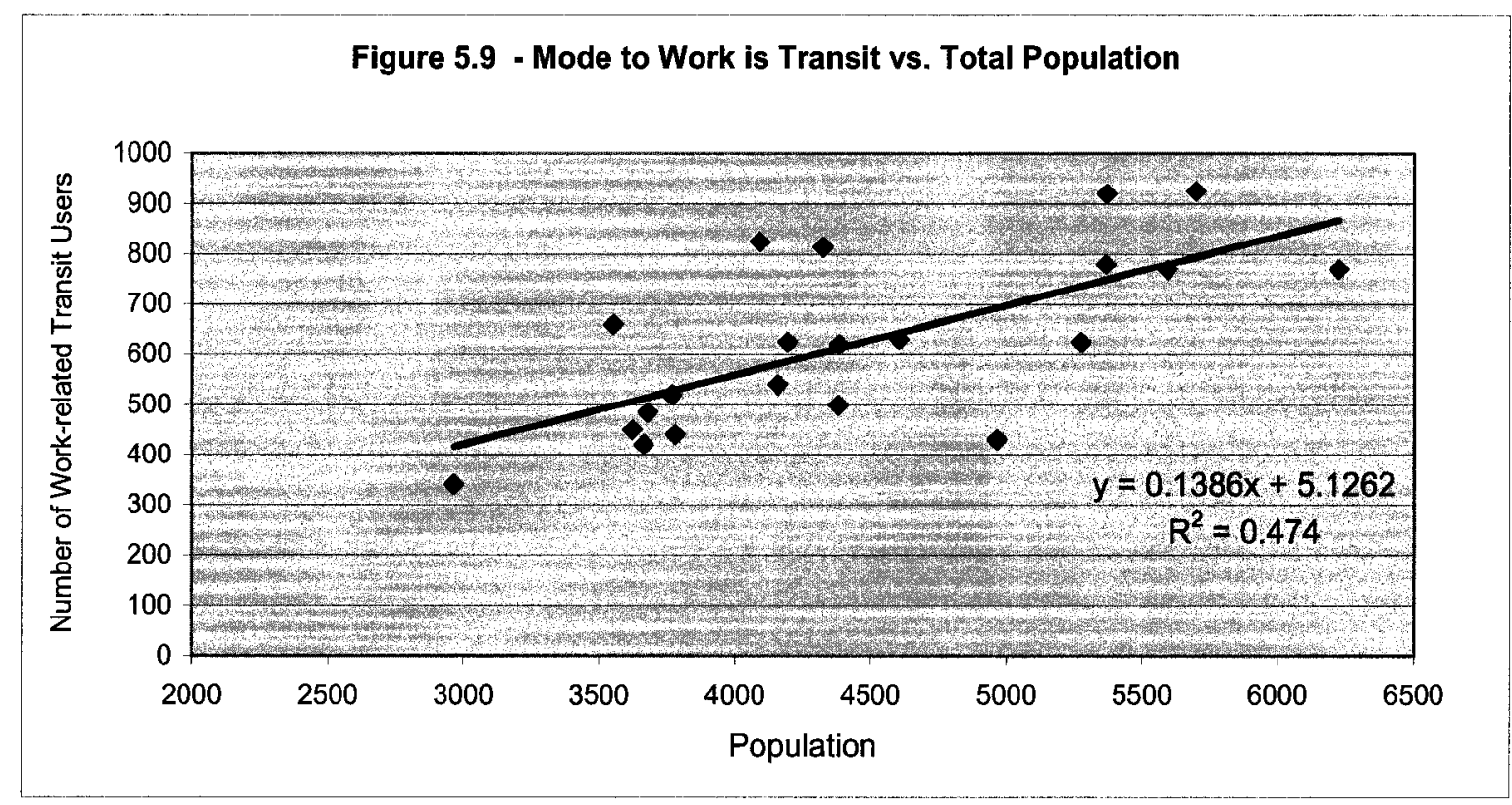

Establishing a relationship between population and workers that use transit is useful for forecasting the number of potential transit users for a future time horizon where growthrelated population predictions are made. Municipal planning departments typically make 
such forecasts for horizons up to 20 years into the future. This would constitute readilyavailable data that transit authorities in smaller municipalities would have access to.

Non-work related trips were defined as the trips related to school, key destinations (e.g. commercial, social, institutional) and discretionary trips (i.e. "other" trips). Each is described in more detail below, including a means to quantify their magnitude.

\section{School Trips}

School-related trips were separated by type of school to determine which had relevance to transit use. The distribution of school-related trips is shown in Table 5.7 and is based on the 2005 NCR origin-destination survey. It should be noted that the survey excludes trips made by school buses.

\section{Table 5.7 - 2005 Origin-Destination Survey School Trip Data}

24-hour Period

National Capital Region (NCR) School Trips for Orléans (All modes)

\begin{tabular}{lcc} 
& Number of Trips & Percent of Trips \\
\hline From District & 9,930 & $42 \%$ \\
To District & 2,520 & $11 \%$ \\
Within District & 11,440 & $48 \%$ \\
\cline { 2 - 3 } & 23,890 & $100 \%$
\end{tabular}

Given that there are no post-secondary education institutions in Orléans, the "From District" school trips were associated with travel to other locations within the City of Ottawa. It was assumed that a similar number of "From District" trips as "To District" trips would occur because of middle schools or high schools located in proximity to the 
border of Orléans. The school-related trips identified as being "Within District" were subject to closer examination.

From Table 5.5, we see that 9,700 trips with a school purpose were made using transit as compared to 5,200 made using the auto mode. Half of school-related trips were assumed to be home-based and thus related to Census characteristics. The other half of schoolrelated trips were assumed to be associated with the geographic locations of middle and high schools (i.e. destination-based). Home base trips were grouped with "other" trip purposes and are discussed below.

To establish the number of geography-based school trips, student populations were identified for area schools that would have transit service available. This information is contained in Table 5.8 .

Table 5.8 - Estimated Transit Use in Orléans Schools

\begin{tabular}{llcc} 
CATEGORY & NAME & Students & Transit Users* \\
\hline Secondary & Garneau (Ecole secondaire cath.) & 800 & 200 \\
Intermediate & Leo-D.-Cote (ecole intermediaire) & 400 & 100 \\
Elementary/Secondary & St. Matthew Catholic E.S. \& H.S. & 1400 & 350 \\
Elementary/Secondary & St. Peter Catholic E.S. \& H.S. & 1900 & 475 \\
Secondary & Cairine Wilson Secondary School & 1000 & 250 \\
Intermediate & Emily Carr Middle School & 700 & 175 \\
Secondary & Sir Wilfrid Laurier Secondary School & 1100 & 275 \\
\hline & & $\mathbf{7 3 0 0}$ & $\mathbf{1 8 2 5}$ \\
\hline
\end{tabular}

* Estimated that $25 \%$ of students take public transit 
Each transit user was assumed to make two trips to a school in a 24-hour period. A total of 3,950 geography-based school trips were assigned to the appropriate Census Districts (i.e. those containing the above-noted schools).

\section{Trips to Key Destinations}

As with geography-based school trips, transit trips made to identifiable destinations within Orléans were estimated. Smaller municipalities can generally rely on better anecdotal information about the major employers, businesses and institutions within their boundaries. Qualitative information can be used to rank each of these transit ridership generators. As suggested earlier, in the absence of more definitive information "high", "medium" and "low" ranks would suit this purpose. These were assigned ridership levels of 10,50 and 100 transit trips, respectively.

The "accessibility" factor applies to these key destinations. A destination must be within close proximity to transit access points (i.e. bus stops) in order to provide transit riders with a good level of service. The same 400 -metre threshold is applied in this case study in order to gauge how well the transit system is serving these destinations but other accessibility targets can be adopted.

The Network Analyst software extension was used to measure which of the destinations fell within the 400-metre range of a bus stop. All 134 of the key locations highlighted as key destinations fell within the target accessibility threshold as shown in Figure 5.10. If some destinations had fallen outside the distance threshold, these would have been 


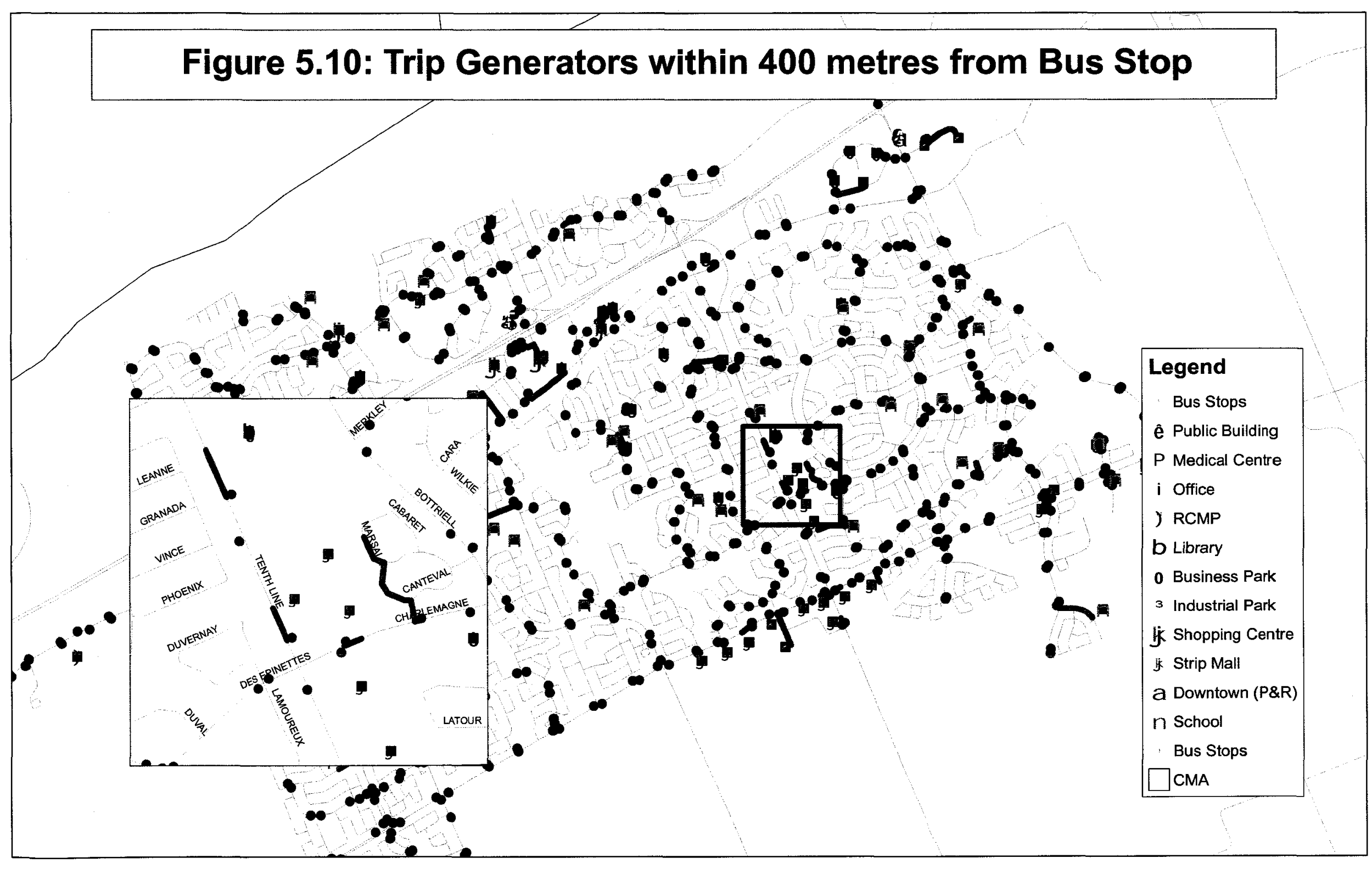


identified as requiring transit service attention, prioritized according to their transit ridership potential rank.

At this point a note of caution must be included with respect to the method of assigning non-connected features to the network (i.e. bus stops and points of interest). As illustrated in some of the figures, bus stops and points of interest are not "attached" to the transportation network. Through a GIS software process, these points are assigned the location of the nearest known transportation network node or segment edge, and the distance from this nearest node is included as an attribute.

The network connectivity issue is illustrated in Figure 5.11 which shows an office building that is physically distant from the transportation network. A 40-metre distance separates the point representing the office from the nearest network node. A slightly shorter distance separates the route end and the nearest bus stop. The total route length calculated between these points could exceed the targeted 400 metres because of these additional connecting links that are not included within the transportation network length calculation. As such, careful attention must be paid to the tolerances accepted when establishing the network.

As described in Chapter 4, the formula to calculate transit ridership potential at key destinations is:

Transit Destination Potential ID $=\left(\mathrm{k}_{\mathrm{l}} * \Sigma_{\mathrm{ID}} \mathrm{P}_{\mathrm{l} I \mathrm{ID}}\right)+\left(\mathrm{k}_{\mathrm{m}} * \Sigma_{\mathrm{ID}} \mathrm{P}_{\mathrm{m} I \mathrm{DD}}\right)+\left(\mathrm{k}_{\mathrm{h}} * \Sigma_{\mathrm{ID}} \mathrm{P}_{\mathrm{h} \text { ID }}\right)$ 


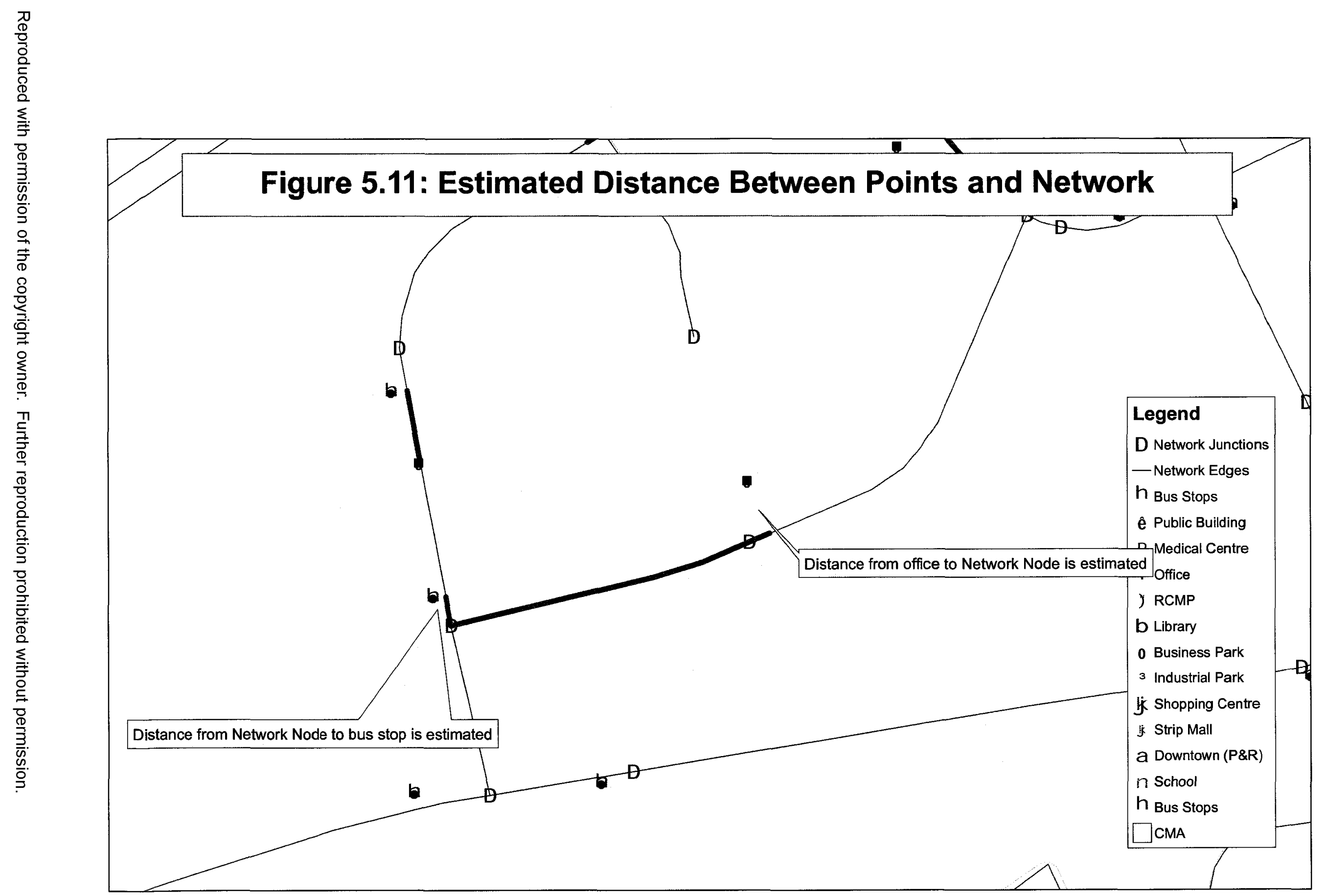


For illustrative purposes, transit potential constants were assigned to each of the ranks as follows:

$$
\begin{aligned}
& \mathrm{k}_{1} \text { ("low" ranked destinations) }=10 \text { transit; } \\
& \mathrm{k}_{\mathrm{m}} \text { ("medium" ranked for destinations) }=50 \text { transit trips; and } \\
& \mathrm{k}_{\mathrm{h}} \text { ("high" ranked for destinations) }=100 \text { transit trips. }
\end{aligned}
$$

In practice, a municipality could define the transit potential for each specific employment, commercial or institutional land use of interest based on local knowledge or surveys.

An example of the calculation of Transit Destination Potential is included below for Census ID $=5050125.07$.

Transit Destination Potential $5050125.07=(3$ low destinations $* 10)$

$$
\begin{aligned}
& +(3 \text { medium destinations } * 50) \\
& +(\text { no high destinations } * 100) \\
& =180 \text { potential transit trips }
\end{aligned}
$$

The following table (Table 5.10) summarizes the destination potential for all Census Districts using the established formula. The Census District and key destinations within it are highlighted in Figure 5.12. 


\section{Table 5.9 - Transit Destination Potential}

\begin{tabular}{|l|c|}
\hline Census ID & $\begin{array}{c}\text { Transit Destination } \\
\text { Potential }\end{array}$ \\
\hline 5050124.01 & 10 \\
\hline 5050124.02 & 110 \\
\hline 5050124.03 & 200 \\
\hline 5050124.04 & 200 \\
\hline 5050125.01 & 20 \\
\hline 5050125.02 & 30 \\
\hline 5050125.04 & 30 \\
\hline 5050125.05 & 620 \\
\hline 5050125.06 & 10 \\
\hline 5050125.07 & 180 \\
\hline 5050125.08 & 100 \\
\hline 5050125.09 & 20 \\
\hline 5050170.01 & 30 \\
\hline 5050170.03 & 60 \\
\hline 5050170.04 & \\
\hline 5050170.05 & 80 \\
\hline 5050170.07 & \\
\hline 5050170.08 & \\
\hline 5050170.09 & \\
\hline 5050170.10 & 30 \\
\hline 5050170.11 & 110 \\
\hline Total & 1840 \\
\hline
\end{tabular}

\section{“Other" Trips}

Trips that were neither related to work nor to school and that were not attributable to a given "key destination" were grouped into a catch-all category. "Other" trips were determined to be related to Census characteristics as opposed to given geographic sites. The second half of school-related trips was also placed in this category.

A multivariate linear regression of over 70 Census characteristics was carried out to determine the relationship between these characteristics and the number of users employing transit for "other" purposes. A step-wise method was used to select noncorrelated independent variables. 
The regression analysis yielded the following relationship:

“Other" Transit Users Census ID $=-19.33 *($ Number of Males Working at Home Census ID)

$+13.3 *$ ( Number of Persons 65 Years and Over Living Alone Census ID) +1212

The "males working at home" variables has a correlation of -0.54 with the number of "other transit trips" while the " 65 year olds living alone" variable has a correlation of 0.42 . These two independent variables have a correlation of 0.13 which is within acceptable limits. Table 5.10 includes other regression statistics that apply to this data.

Table 5.10 - Regression Statistics for "Other" Transit Trips

\begin{tabular}{ll}
\hline \multicolumn{2}{c}{ Regression Statistics } \\
\hline Multiple R & 0.739 \\
R Square & 0.546 \\
Adjusted R Square & 0.495 \\
\hline
\end{tabular}

The predicted number of "other" transit trips was adjusted to account for certain Census districts where values were less than zero. Totals were then normalized to maintain a consistent total number of "other" transit trips overall (i.e. 9,900 trips).

\section{Total Predicted Transit Ridership}

The final estimate of transit ridership within each Census districts combines all transit trip types (i.e. work, school, key destinations and "other"). Results are presented in Table 5.11. Figure 5.13 highlights the difference between actual and predicted ridership. 
Table 5.11 - Summary of Transit Ridership by Census District

\begin{tabular}{|c|c|c|c|c|c|c|c|c|}
\hline \multirow[t]{2}{*}{ Census ID } & $\begin{array}{c}\text { Population } \\
\text { (2001 Census) }\end{array}$ & $\begin{array}{c}\text { Mode to Work is } \\
\text { Transit } \\
\text { (2001 Census) }\end{array}$ & $\begin{array}{c}\text { Transit Activity } \\
\text { Total } \\
\text { (daily boardings } \\
\text { and alightings) }\end{array}$ & $\begin{array}{c}\text { Estimated } \\
\text { Work-related } \\
\text { Transit Trips* }\end{array}$ & $\begin{array}{c}\text { Estimated } \\
\text { School-based } \\
\text { Transit Trips ** }\end{array}$ & \begin{tabular}{c|} 
Estimated \\
Transit Trips \\
$\quad$ for Key \\
Destinations**
\end{tabular} & $\begin{array}{l}\text { Estimated "Other" } \\
\text { Transit Trips } \\
\text { (based on Census } \\
\text { characteristics) }\end{array}$ & $\begin{array}{l}\text { Total of All Transit } \\
\text { Trip Types (work, } \\
\text { school, other) }\end{array}$ \\
\hline & \multicolumn{2}{|c|}{ [number of persons] } & \multicolumn{6}{|c|}{ [number of transit trips] } \\
\hline 5050124.01 & 3,622 & 450 & 4,210 & 675 & & 10 & 1,735 & 2,420 \\
\hline 5050124.02 & 4,090 & 825 & 2,836 & 1,238 & 700 & 110 & 973 & 3,021 \\
\hline 5050124.03 & 5,370 & 920 & 3,773 & 1,380 & 500 & 200 & 477 & 2,557 \\
\hline 5050125.01 & 5,276 & 625 & 1,234 & 938 & 175 & 20 & 0 & 1,133 \\
\hline 5050125.02 & 3,679 & 485 & 1,504 & 728 & 175 & 30 & 601 & 1,534 \\
\hline 5050125.04 & 4,379 & 500 & 1,259 & 750 & & 30 & 0 & 780 \\
\hline 5050125.05 & 5,699 & 925 & 2,015 & 1,388 & 600 & 620 & 166 & 2,774 \\
\hline 5050125.06 & 4,964 & 430 & 1,062 & 645 & & 10 & 336 & 991 \\
\hline 5050125.07 & 3,664 & 420 & 1,606 & 630 & & 180 & 601 & 1,411 \\
\hline 5050125.08 & 5,367 & 780 & 1,154 & 1,170 & & 100 & 0 & 1,270 \\
\hline 5050125.09 & 3,779 & 440 & 1,032 & 660 & & 20 & 810 & 1,490 \\
\hline 5050170.01 & 4,324 & 815 & 1,121 & 1,223 & & 30 & 0 & 1,253 \\
\hline 5050170.04 & 4,193 & 625 & 1,268 & 938 & & & 872 & 1,810 \\
\hline 5050170.05 & 4,157 & 540 & 1,012 & 810 & & 80 & 353 & 1,243 \\
\hline 5050170.07 & 6,224 & 770 & 1,974 & 1,155 & 750 & & 54 & 1,959 \\
\hline 5050170.08 & 2,965 & 340 & 1,070 & 510 & & & 320 & 830 \\
\hline 5050170.09 & 5,593 & 770 & 1,733 & 1,155 & 750 & & 155 & 2,060 \\
\hline 5050170.10 & 4,382 & 620 & 2,087 & 930 & & 30 & 1,407 & 2,367 \\
\hline 5050170.11 & 3,768 & 520 & 851 & 780 & & 110 & 0 & 890 \\
\hline TOTAL & 105,871 & 13,090 & 35,227 & 19,635 & 3,925 & 2,040 & 9,875 & 35,750 \\
\hline$\%$ of Transit & ity Total & & $100 \%$ & $56 \%$ & $11 \%$ & $6 \%$ & $28 \%$ & \\
\hline
\end{tabular}

* Work-related transit trips estimated based on number of work-related transit users, transit activity and NCR origin-destination data.

** Estimation based on geographic location 
Figure 5.13 - Comparison of Actual and Predicted Transit Ridership Levels

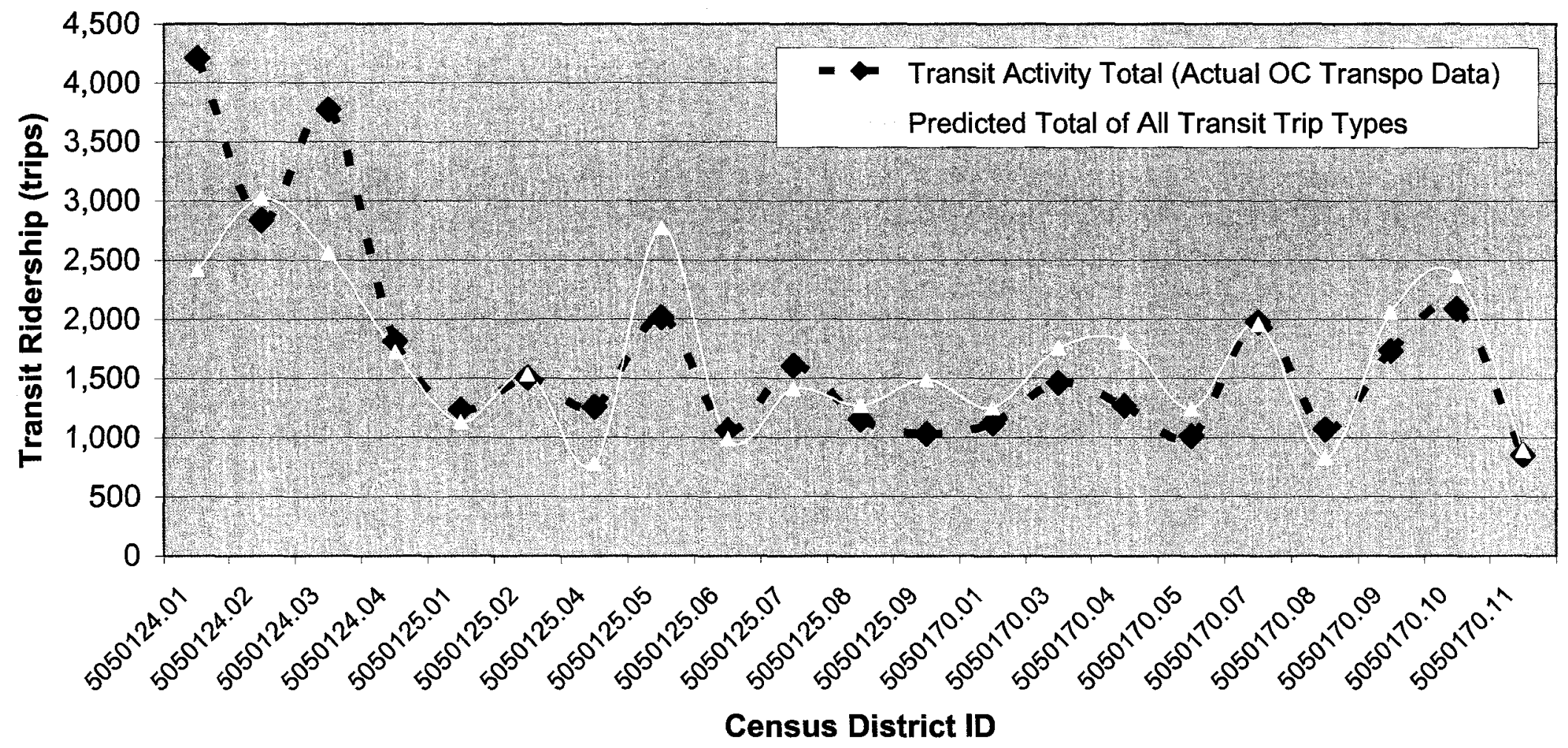




\subsection{Future Growth Considerations}

An important consideration for transit planners is the future time horizon. The Orléans population is expected to increase to 140,000 by 2021 . This represents a $40 \%$ increase over 2001. The high transit modal share in Orléans in 2001 must continue to grow to compensate for limited opportunities to accommodate travel demand growth by increasing roadway capacity (City of Ottawa, 2003).

The transit ridership forecasting tool developed allows the user to incorporate future growth considerations. The user can adjust population levels to reflect future levels or can modify expected transit ridership values for specific geographic-based land use types (e.g. schools, employment, commercial, recreational, etc.) and establish the resulting transit ridership by Census district.

The analysis carried out thus far should be combined with future population and employment growth plans to determine whether transit improvement priorities should be adjusted. Alternatively, other means to attract transit riders could be pursued or a combination of both. Flexible transit services can provide an alternative to conventional fixed route transit service and can reach different transit ridership markets (Koffman, 2004). 


\section{Chapter 6: Conclusions and Recommendations}

Transit systems are under constant pressure to deliver cost-effective, convenient and frequent service to their customers (CUTA, 1993). In smaller transit systems, these pressures are generally compounded by a need to concentrate efforts on service operations as opposed to service planning. This makes it difficult to assess opportunities to enhance service through route changes or implementation of new routes.

Advances in the availability and quality of spatial data combined with an increased use of GIS software within transit or other municipal departments offer transit systems better opportunities to undertake service planning initiatives. Such initiatives will become increasingly important as shifts in transit funding at provincial and federal levels are leading to increased budgets for transit systems. Funds must be spent strategically in order to make the most effective service improvement decisions.

\subsection{Conclusions}

The need for small municipalities with transit systems to forecast transit ridership is met through the GIS-based tool developed through this thesis. The tool is appropriate to forecast transit ridership potential given the readily-available Census data from Statistics Canada. Use of this tool would reduce the time and effort that a municipality would set aside to undertake its own survey and assessment of ridership potential. 
Census information is supplemented by local knowledge of key destinations such as employment, institutional and recreational land uses is also incorporated to provide both origin and destination transit ridership potentials. A final element of accessibility is incorporated by including bus stop locations and pedestrian linkages into a GIS and using a network analysis software extension within the GIS.

Through use of readily available data this GIS-based tool is within the realm of products a small municipality with limited resources can use. It provides a good foundation upon which small municipalities can assess the transit implications of future growth. The predictive aspect of the tool produced good results by grouping transit trip purposes into work, school and "other" categories. Additional efforts would be useful to establish trends between Census characteristics and actual transit ridership.

The presence of pedestrian linkages in a transportation network is important. The accessibility of transit bus stops improves when such links are present. This should be an important consideration in neighbourhood planning and design. Deficiencies in accessibility are highlighted by the GIS-based tool developed and can help municipal planners define and prioritize pedestrian network improvements. The Case Study showed that the pedestrian transportation in Orléans is well-suited to transit use with much of the developed area located within a 400-metre distance from transit stops.

The Canadian Census survey collects and processes a tremendous amount of data that can be useful to the transportation planning sector. Transit planners should take advantage of 
socio-economic, demographic and "travel to work" data available through the Canadian Census to assess transit ridership potential. Indices can be tailored to each municipality and validated using actual ridership data.

Since planning initiatives focus on the longer term, the five-year Census cycle is wellsuited for the purpose of transit planning. This represents a cost-effective means to gain an understanding of a community's transit ridership potential which could be supplemented by additional, focused surveys or data collection exercises.

Smaller municipalities have a better opportunity to define their "destinations" for transit trips. Transit staff should work with municipal planning staff to maintain up to date records of key destinations. A good understanding of land use patterns is essential in understanding impacts on transit demand (Verma and Dhingra, 2005). Periodic workplace surveys could be used to supplement transit ridership estimates. In addition, information about planned developments and their related transit ridership potential should be factored into any system changes. Best practices suggest that a higher rate of transit ridership success should be expected when the provision of transit service precedes development (Cervero et al., 2004).

The increasing use of GIS tools within the municipal context provides additional opportunities for analysis support to smaller transit systems that might not have the human resource capacity or analytic skills to undertake such analysis on their own. 
Improvements and/or changes to the transit system must be evaluated over time. Research has shown that it is difficult to quantify the effect of service changes on ridership. However, transit ridership appears to maintain stability even through transit service changes (Pratt, 2004).

It is important to quantify transit ridership improvements in terms of additional transit users as opposed to gauging through increased number of passenger boardings and alightings. The latter could be related to routing changes that require passengers to transfer more frequently while not necessarily providing additional service (Pratt, 2004).

Measuring the success of transit service changes can be difficult. It can take anywhere from one to three years for new routes or systems to fully be established and patronized. And while restructuring of routes and/or transit service may cause disruption to transit users, there is little proof that suggests this will detrimentally impact ridership. Still, any route structure or service changes should be carefully assessed to ensure that transit users will experience a net benefit from such changes. It is suggested that public consultation be included within the analysis to gauge support for proposed changes prior to their consideration for implementation (Pratt, 2004).

The dimension of time as it relates to transit service was not addressed within this thesis. The GIS-tool developed is best suited for long term system planning as opposed to individual route analysis and as such the temporal relationship was not a component that 
was included. In trying to attract more transit users to the system however, travel time is important.

Best practices suggest that municipal assets be tracked through their useful life so that appropriate life-cycle planning can be carried out. For transit, this means buses, transit garages, bus shelters, etc. There is an opportunity to include GIS within the transit "toolbox" and use it for two different purposes: transit planning and asset management.

\subsection{Recommendations}

It would be useful to pursue a number of areas as a follow up to this thesis research. Transit ridership is dependant on a multitude of characteristics including family income, education, sex, home ownership, employment, household size, etc. Representative indices for the characteristics are available within Census tabulations. A ridership forecasting tool should consider that the inter-relationship between these characteristics is likely different within every small municipality or varies by community within large cities. Further study is required to refine and test the relationships between the demographic and socio-economic characteristics available from the Canadian Census for use in forecasting transit ridership potential.

Research is currently underway through the Canadian Urban Transit Association (CUTA) to establish a Canadian transit rider profile. It would be useful to compare the findings of the CUTA research (i.e. characteristics of Canadian transit users) with the Census characteristics selected in the transit user potential component of the GIS-based tool 
developed. Also, an opportunity to utilize the capabilities of Artificial Neural Networks exists in the examination of the Canadian transit rider profile. Further study in this area could be carried out in conjunction with the ongoing CUTA ridership profile study.

Suggestions for enhancement to the Canadian Census questionnaire are being sought by the Transportation Association Canada through their Urban Transportation Council and their Transportation Planning and Research Standing Committee (Transportation Association of Canada, 2007). Transportation planners would benefit from additional information that relates to travel to school, car availability, location of workplace and commute time. 


\section{References}

Alshalalfah, B.W. and A.S. Shalaby, Case Study: Relationship of Walk Access Distance to Transit with Service, Travel and Personal Characteristics, Journal of Urban Planning and Development, American Society of Civil Engineering, June, 2007.

Bach $\mathrm{L}$, The problem of aggregation and distance for analyses of accessibility and access opportunity in location - allocation models, Environment and Planning A, 13(8) $955-978,1981$. June 2007

Canadian Urban Transit Association, National Transit Strategy, Press release http://www.cutaactu.on.ca/en/node/1626

Canadian Urban Transit Association, Canadian Transit Handbook, Third Edition, Toronto, 1993.

Cervero, Robert, Steven Murphy, et. al, Transit-Oriented Development in the United States: Experiences, Challenges, and Prospects, Transit Cooperative Research Program (TCRP), TCRP Report 102, Transportation Research Board, Washington, 2004.

Chavarria, M., and J. Volinski, Identifying the Characteristics of Successful Local Transit Circulator Systems in Residential Areas of Southeast Florida, National Centre for Transportation Research, Centre for Urban Transportation Research, University of South Florida, Tampa, Florida, December 2004.

City of Ottawa, Transportation Master Plan, [online], http://www.ottawa2020.com

Czerniak, Robert J., Deming, New Mexico Transit Plan, New Mexico State University, Department of Geography, Presentation to the Institute of Transportation Engineering Annual Meeting, 2005.

Department of Finance Canada, Delivering on Commitments, Budget 2005, A New Deal for Canada's Communities, http://www.fin.gc.ca/budget05/pamph/pacome.htm (Last Updated: 2005-02-23)

ESRI, ArcGIS Network Analyst Tutorial, Redlands, California, 2006.

Federal Transit Administration, Best Practices for Using Geographic Data in Transit: A Location Referencing Guidebook, Defining Geographic Locations of Bus Stops, Routes and other Map Data for ITS, GIS and Operational Efficiencies, , U.S. Department of Transportation, Washington, DC 20590, April 2005, (Report Number: FTA-NJ-26-7044-2003.1)

Golden, Anne and Natalie Brender, Sustainable Urban Transportation, A Winning 
Strategy for Canada, The Conference Board of Canada, 2007

Henk, Russell H. and Sarah M. Hubbard, Developing an Index of Transit Service Availability, Transportation Research Record 1521, Washington, 1996.

Karimi, Hassan A., Ratchata Peachavanish, Robert, Steven Murphy, et. al, Finding Optimal Bus Service Routes: Internet-Based Methodology to Serve Transit Patrons, Journal of Computing in Civil Engineering, American Society of Civil Engineers, April, 2004.

Kittelson \& Associates Inc., KFH Group Inc., et al., Transit Capacity and Quality of Service Manual, Transit Cooperative Research Program (TCRP), TCRP Report 100, Transportation Research Board, Washington, 2003.

Koffman, David, Operational Experiences with Flexible Transit Services: $A$ Synthesis of Transit Practice, Transit Cooperative Research Program (TCRP), TCRP Synthesis 53, Transportation Research Board, Washington, 2004.

Ministry of Transportation Ontario, Ontario Provincial Gas Tax Funding http://www.mto.gov.on.ca/english/news/provincial/2004/102204b.htm (last modified October 22, 2004)

http://www.ptvamerica.com/main.html

Multisystems Inc., and Applied Geographics Inc., Using Geographic Information Systems for Welfare to Work Transportation Planning and Service Delivery: A Handbook, Transit Cooperative Research Program (TCRP), TCRP Synthesis 60, Transportation Research Board, Washington, 2000.

Ormsby, Tim, Eileen Napoleon, et.al., Getting to Know ArcGIS Desktop, ESRI Press, Redlands, California, 2004.

Pratt, Richard H. and John E. Evans, IV, et. al, Traveler Response to Transportation System Changes, Chapter 10-Bus Routing and Coverage, Transit Cooperative Research Program (TCRP), TCRP Report 95, Transportation Research Board, Washington, 2004.

Pulugurtha, S.S. and Shashi S. Nambisan, Evaluating Transit Market Potential and Selecting Locations of Transit Service Facilities Using GIS, Journal of Public Transportation, Vol. 2, No. 4, 1999.

Preparing Street Network Data for Use with the Network Dataset, ESRI, Redlands, California, U.S., September 2005. 
Regional Transportation Commission of Clark County, Metropolitan Planning Organization Division, Citizens Area Transit: Bus Stop Guidelines, Las Vegas, Neveda, U.S., 1999.

Riley, Sarah J., Development of a Public Transit Information System Using GIS and ITS Technologies, Carleton University, Ottawa, 2002.

Ruel, J., Utilisation des données sure les déplacements domicile-travail, suivi et caractérisation des navetteurs: une perspective sur 20 ans, Transportation Association of Canada Conference, 2004, http://www.tac-atc.ca/english/pdf/conf2004/ruel.pdf.

Rosenbloom, S., Transit Markets of the Future: The Challenge of Change, Transit Cooperative Research Program (TCRP), TCRP Report 28A, Transportation Research Board, Washington, 1998.

Statistics Canada. n.d. 2001 Population and Dwelling counts, 2001 Census of Population (46 Large Urban Centres, Census Tracts (neighbourhoods))(database). Using E-STAT (distributor). Version updated July 5, 2004. http://estat.statcan.ca/cgiwin/CNSMCGI.EXE?ESTATFILE=EStat $\backslash$ English $\backslash$ E-Main.htm (accessed August 16, 2005).

Statistics Canada. n.d. 2001 Labour Force Activity, Class of Worker, Occupation, Industry, Place of Work, Mode of Transportation, Language of Work and Unpaid Work, 2001 Census of Population (46 Large Urban Centres, Census Tracts (neighbourhoods))(database). Using E-STAT (distributor). Version updated July 5, 2004. http://estat.statcan.ca/cgi-win/CNSMCGI.EXE?ESTATFILE=EStat English $\backslash \square \underline{\text { E- }}$ Main.htm (accessed August 16, 2005).

Statistics Canada. n.d. 2001 School Attendance, Education, Field of Study, Highest Level of Schooling and Earnings, 2001 Census of Population (46 Large Urban Centres, Census Tracts (neighbourhoods))(database). Using E-STAT (distributor). Version updated July 5, 2004. http://estat.statcan.ca/cgiwin/CNSMCGI.EXE?ESTATFILE=EStat $\backslash$ English $\backslash \square$ E-Main.htm (accessed August 16, 2005).

Statistics Canada. n.d. 2001 Income and Social and Economic Characteristics of Individuals, Families and Households; Housing Costs and Religion, 2001 Census of Population (46 Large Urban Centres, Census Tracts (neighbourhoods))(database). Using E-STAT (distributor). Version updated July 5, 2004. http://estat.statcan.ca/cgiwin/CNSMCGI.EXE?ESTATFILE=EStat $\backslash$ English $\backslash$ E-Main.htm (accessed August 16, 2005).

Sutton, J.C., Geographic Information Systems Applications in Transit: $A$ Synthesis of Transit Practice, Transit Cooperative Research Program (TCRP), TCRP Synthesis 55, Transportation Research Board, Washington, 2004. 
TRANS Organization, [online], November, 2007, http://www.ncr-trans-rcn.ca

TransCAD, [online], August, 2007, http://www.caliper.com/

Transportation Association of Canada, [online], August, 2007, http://www.tac-atc.ca/english/informationservices/tacnews/summer2007\%2D8.htm

Transportation Case Studies in GIS, Case Study 6: GIS for Transit Planning at OCTA (Orange County), Federal Transit Administration, Washington, D.C., 2001 [online], http://tmip.fhwa.dot.gov/clearinghouse/docs/gis/octa/octa.pdf

Transportation Research Board, Making Transit Work, Insight from Western Europe, Canada and the United States, Special Report 257, National Research Council, National Academy Press, Washington, 2001.

Verma, Ashish and S.L. Dhingra, Optimal Urban Rail Transit Corridor Identification within Integrated Framework Using Geographical Information System, Journal of Urban Planning and Development, American Society of Civil Engineers, 2005.

Victoria Transportation Policy Institute, [online], August, 2007, http://www.vtpi.org/tdm/tdm84.htm

VISUM, [online], August, 2007, http://www.ptvamerica.com/main.html

Urban Transportation Monitor, Urban Transportation Planning Software, Part II, Lawley Publications, Burke, VA, June 25, 2004.

U. S. Department of Transportation, Intermodal Surface Transportation Equity Act, [online], August, 2007, http://www.dot.gov/ost/govtaffairs/istea/isteap\&p.html

Wright, Paul, Highway Engineering, 6th Edition, Wiley, 1996. 


\section{Appendix A Small Municipality Survey}




\section{McNeely, Stephanie}

Subject: $\quad$ FW: Small Transit Systems survey

Attachments: Small Sys Issues.doc; Transit_stats.xls

\section{Good Day,}

My name is Stephanie McNeely and I am a part-time student working on a research thesis at Carleton University in Ottawa. I recently attended the CUTA conference in Halifax but was not able to meet with everyone that I had hoped.

I am working on developing a Geographic Information System (GIS) tool for smaller transit systems to use to assess their ridership potential, based on Census data and other factors. As part of my research I am contacting a few Canadian transit systems with some questions.

I would like to confirm that in small systems, there isn't much time (or resources) for planning initiatives. Feel free to add any comments you want at the bottom of the survey.

I am also attaching a "quick statistics" table. If you have any of this info for your transit system that you could fill in that would be great. If not that's fine too. If you are able to get this back to me in the next week or two that would be much appreciated. I'm on the critical path with my project, and will be submitting my final research later this month. In exchange for your participation I will forward you a copy when I am done in case it can be of use to you.

Thanks in advance,

Stephanie

Stephanie McNeely, P.Eng

Associate

Dillon Consulting Limited

5310 Canotek Road, Suite 200

Gloucester, Ontario K1J 9N5

Phone: 613.745 .2213 ext. 103

Fax: 613.745.3491

Mobile: 613.864 .1711

Email: smcneely@dillon.ca 


\section{Survey Questionnaire}

How much time do you spend on operational issues versus planning issues?

What indices do you use to predict the effect of service changes (e.g. improvements/ expansion)?

Does your transit system currently use any GIS-based tools for data collection, service planning, information dissemination or other reason?

Is there human resource capacity within your organization for someone to learn how to use a new GIS-based tool to gauge the effect of service changes?

How important is it for your organization to be able to predict the impact of transit service improvements (i.e. increase service coverage and associated cost)?

What is the transit mode share versus private automobile (rough \%)? 


\section{Small Transit System Characteristics}

\begin{tabular}{|c|c|c|c|c|c|c|c|c|}
\hline City & Province & Population & $\begin{array}{l}\text { Land Mass } \\
\text { Total(sq.km) }\end{array}$ & $\begin{array}{c}\text { Land Mass } \\
\text { Served by } \\
\text { Transit (sq.km) }\end{array}$ & $\begin{array}{c}\text { Number of } \\
\text { Management/ } \\
\text { Planning staff }\end{array}$ & $\begin{array}{l}\text { Ridership } \\
\text { (annual) }\end{array}$ & $\begin{array}{c}\text { Revenue } \\
\text { Kilometres }\end{array}$ & Comments \\
\hline Brandon & Manitoba & 41,500 & 76.9 & 61 & 1 & 977,376 & $1,138,645$ & \\
\hline Rimouski & Quebec & 42,200 & 258 & \multicolumn{5}{|c|}{ No response received } \\
\hline Cornwall & Ontario & 46,000 & 61.5 & $53(85 \%)$ & \begin{tabular}{|c|} 
0.5: Part of \\
Division Manager's \\
role
\end{tabular} & 505,000 & 780,000 & \\
\hline Belleville & Ontario & 48,800 & 246.8 & 241.7 & $2^{*}$ & 917,258 & 694,485 & \\
\hline Saint-Hyacinthe & Quebec & 51,600 & 189 & \multicolumn{5}{|c|}{ No response received } \\
\hline Milton & Ontario & 54,000 & 366.6 & - & 1 & 85,994 & 353,858 & \\
\hline St. Albert & Alberta & 57,700 & 36.0 & 36.0 & 3 & $1,140,433$ & $1,812,207$ & \\
\hline Saint John & New Brunswick & 68,000 & 315.5 & 235 & $\begin{array}{c}\text { 2: General } \\
\text { Manager and } \\
\text { Operations } \\
\text { Manager } \\
\end{array}$ & $2,600,000$ & $1,791,601$ & \\
\hline Sarnia & Ontario & 71,400 & 165 & \multicolumn{5}{|c|}{ No response received } \\
\hline Lethbridge & Alberta & 78,713 & 124.3 & $70-80$ & $\begin{array}{c}\text { 1: Planning } \\
\text { Manager }\end{array}$ & $2,268,468$ & $2,133,062$ & \\
\hline Peterborough & Ontario & 74,900 & 58 & \multicolumn{5}{|c|}{ No response received } \\
\hline Red Deer & Alberta & 82,800 & 69 & \multicolumn{5}{|c|}{ No response received } \\
\hline St. John's & Newfoundland & 100,600 & 446 & \multicolumn{5}{|c|}{ No response received } \\
\hline Cape Breton (RM) & Nova Scotia & 102,200 & 2,433 & \multicolumn{5}{|c|}{ No response received } \\
\hline Kelowna & British Columbia & 106,700 & 211.7 & - & $\begin{array}{c}\text { Alternative Service } \\
\text { Delivery }\end{array}$ & $3,118,000$ & $1,520,000$ & \\
\hline Guelph & Ontario & 115,000 & 88.0 & 88 & \begin{tabular}{|c|}
5 \\
\end{tabular} & $5,115,929$ & $3,915,929$ & \\
\hline Kingston & Ontario & 117,207 & 450.4 & 131,170 & \begin{tabular}{|c|} 
5: Manager plus 4 \\
Operational \\
Supervisors)*
\end{tabular} & $2,952,643$ & $2,701,360$ & \\
\hline Sudbury & Ontario & 157,900 & 3,201 & \multicolumn{5}{|c|}{ No response received } \\
\hline Burlington & Ontario & 164,400 & 185.7 & 98 & 7 & $1,672,787$ & $2,738,975$ & \\
\hline Oakville & Ontario & 165,600 & 139 & \multicolumn{5}{|c|}{ No response received } \\
\hline
\end{tabular}




\section{Appendix B Statistics Canada Census Divisions}




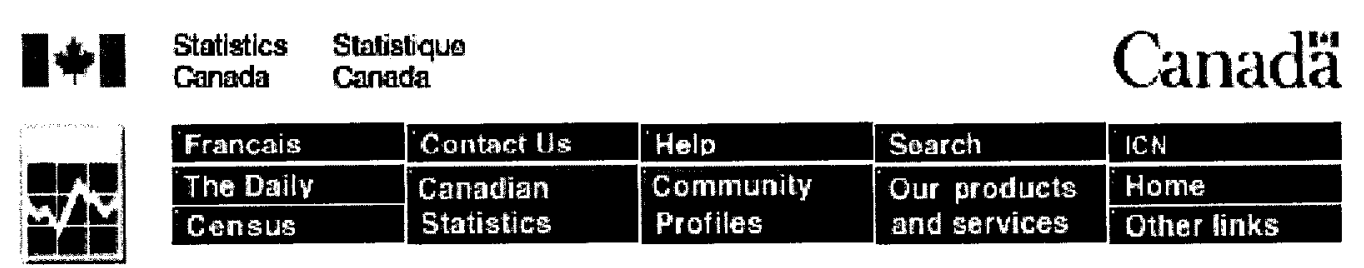

Introduction to the Dictionary, $A$ to $Z$ Index, Modifications, Troubleshooting PDFs

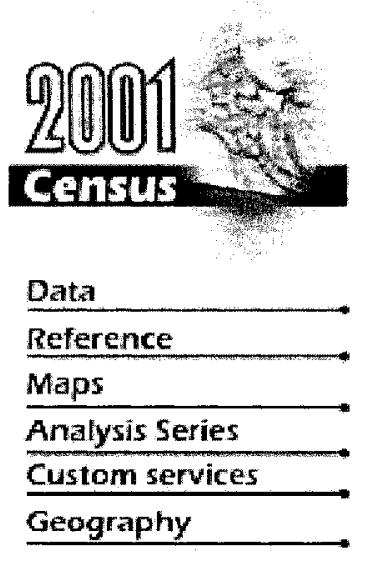

About the census

Teacher's kits

Census of Agriculture

1996 Census

2006 Census

Communtade

\section{Introduction to the Geography Section}

This section of the dictionary defines terms related to geography concepts, infrastructure, products and services. For 2001, there are a number of new geographic concepts being introduced and there are significant changes and quality improvements to the geographic infrastructure used to create geographic products and to deliver services. These are briefly outlined in this introduction. For further details, refer to the individual definitions of terms highlighted in bold text below.

\section{Geographic Areas}

Census data are disseminated for a number of standard geographic areas. These areas are either administrative or statistical. Administrative areas are defined, with a few exceptions, by federal and provincial statutes. Statistical areas are defined by Statistics Canada as part of the spatial frame for disseminating census data. Figure 20 shows the hierarchy of all standard geographic units for dissemination and Table 1 shows the number of geographic units by province and territory.

\section{What's New for 2001?}

\section{- Improved coverage and quality of the digital geographic infrastructure}

There is now $100 \%$ digital geographic coverage of Canada, whereas previously, digital coverage was limited to major urban centres (that covered less than $1 \%$ of the land area and $62 \%$ of the population). The new spatial data infrastructure brings together the boundaries and related attributes of the geographic areas with roads and other cartographic features of the National Topographic Database (NTDB) and Digital Chart of the World (DCW) and streets and address range updates from Elections Canada. Links to other data holdings, such as the address register and postal code, are incorporated into the database. All the spatial information is now based on the North American Datum of 1983 (NAD83) instead of NAD27, which was used for previous censuses. The spatial information is stored and maintained on the National Geographic Base (NGB) and geography products are derived from this base.

\section{- New standard geographic areas and classification}

The national road coverage and related geographic attributes permit the creation of a new basic geographic unit - the block. A block is an area bounded on all sides by roads and/or boundaries of standard geographic areas.

These blocks are used to automatically generate dissemination areas (DAs). The dissemination area is a small, relatively stable geographic unit 
composed of one or more blocks. DAs cover all the territory of Canada and replace the enumeration areas (which are still used for census collection) as the smallest standard geographic areas for which census characteristic data are disseminated.

Census metropolitan areas (CMAs) and census agglomerations (CAs) are widely used statistical areas composed of groups of adjacent, largely urban municipalities (census subdivisions) that have a high degree of social and economic integration. While CMAs and CAs contain approximately $78 \%$ of the population of Canada, they cover only $4 \%$ of the land area. The census metropolitan area and census agglomeration influenced zone (MIZ) is a new concept applied to census subdivisions (CSDs) outside CMAs and CAs to further differentiate this vast, largely rural area of Canada. These nonCMA/CA census subdivisions are assigned to four categories according to the degree of influence (strong, moderate, weak and no influence) that CMAs and CAs collectively have on each of them. CSDs with the same degree of influence tend to be clustered into zones around the CMAs and CAs.

The new Statistical Area Classification (SAC) can be applied to census subdivisions (municipalities) for data dissemination purposes. SAC permits census data to be summarized for census metropolitan areas (CMAs), census agglomerations (CAs), census metropolitan area and census agglomeration influenced zones (MIZ), and the three territories. It is expected that the application of this classification to CSD data will reveal previously hidden details and help users to study the diversity of nonCMA/CA areas of Canada.

For the first time, urban areas are defined using population counts and population density data from the current census, instead of from the previous census. The population density data are block-based rather than enumeration-area based as for previous censuses.

\section{- Impact of municipal restructuring}

The boundaries and names of municipalities (census subdivisions) can change from one census to the next because of annexations, dissolutions and incorporations. However, since the 1996 Census, the changes are more numerous and more dramatic, especially in the provinces of Quebec, Ontario and British Columbia. In general, data from the 2001 Census are available for fewer and larger census subdivisions, and historical analyses are more complex. To bridge the impact of these municipal changes on data dissemination, the 2001 Census is producing a profile for dissolved census subdivisions.

In addition, the concept of locality is established to maintain a record of historical place names of former census subdivisions (municipalities), former designated places and former urban areas, as well as the names of other entities, such as neighbourhoods, post offices, communities and unincorporated places.

\section{- Adjustment of population counts}

Statistics Canada is taking additional measures to protect the privacy of all Canadians and the confidentiality of the data they provide to us. Starting with the 2001 Census, some population counts are adjusted in order to ensure confidentiality. 
Counts of the total population are rounded to a base of 5 for any block having a population of less than 15 . Population counts for all standard geographic areas above the block level are derived by summing the adjusted block counts. The adjustment of block counts is controlled to ensure that the population counts for dissemination areas will always be within 5 of the actual values. The adjustment has no impact on the population counts of census divisions and large census subdivisions. Dwelling counts are unadjusted.

\section{- Discontinued geography concepts}

Consolidated census agglomeration, consolidated census metropolitan area, primary census agglomeration and primary census metropolitan area are discontinued as dissemination concepts for 2001.

The unincorporated place concept is discontinued, as the information is no longer collected by the census. Names of unincorporated places collected by previous censuses are included as locality names.

\section{- New and discontinued geography products}

Geography products for the 2001 Census reflect both the changes to geography concepts as well as the more precise geometry and more detailed cartographic features (such as water, roads and road names). For 2001, Cartographic Boundary Files (CBFs) replace Digital Cartographic Files (DCFs), and Digital Boundary Files (DBFs) are discontinued. The Road Network Files (RNFs), which cover all of Canada, replace Street Network Files (SNFs), which covered only large urban centres in Canada. The Block-face Data File (BFDF) is discontinued.

A fully digital dissemination system is introduced to make reference maps and other geographic products available in a variety of media, including the Internet. Tools are provided for users to find and view their geographic area of interest on the Internet.

\section{Census Geography Products and Services}

Geography products include reference and data products and digital spatial and attribute products. As well, a variety of services is available, including custom mapping, custom data extraction and the development of custom geography products.

Reference maps are published to show the boundaries, names and codes of the standard geographic areas. Cartographic Boundary Files (CBFs) are available for most of the standard geographic areas and are appropriate for small-to-medium-scale thematic mapping. The Road Network Files (RNFs) include the road network, street names, address ranges, shorelines and province/territory boundaries. The CBFs and RNFs enable users with geographic information systems (GIS) or other mapping software to produce their own maps or do geographic analysis.

It is important that users of geospatial data understand the principles of coordinate system, map projection and datum. For example, although the spatial products are disseminated in latitude/longitude coordinates, maps should not be generated using these spherical coordinates as they are unprojected, resulting in a map that is distorted (see Figure 33). The latitude and longitude coordinate reference system is merely a convenient way of transferring geographic data; users can then use GIS software to 
convert latitude/longitude coordinates to the desired map projection(s). Users should also be aware that different spatial datasets can be in the same coordinate system or projection but not in the same datum, in which case the data will not be spatially coincident. Data overlay discrepancies will thus occur if spatial data from the 2001 Census, which are now based on NAD83, are overlaid with users' data that are based on NAD27.

The Geocoding Service allows users to define their own geographic areas for census data tabulations. With the geocoding system, households and associated data are geographically linked to the corresponding block-face or block representative point. Census data for user-defined areas are then retrieved by aggregating the representative points within each user-defined area.

Figure 20. Hierarchy of Standard Geographic Units for Dissemination, 2001 Census

As of April 17, 2002 


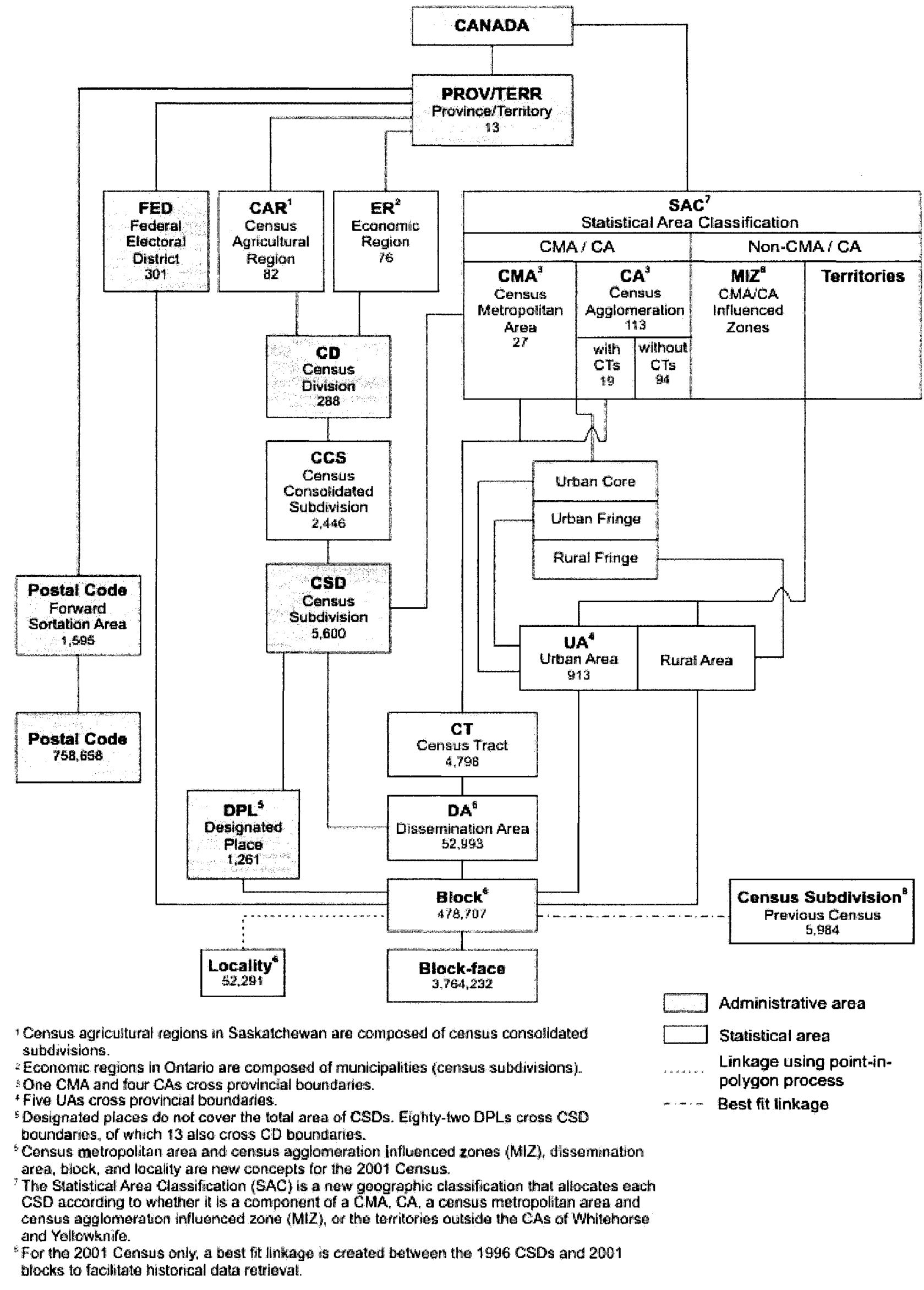




\begin{tabular}{|c|c|c|c|c|c|c|c|c|c|c|c|c|c|c|c|}
\hline alis & C. & and & & & & 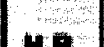 & & 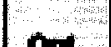 & & & & & 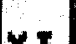 & & \\
\hline 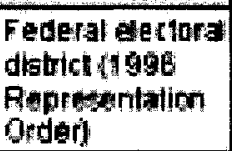 & 295 & 301 & 7 & 4 & 11 & 10 & 75 & 7103 & 14 & 14 & 76 & 34 & 1 & 1 & 1 \\
\hline Ecornomic repian & 74 & 76 & 1 & 1 & 5 & 5 & 17 & 11 & 日 & 6 & 8 & a & 1 & 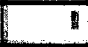 & 1 \\
\hline $\begin{array}{l}\text { Census } \\
\text { agricultural } \\
\text { egion }\end{array}$ & 78 & 2 & 3 & 3 & 5 & 4 & 14 & 5 & 12 & 20 & t & 9 & - & - & - \\
\hline Cansus dusion & 260 & 369 & 10 & 3 & 10 & 15 & 89 & 19 & 23 & 10 & 19 & 20 & 1 & 2 & 3 \\
\hline $\begin{array}{l}\text { Consus } \\
\text { corrsolidatid } \\
\text { subdhision }\end{array}$ & 2.007 & 2,444 & 97 & 6 & 47 & 151 & 1,111 & 310 & 127 & 301 & $n$ & 157 & 1 & 2 & 9 \\
\hline $\begin{array}{l}\text { Consus } \\
\text { stodmsion }\end{array}$ & - & $5 E D$ & 39 & 113 & 78 & 275 & 1,476 & 54 th & 298 & 1,002 & 45 & 815 & 35 & 37 & 31 \\
\hline 1996 Cansus & $5.5 e 4$ & - & 301 & 113 & 110 & 203 & 1599 & sin & 24 & 970 & 467 & 713 & $x$ & 68 & MIA \\
\hline 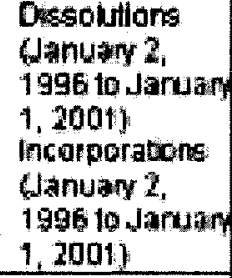 & 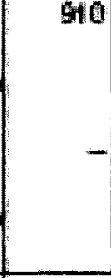 & 526 & - & - & 14 & 12 & 109 & 368 & 3 & 50 & 16 & 100 & 1 & 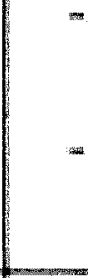 & Nia \\
\hline $\begin{array}{l}\text { Dasipnabed } \\
\text { place }\end{array}$ & $82 \mathrm{a}$ & 1,251 & 182 & $=$ & 59 & 172 & 78 & 31 & 51 & 150 & 260 & 219 & 1 & - & - \\
\hline $\begin{array}{l}\text { Cartos } \\
\text { mentoplion } \\
\text { area }\end{array}$ & 25 & 27 & 1 & - & 1 & 1 & E & 11 & 1 & 7 & 7 & 3 & - & - & - \\
\hline $\begin{array}{l}\text { Cansus } \\
\text { agotamkraton }\end{array}$ & 112 & 113 & 4 & $\frac{2}{2}$ & 4 & 5 & 70 & 20 & 3 & $I$ & 10 & 2 & 1 & 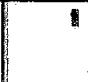 & $=$ \\
\hline $\begin{array}{l}\text { With censas } \\
\text { tacts }\end{array}$ & 10 & 19 & - & - & - & 1 & * & 1 & - & - & 3 & 4 & - & - & - \\
\hline $\begin{array}{l}\text { Withoun cersus } \\
\text { macts }\end{array}$ & $\$ 4$ & 94 & $\downarrow$ & s & 4 & \pm & 13 & $z$ & 3 & $I$ & $Z$ & 19 & 1 & 1 & - \\
\hline Censug bract & 4,23 & 4,789 & 45 & $=$ & 98 & 71 & 1,263 & 2013 & 165 & 101 & 497 & 597 & - & $=$ & - \\
\hline Untoun atras & 80 & 93 & 3 & 7 & 39 & 4 & 24 & 25 & 2 & 85 & 10 & 9 & 1 & 3 & 3 \\
\hline Locally & Wha & 52,291 & $12+20$ & 964 & 3920 & 3,445 & 12,46 & 10,609 & 2,359 & 3680 & 3,466 & 7,699 & 362 & 173 & 20 \\
\hline $\begin{array}{l}\text { Dussemnation } \\
\text { anea }\end{array}$ & Nus & $\$ 2,53$ & 1,23 & 275 & 1.397 & 1.349 & 12,153 & 16,95 & 2,295 & 2.997 & 5,140 & 7.46 & 117 & 92 & 55 \\
\hline $\begin{array}{l}\text { Enimaration } \\
\text { area }\end{array}$ & 79.36 & $2 \times 851$ & 1.204 & 225 & $1,39 \mathrm{P}$ & 1,216 & 9,139 & 14,753 & 1.645 & 2,699 & 4,129 & e. $\mathrm{EBd}$ & 117 & 52 & 34 \\
\hline Elork & Wu & 478,707 & B.3a1 & 2,851 & 15,161 & 13,929 & 109,760 & 100327 & 30567 & EF, 040 & 60,061 & 53.147 & 674 & 745 & 134 \\
\hline Sloth tate & 617,73 & $4,164,202$ & 60,16 & 19,054 & 168640 & 138,31 & 865,600 & PSS,017 & moses & 3978 & ESGOH & 199,38 & Dgat & 1204 & 13 \\
\hline $\begin{array}{l}\text { Fonvard } \\
\text { sondaton areg }\end{array}$ & 1,47 & 1.585 & 33 & 7 & 74 & 110 & 390 & 517 & 64 & 47 & 147 & 100 & 3 & 3 & 3 \\
\hline Postal cose & 690.910 & 758659 & 7,90 & 2,858 & $23 \times 54$ & $55,1 \mathrm{~A}$ & 168,427 & 604,757 & 29,250 & $20,1 \mathrm{BA}$ & 70,672 & 104.75 & Bef & 487 & 30 \\
\hline
\end{tabular}

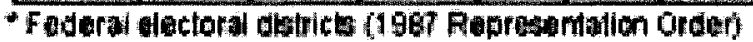

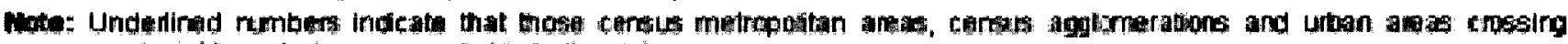
provificial boundarles are counced in boh provinces 


\section{Appendix C Sample OC Transpo Data}


PROCESSED: 2007-06-04 09:37:19

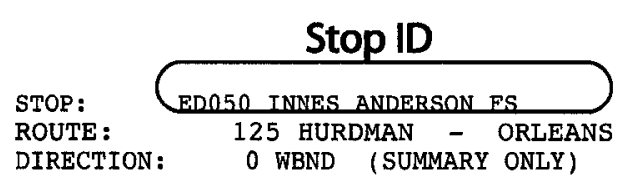

T I M E

\begin{tabular}{crrr} 
RUN & PAT & EXPECTED & ACTUAL \\
\hline $125005 \mathrm{~A}$ & 1 & $15: 48$ & $15: 48$ \\
$125007 \mathrm{~A}$ & 1 & $16: 18$ & $16: 20$ \\
$125002 \mathrm{~A}$ & 1 & $16: 48$ & $16: 57$ \\
$125003 \mathrm{~A}$ & 1 & $17: 18$ & $17: 19$ \\
$125001 \mathrm{~A}$ & 1 & $17: 48$ & $17: 49$ \\
$125006 \mathrm{~A}$ & 1 & $18: 18$ & $18: 17$ \\
$125004 \mathrm{~A}$ & 7 & $18: 48$ & $18: 49$ \\
$125005 \mathrm{~A}$ & 7 & $19: 18$ & $19: 18$ \\
$125007 \mathrm{~A}$ & 7 & $19: 48$ & $19: 55$ \\
$125002 \mathrm{~A}$ & 7 & $20: 18$ & $20: 17$ \\
$125003 \mathrm{~A}$ & 7 & $20: 48$ & $20: 47$ \\
$125001 \mathrm{~A}$ & 7 & $21: 18$ & $21: 16$ \\
$125006 \mathrm{~A}$ & 7 & $21: 48$ & $21: 47$ \\
$125004 \mathrm{~A}$ & 7 & $22: 18$ & $22: 19$ \\
$125005 \mathrm{~A}$ & 7 & $22: 48$ & $22: 46$ \\
$125007 \mathrm{~A}$ & 7 & $23: 18$ & $23: 17$ \\
$125002 \mathrm{~A}$ & 7 & $23: 48$ & $23: 45$ \\
$125003 \mathrm{~A}$ & 7 & $24: 15$ & $24: 14$
\end{tabular}

\section{Description of APC Report:}

- Run identifies which route and sequence is reported

- Pat is the route pattern used

- Expected relates to the scheduled arrival time at the given stop

- Actual is the time at which bus was recorded to arrive at the stop

- Difference is the difference between scheduled and actual arrival time

- Ons is the number of passengers that boarded at the stop

- Offs is the number of passengers that alighted at the stop

- Load at departure represents the number of passengers already on board
BOOKING: SEP02

PERIOD: 2002-09-01 TO 2002-12-21

TIME: ALL DAY

DAY OF THE WEEK: MON TUE WED THU FRI

\begin{tabular}{cccr} 
DIFFERENCE & ONS & OFFS & $\begin{array}{r}\text { LOAD AT } \\
\text { DEPARTURE }\end{array}$ \\
\hline 0 & 0 & 0 & $16(7)$ \\
9 & 0 & 0 & $13(4)$ \\
1 & 1 & 0 & $8(5)$ \\
1 & 0 & 0 & $2(3)$ \\
-1 & 0 & 0 & $10(4)$ \\
1 & 0 & 0 & $8(5)$ \\
0 & 0 & 0 & $7(4)$ \\
7 & 0 & 0 & $6(6)$ \\
-1 & 0 & 0 & $5(2)$ \\
-2 & 0 & 0 & $8(7)$ \\
-3 & 0 & 0 & $6(4)$ \\
-2 & 0 & 0 & $11(4)$ \\
1 & 0 & 0 & $7(4)$ \\
-3 & 0 & 0 & $5(3)$ \\
-1 & 0 & 0 & $5(4)$ \\
-3 & 0 & 0 & $2(3)$ \\
-1 & 0 & 0 & $5(2)$ \\
\hline & 0 & 0 & $1(3)$
\end{tabular}


Area Code

AREA: SM36 EI
AUTOMATIC PASSFNGER COUNTTNG SYSTFM PASSENGER ACTIVITY BY AREA BY TIME PERIOD WEEKDAY SERVICE APC Report Type

PERIOD: 2002-09-01 TO 2002-12-21 DAY TYPE: WEEKDAY

\begin{tabular}{|c|c|c|c|c|c|}
\hline \multirow[b]{2}{*}{ ROUTE } & \multirow[b]{2}{*}{ STATISTICS } & \multicolumn{2}{|c|}{$03: 01-06: 30$} & \multicolumn{2}{|c|}{$06: 31-09: 30$} \\
\hline & & ONS & OFFS & ONS & OFES \\
\hline---- & 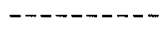 & ----- & ----- & $-\cdots--$ & $-\cdots--$ \\
\hline \multirow[t]{9}{*}{25} & MINIMUM & 0 & 0 & 0 & 0 \\
\hline & MAXIMUM & 0 & 0 & 0 & 0 \\
\hline & MEDIAN & 0 & 0 & 0 & 0 \\
\hline & AVERAGE & 0.00 & 0.00 & 0.00 & 0.00 \\
\hline & STD DEV & 0.00 & 0.00 & 0.00 & 0.00 \\
\hline & OBSERVED & 1 & 1 & 6 & 6 \\
\hline & SAMPLED & 100 & 100 & 86 & 86 \\
\hline & TOTAL ACT. & 0 & 0 & 0 & 0 \\
\hline & SCHEDULED & 1 & 1 & 7 & 7 \\
\hline \multirow[t]{9}{*}{28} & MINIMUM & 17 & 0 & 2 & 0 \\
\hline & MAXIMUM & 22 & 0 & 29 & 3 \\
\hline & MEDIAN & 22 & 0 & 20 & 1 \\
\hline & AVERAGE & 19.50 & 0.30 & 18.80 & 0.79 \\
\hline & STD DEV & 2.97 & 0.14 & 8.30 & 0.70 \\
\hline & OBSERVED & 2 & 2 & 9 & 9 \\
\hline & 号 SAMPLED & 100 & 100 & 90 & 90 \\
\hline & TOTAL ACT. & 39 & 1 & 188 & 8 \\
\hline & SCHEDULED & 2 & 2 & 10 & 10 \\
\hline \multirow[t]{9}{*}{31} & MINIMUM & 21 & 0 & 0 & 0 \\
\hline & MAXIMUM & 21 & 2 & 33 & 2 \\
\hline & MEDIAN & 21 & 2 & 25 & 1 \\
\hline & AVERAGE & 20.92 & 0.92 & 20.88 & 0.68 \\
\hline & STD DEV & 0.59 & 0.82 & 9.08 & 0.52 \\
\hline & OBSERVED & 2 & 2 & 14 & 14 \\
\hline & 응 SAMPLED & 100 & 100 & 93 & 93 \\
\hline & TOTAL ACT. & 42 & 2 & 313 & 10 \\
\hline & SCHEDULED & 2 & 2 & 15 & 15 \\
\hline
\end{tabular}

Description of APC Report:

- Area Code identifies which area is being reported on

- Route is the bus route number reported
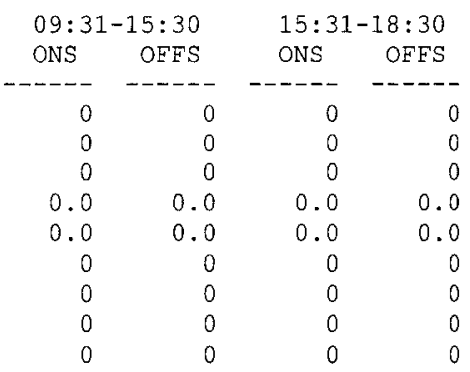

$18: 31-03: 00$

TOTAL

ONS OFFS

ONS OFFS

$\begin{array}{ll}0 & 0 \\ 0 & 0\end{array}$

$\begin{array}{rr}0 & 0 \\ 0 & 0 \\ 0 & 0\end{array}$

$0.00 \quad 0.00$

$0.00 \quad 0.00$

0.0

$\begin{array}{rr}88 & 88 \\ 0 & 0\end{array}$

$\begin{array}{rrrr}0 & 0 & 0 & 11 \\ 0 & 0 & 2 & 29 \\ 0 & 0 & 0 & 20 \\ 0.0 & 0.0 & 0.28 & 20.17 \\ 0.0 & 0.0 & 0.51 & 4.56 \\ 0 & 0 & 10 & 10 \\ 0 & 0 & 91 & 91 \\ 0 & 0 & 3 & 222 \\ 0 & 0 & 11 & 11\end{array}$

$\begin{array}{ll}0 & 13 \\ 0 & 13\end{array}$

0

$0.00 \quad 0.00$

0.00
1

100
13

$10.86 \quad 10.21$

22

92

243

24

$\begin{array}{rrrr}0 & 0 & 0 & 13 \\ 0 & 0 & 4 & 34 \\ 0 & 0 & 2 & 26 \\ 0.0 & 0.0 & 1.79 & 24.06 \\ 0.0 & 0.0 & 1.09 & 6.16 \\ 0 & 0 & 12 & 12 \\ 0 & 0 & 100 & 100 \\ 0 & 0 & 21 & 289 \\ 0 & 0 & 12 & 12\end{array}$

- Statistics for each route:

- Minimum, Maximum, Median, Average and Std Deviation report number of passengers

- Observed lists number of buses captured in data capture

- \% sampled reports number sampled versus total scheduled

- Total act. reports adjusted number of pasengers (ons and offs)

- Scheduled lists number of scheduled buses

- Data is reported by time period (e.g.3:01 am to 6:30am)

- Total represents the daily total 